\title{
WestVirginiaUniversity
}

THE RESEARCH REPOSITORY @ WVU

Graduate Theses, Dissertations, and Problem Reports

1998

\section{Two-stroke linear engine}

Subhash Nandkumar

West Virginia University

Follow this and additional works at: https://researchrepository.wvu.edu/etd

\section{Recommended Citation}

Nandkumar, Subhash, "Two-stroke linear engine" (1998). Graduate Theses, Dissertations, and Problem Reports. 928.

https://researchrepository.wvu.edu/etd/928

This Thesis is protected by copyright and/or related rights. It has been brought to you by the The Research Repository @ WVU with permission from the rights-holder(s). You are free to use this Thesis in any way that is permitted by the copyright and related rights legislation that applies to your use. For other uses you must obtain permission from the rights-holder(s) directly, unless additional rights are indicated by a Creative Commons license in the record and/ or on the work itself. This Thesis has been accepted for inclusion in WVU Graduate Theses, Dissertations, and Problem Reports collection by an authorized administrator of The Research Repository @ WVU. For more information, please contact researchrepository@mail.wvu.edu. 


\title{
Two-Stroke Linear Engine
}

By

Subhash Nandkumar

\author{
A Thesis \\ Submitted to \\ The College of Engineering and Mineral Resources \\ at \\ West Virginia University \\ in partial fulfillment of the requirements \\ for the degree of \\ Master of Science \\ In \\ Mechanical Engineering
}

Department of Mechanical and Aerospace Engineering

Morgantown, West Virginia

1998 


\section{ACKNOWLEDGEMENT}

I would like to thank Dr. Nigel Clark for providing me with an opportunity to work with him, and for his guidance and technical advice. His support and patience during the course of my research work deserve a special mention. I would also like to thank Dr. Chris Atkinson and Dr. Parviz Famouri, for their technical guidance and advice. I thank the U.S. Department of Defense for funding this research.

I wish to express my sincere thanks to Tom McDaniel and Richard Atkinson, for building the test setup and providing support with the testing and data acquisition, and without whose help this research thesis would not have been possible. I thank Ali Ihsan Karamavruc for his help in part of the mathematical modeling. Chris Tennant, Mike Traver, Ron Jarrett, Jim Daley, Tom Spencer, Ravi Ramamurthy, Clarence Gadapati, Sumit Bhargava, Talus Park, Marcus Gilbert, Ralph Nine, Dave Mckain, Sorin Petreanu, and last but not the least, Jenn Hoppie, all deserve special thanks for their support and help.

Finally, I would like to thank my parents, my family and Sam for their moral support and encouragement throughout my graduate studies. I dedicate my research thesis to them. 


\begin{abstract}
Linear, crankless, internal combustion engines may find application in the generation of electrical power without the need to convert linear to rotary motion. The elimination of the connecting rod and crankshaft can improve the efficiency of the engine significantly and the reduced weight and cost are added advantages. A linear, crankless, internal combustion engine prototype has been developed for electrical power generation in combination with a linear alternator. The operation of this engine is distinct from that of a conventional slider-crank mechanism engine, insofar as the motion of the two horizontally opposed pistons is not externally constrained. A two-stroke engine prototype, with a bore of $36.5 \mathrm{~mm}$ and a maximum stroke of $50 \mathrm{~mm}$, operating in a gasoline-fueled spark-ignited mode, was tested successfully under varying externallyapplied load and ignition timing conditions. It was found by analysis of the pressurevolume diagrams that the ignition timing had to be highly advanced in the no-load (or idling) case, in order to perform the adverse work required to slow the piston near the end of the compression stroke. As the load on the engine was increased (initially through the application of a friction brake, and later with an electrical alternator load), the ignition timing was required to be retarded, thus reducing and finally eliminating the adverse work, while concomitantly increasing the net positive work output of the engine. The incylinder pressure versus time traces showed significant cycle-to-cycle variations, as indicated by the coefficient of variation (COV) of the gross indicated mean effective pressure $\left(\mathrm{IMEP}_{\mathrm{g}}\right)$. It was seen that the $\mathrm{COV}\left(\mathrm{IMEP}_{\mathrm{g}}\right)$ was high in the no-load (idling) case, and was substantially reduced (to below 10\%) with the application of load and retarding of the ignition timing. An idealized model analysis also provided an insight into the behavior of the linear engine for different stroke-to-bore $(\mathrm{L} / \mathrm{b})$ ratios and under different air-to-fuel ratios. It was concluded that unthrottled operation was desirable for the most efficient operation of the engine.
\end{abstract}


Title page

Acknowledgement

Abstract

Table of Contents

List of Tables

List of Figures

Nomenclature

1. Introduction

2. Literature Review

3. Fundamental Analysis of A Two-Stroke Linear Engine 7

1. Introduction

2. Engine Model

3. Assumptions

4. Mathematical Model

5. Results

6. Conclusions

4. Additional Analyses using Idealized Model Equations 34

1. Effect of Engine Bore on Engine Speed 34

2. Effect of Air-Fuel Ratio on Engine Speed 36

3. Energy Analysis 39

5. Engine Prototype $\quad 42$

1. Description 42

2. Engine Controller 45

3. Simulation of Alternator Load 46

6. Analysis of Data $\quad 49$

1. Operating Conditions 49

2. Experimental Results (single typical cycle analysis) 49

3. Experimental Results (20 cycles of operation) 55

4. Cycle-to-Cycle Variations $\quad 58$

5. Heat Release Rate Calculations 65

$\begin{array}{ll}\text { 7. Conclusions } & 67\end{array}$ 
$\begin{array}{ll}\text { References } & 69\end{array}$

Appendix A Data Reduction Program: Omnipeak $\quad 71$

Appendix B Fundamental Anaysis Program 72

Appendix C Air-Fuel Ratio Effect Determination Program 73 


\section{LIST OF TABLES}

Table 1 Values of compression ratio and load ratio, for different values of stroke ratio.

Table 2 Heat input and ratio of midpoint pressure values for different values of compression ratio and frictional force.

Table 3 The effect of changing the engine bore for different compression ratios.

Table 4 Effect of varying the AFR for different stroke-to-bore $(\mathrm{L} / \mathrm{b})$ ratios. $\quad 39$

Table 5 Benchtop model component descriptions. 48

Table 6 Experimental data from benchtop model. 56

Table 7 Average data over 20 cycles of operation. 65 


\section{LIST OF FIGURES}

Figure 1 The ideal engine model at the beginning of a left to right compression stroke.

Figure 2 The ideal engine model with the pistons at the midpoint position. 9

Figure 3 Plot of Stroke Function versus Stroke Ratio. 22

Figure 4 Plot of Stroke Function versus Compression Ratio r. 22

Figure 5 Dimensionless Piston Velocity versus Dimensionless Piston Position for $r=10$. 23

Figure 6 Dimensionless Piston Velocity versus Dimensionless Piston Position for $r=15$.

Figure 7 Dimensionless Piston Velocity versus Dimensionless Piston Position for $r=20$.

Figure 8 Dimensionless Piston Velocity versus Dimensionless Piston Stroke for $r=10$.

Figure 9 Dimensionless Piston Velocity versus Dimensionless Piston Stroke for $r=15$.

Figure 10 Dimensionless Piston Velocity versus Dimensionless Piston Stroke for $r=20$.

Figure 11 Dimensionless Piston Position versus Dimensionless Stroke Time for $r=10$.

Figure 12 Dimensionless Piston Position versus Dimensionless Stroke Time for $r=15$.

Figure 13 Dimensionless Piston Position versus Dimensionless Stroke Time for $r=20$.

Figure 14 The dimensionless in-cylinder pressures versus the dimensionless Piston position for a specific value of compression ratio, $r$ and load ratio.

Figure 15 Load Ratio versus the ratio of midpoint cylinder pressures for different values of compression ratio, $r$.

Figure 16 The idealized motion plot for $r=15$ and load ratio $=7.815$.

Figure 17 The engine speed plotted against the engine bore for different values of compression ratios. The increase in the engine speed with the increase in engine bore was as predicted.

Figure 18 The engine speed is plotted against the air-fuel ratio (AFR), for different $\mathrm{L} / \mathrm{b}$ ratios.

Figure 19 The potential and kinetic energy plotted versus piston displacement. The total energy in the system is seen to be constant as expected.

Figure 20 The change in potential energy in the two cylinders is plotted against the piston displacement.

Figure 21 Benchtop Model.

Figure 22 Simple Dimensional Sketch of Engine Cylinder. 45

Figure 23 Benchtop Model Controller Block Diagram. 46

Figure 24 Richard Atkinson and Tom McDaniel performing a test of the benchtop model. 
Figure 25 The benchtop model is shown with the steel plate bed to reduce the severity of vibrations. Tuning success after the construction of this table dramatically reduced the vibrations.

Figure 26 The P-V diagram for the right cylinder under no load (idle) condition is shown here. The check box denotes the point of spark ignition.

Figure 27 The P-V diagram for the right cylinder under load due to friction braking.

Figure 28 The effect of retarding the timing for the same load.

Figure 29 A plot resembling the conventional slider-crank engine is obtained by highly retarding the timing under the same load condition.

Figure 30 A comparison between the instantaneous indicated power versus time, for the no load condition and highly advanced timing under load condition.

Figure 31 The piston position and piston velocity plotted against time; the Piston velocity has been magnified to improve clarity.

Figure 32 The piston velocity when plotted against the piston displacement is seen to be similar to the idealized motion described earlier.

Figure 33 The P-V traces for the no-load (idle), highly advanced ignition timing case for the right cylinder, over 20 successive cycles of operation.

Figure 34 The P-V diagram for the loaded case with highly advanced timing for the right cylinder (for 20 successive cycles). The adverse work area has been reduced by the application of load.

Figure 35 The P-V diagram for 20 cycles of operation, for the loaded condition with retarded timing.

Figure 36 Pressure-volume relationship for the linear engine obtained by varying the ignition timing for the same load. This plot resembles the trace that would be expected from a conventional two-stroke slider-crank engine.

Figure 37 Pressure-time trace for the no load, highly advanced ignition timing case.

Figure 38 The application of load, for the same ignition timing as in figure 33, increased the average net positive work done and reduced the value of COV.

Figure 39 Retarding the timing for the same load increased the net positive work output and reduced the COV significantly.

Figure 40 Further retarding of the ignition timing, increased the peak pressure and the stroke of the engine. The variations from cycle to cycle were reduced significantly.

Figure 41 The heat release and in-cylinder pressure versus time plot for the no load (idle) case, shows the large amount of compression stroke work done by the piston on the gases.

Figure 42 The trace showing the occurrence of heat release and peak pressure at the optimum time in the compression stroke (highly retarded timing under load case). 


\section{NOMENCLATURE}

$b$

$m_{s}$

$m_{f}$

n

$r$

$t_{c}$

$x_{m}$

$x_{s}$

$x$

$F_{f}$

$Q_{\text {in }}$

$P_{m}$

$P_{u}$

$P_{l}$

$P_{r}$

$V_{m}$

$V_{l}$

$V_{r}$

$W_{f}$

$\eta$

$T_{m}$

$t^{*}$

$t$

$x^{*}$

$v^{*}$ bore diameter of the engine

mass of the piston

mass of fuel

ratio of specific heats

compression ratio

characteristic time

maximum theoretical half-stroke length of the engine

maximum actual half-stroke length of the engine

instantaneous piston position

friction force required to move the piston

quantity of heat added during one cycle

midpoint pressure of the compression cylinder

midpoint pressure of the expansion cylinder

instantaneous pressure in the left (expansion) cylinder

instantaneous pressure in the right (compression) cylinder

midpoint volume of the compression cylinder

instantaneous volume of the left (expansion) cylinder

instantaneous volume of the right (compression) cylinder

mechanical work done in one stroke

Otto cycle efficiency

midpoint temperature

dimensionless stroke time

dimensional stroke time

dimensionless piston position

dimensionless piston velocity 


$\begin{array}{ll}v & \text { dimensional piston velocity } \\ C^{*} & \text { constant of integration } \\ \mathrm{COV} & \text { coefficient of variation } \\ \mathrm{cpm} & \text { cycles per minute } \\ \mathrm{IMEP}_{\mathrm{g}} & \text { gross indicated mean effective pressure } \\ \sigma & \text { standard deviation } \\ \delta Q_{R} & \text { heat release rate } \\ \mathrm{AFR} & \text { air-fuel ratio } \\ \mathrm{L} & \text { stroke length } \\ \mathrm{KE} & \text { kinetic energy } \\ \mathrm{PE} & \text { potential energy }\end{array}$




\section{INTRODUCTION}

The present day internal combustion engine has been eminently successful in delivering power by converting the reciprocating motion of the piston into rotary motion of the crankshaft with the help of the connecting rod. However, a third of the total frictional losses occurring in the internal combustion engine of this type were due to the presence of additional moving parts like the crankshaft, connecting rod and bearings [1]. Thus it was clear that the elimination of the connecting rod and crankshaft would significantly improve the efficiency of the engine in applications where power can be extracted directly from the linear motion. The added advantage of reduced weight and cost has led to intense investigation and development of free piston engines over the past few years. Researchers argued that free piston engines were advantageous in applications where the power generated in the engine can be extracted in the form of hydraulic energy, electrical energy or in applications that use the energy for driving an air pump. However, the model presented herein differs completely in operation from such engines as the General Motors Research-Cleveland Diesel Engine Division [2] free piston gas generator. The work presented was aimed towards the generation of electrical energy by coupling a free piston engine to a linear alternator.

The engine that was contemplated consisted of two pistons, connected solidly by a rod, which reciprocated with precisely the same motion. The motion of the piston was not mechanically prescribed but was rather a result of the balance of in-cylinder pressures, inertia forces, friction forces and the applied load. Idealized modeling of a twostroke linear engine, assuming Otto cycle of operation, yielded a closed form solution for piston motion. A benchtop prototype of a linear engine was constructed and tested. The 
prototype was a gasoline-fueled spark-ignited one and was successfully tested under various operating conditions. In-cylinder pressure data and linear piston position data were measured and documented. Statistical analysis was carried out to provide thermodynamic insight into the working of a linear engine. Cycle-to-cycle variations of pressure were also studied. The idealized mathematical model was utilized to conduct analysis into the effect of air-fuel ratio, compression ratio and engine size on the engine speed, which is an important parameter for the conversion of chemical energy input to the engine to electrical energy output of the linear alternator. 


\section{LITERATURE REVIEW}

Various applications of the free-piston engine have been under scrutiny by investigators for a long time. A study of patents and literature emphasizing the same was conducted and has been presented in this chapter.

The different types of free piston engines and the conceptual differences between them was studied and documented by Achten [3] in his review paper. The use of freepiston engines supplying gas to drive a turbine for automotive applications was presented by Underwood [4], while Flynn [5] investigated the performance, power, economy and reliability of free-piston engines over the more conventional diesel engines. An automotive-size free-piston engine with matching turbine was designed, built and tested by Frey et al. [6].

General Motors Research and Cleveland Diesel Engine Division [2] were active in the investigation and application of free piston engine usage for marine propulsion and general power plant installations. The free piston gas generator developed by them, consisted of a supercharged two-stroke, uniflow scavenged diesel engine where the expansion of the exhaust gas continued in a turbine, down to atmospheric pressure. The energy in the fuel was utilized to perform work in a free piston diesel cylinder, for the compression of air supplied to a turbine. The engine consisted essentially of a two-stroke diesel engine with opposed diesel pistons rigidly connected to the compressor pistons. The pistons were of equal and symmetric stroke, with the power cylinder in the center. The pistons compressed air on their inward motion and a mechanical linkage synchronized the motion of the pistons and connected the two reciprocating masses. The single acting compressor cylinders were located on both ends of the center housing and 
the end spaces constituted the cushion chambers, which stored energy for the return stroke. The air pressure in the cushions was automatically controlled by means of a stabilizer mechanism, which gave a compression pressure suited to a given power. The General Motors model consisted of inward compressing pistons, while the model presented in this paper is outward compressing type with the pistons moving in tandem with one another. Only a rigid link rod connects the pistons as opposed to the mechanical linkage used in the General Motors model.

Widener and Ingram [7] recently submitted a numerical model of a free piston linear generator for a hybrid vehicle modeling study. The model addressed the use of a freepiston engine coupled with a linear generator as a potential auxiliary power unit in hybrid electric vehicles. The feasibility of such a model was analyzed with regards to power output and efficiency of the unit with reference to conversion of mechanical power output of the linear engine to electrical power output. The study was conducted on a two-stroke cycle engine and a reciprocating rig developed to study and characterize the working of the generator.

Galitello [8] patented a variable compression, free-piston, two-stroke cycle engine with an integral supercharging chamber. It was comprised of two directly opposed identical internal combustion cylinders, each providing a sealed cavity. An assembly included a piston in each cylinder and a piston rod that joined the pistons. The freely floating piston rod assembly underwent a power pulse sending the mass moving towards compression and ignition in the opposing cylinders, due to the combustion of the fuel. Along the way, energy was extracted from the moving mass via hydraulic cylinders moving a fluid or electrical energy generated from moving magnets within coils. Thus the 
engine could be connected to an electric generator or to a hydraulic power system. Compression ratios were variable and a computer operating system sensed power desired, combustion properties of the fuel and energy generated from the fuel on detonation. This enabled alteration of the power extracted from the moving mass of the piston rod assembly and the fuel ratios, thereby enabling the engine to operate through a wide range of fuels and power outputs. The engine used spark ignition for starting and then worked in the compression ignition mode. The engine, according to the inventor, was capable of running at ultra high speeds and hence was vibration free.

The possibility of the free-piston engine being ideal for remote power applications, due to its almost maintenance-free performance, was presented by White et al. [9]. Their proposal employed a Stirling cycle engine and extracted the power through a linear electrical generator.

A two-stroke compression ignition engine with two oppositely arranged combustion cylinders was designed by Bock [10]. The two pistons were rigidly connected by a common piston rod. A pump cylinder was provided in the central part of the engine, between the two combustion cylinders, with a pump piston fixed to the piston rod that divided the pump cylinder into two chambers. A common suction chamber and a common pressure chamber complete with inlet and outlet valves were also provided in the central part of the engine. The engine was gas cushioned and nitrogen filled elastic annular body served as a shock absorbing body. The combustion chambers were surrounded by outer jackets that had cooling chambers with oil flowing in them, thereby providing cooling for the engine. 
Kos [11] patented a hybrid engine that used a reciprocating piston controlled by an electromagnetic transducer. A piston-rod magnet unit constrained to move translationally in one axis by means of bearings, was used to generate electric current in the windings of the yoke of the transducer. The motion of the piston and the magnet was controlled using an impedance-based computer control system. The two-stroke cycle engine was designed for multifuel operation and could be spark ignited or compression ignited and the fuel injection, valve timing and ignition timing were computer controlled. The stroke was adjusted using the computer and the opposed piston arrangement using a common link rod was also deemed operational.

Other significant patents reviewed were by Deng et al. [12], Nerstrom [13], Iliev et al. [14], Allais [15], Heintz [16], and Rittmaster et al. [17]. These patents emphasize different applications of a free-piston engine and the advantages of reduction of moving parts like connecting rod and crankshaft in an engine thereby leading to ease of maintenance, reduced cost and lower frictional losses leading to higher mechanical efficiency of the engine. 


\section{FUNDAMENTAL ANALYSIS OF A TWO-STROKE LINEAR}

ENGINE

\section{3.(1) INTRODUCTION}

The analysis presented below examines an ideal two-stroke engine with two opposed pistons connected solidly by a link rod and following the air-standard Otto cycle of operation. A simple case of an idling engine or an engine from which power was extracted with constant force was examined. The air standard Otto cycle of operation was assumed so as to provide us with pressures prevalent within the cylinders during idling operation of the engine. This helped create a fundamental analysis, that was useful in the study of effects of load changes, timing variations and changes in compression ratio on the working of a linear two-cylinder internal combustion engine.

It was understood that real systems were far more complex in comparison to the ideal case assumed in the following analysis and that a numerical analysis might have to be employed in order to understand better the complex system. However, the fundamental analysis presented provided a basic understanding of the linear two-cylinder internal combustion engine, much in the way an air-standard Otto cycle or Diesel cycle provides basic understanding of engine thermodynamic trends.

\section{3.(2) ENGINE MODEL}

The ideal engine model used in the analysis consisted of a linear two-cylinder two-stroke cycle internal combustion engine that follows an idealized Otto cycle of operation, with heat addition at the outermost position and heat rejection at the innermost. In reality, the cylinder pressures during scavenging will stray from the Otto cycle, but this 
model was considered to be acceptable since major forces occurring during expansion and compression were properly incorporated. It consisted of two opposed pistons connected by a rigid link rod. The pistons had equal and symmetric strokes and were outward compressing. The engine was assumed to have instantaneous intake and exhaust at the innermost position and instantaneous heat release at the outermost position. The engine being a linearly reciprocating type, the piston did not encounter a top dead center position or a bottom dead center position, but rather had an innermost (for the left piston; $x=x_{s}$ ) and outermost position (for the left piston; $x=-x_{s}$ ). The analysis was carried out in a dimensionless form on this idealized engine, based on the assumption that an idling case of operation was in progress and the only load encountered was a frictional force. A better understanding of the model can be gained from the schematic presented in Fig. 1. The maximum theoretical half stroke length (i.e. the point at which the piston would contact the head) of the piston was $x_{m}$, while the maximum actual half stroke length (allowing for clearance area) of the piston was $x_{s}$ as seen from Fig. 2. The piston on a left to right stroke traverses from $-x_{s}$ to $+x_{s}$. A dimensionless analysis was carried out by taking into consideration the heat added during one cycle, the midpoint pressures in the two cylinders, the friction force encountered by the pistons during their motion from the outermost position to the innermost position and the stroke ratio, that is, the ratio of the instantaneous piston position to the maximum theoretical half stroke of the piston. The compression ratio values were chosen to represent realistic engines with slider-crank mechanisms, while the ratio of specific heats of the working gas was assumed to be constant. The analytical model permitted a thorough understanding of the piston motion under various loading conditions and under different compression ratios. It assisted in 
developing a relationship between the piston velocity, the piston position and the time required for one stroke. An approach towards injection timing control and piston position control could be made on the basis of the following analysis.

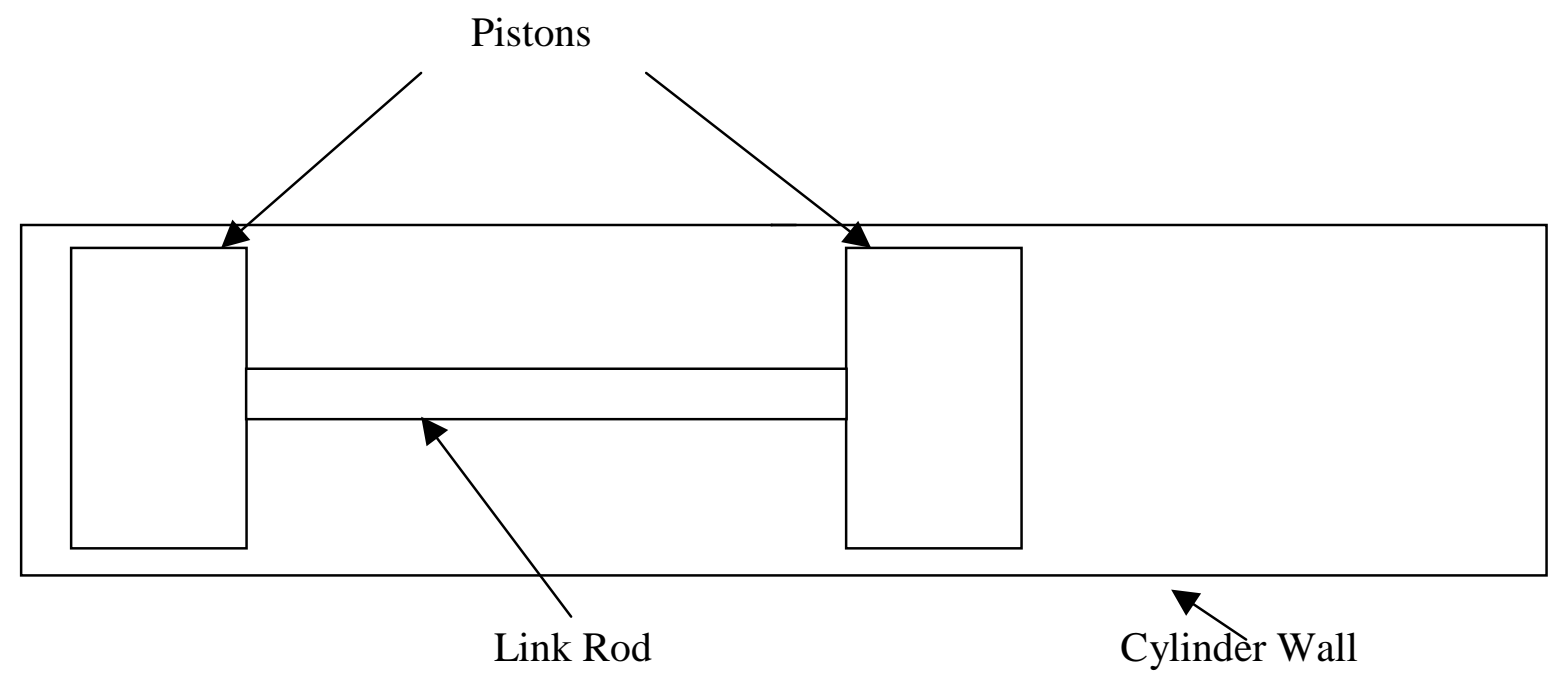

Figure 1 The ideal engine model at the beginning of a left to right compression stroke $\left(x=-x_{s}\right)$.

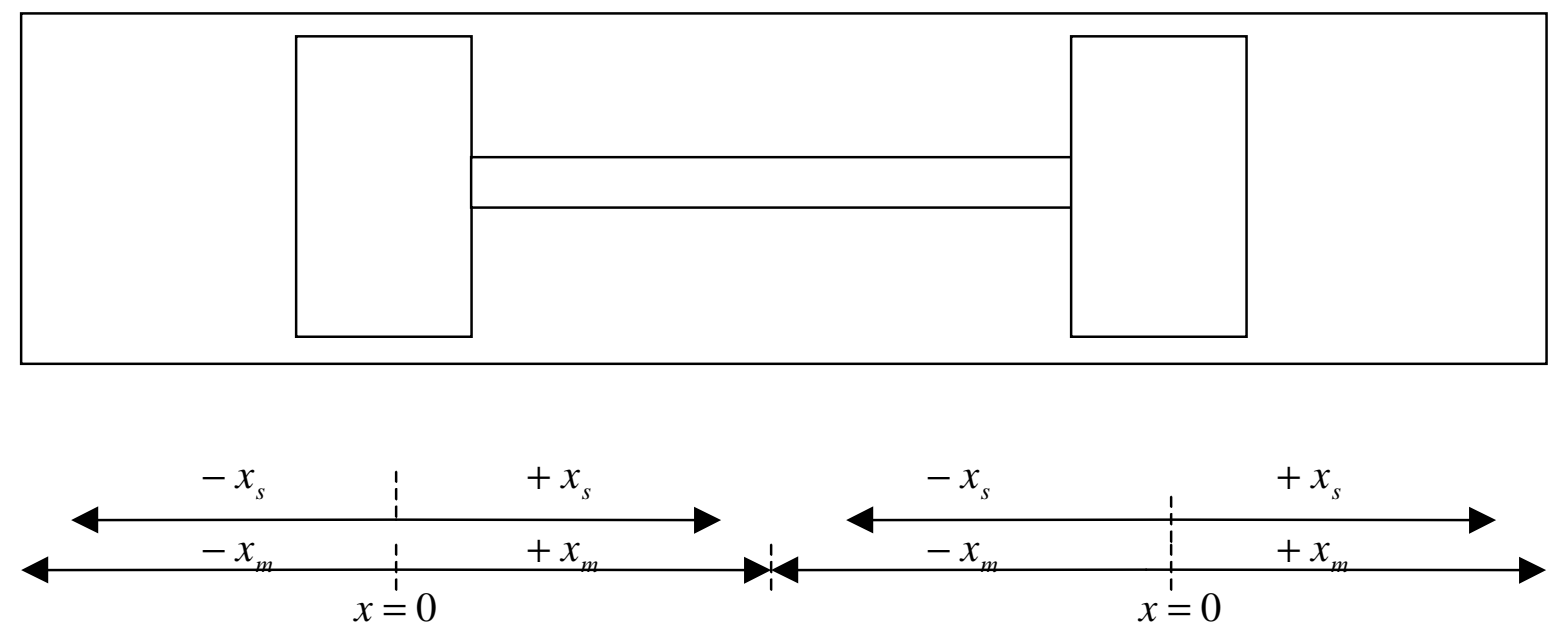

Figure 2 The ideal engine model with the pistons at the midpoint position $(x=0)$. 


\section{3.(3) ASSUMPTIONS}

The fundamental analysis was carried out on an ideal engine model using the following assumptions:

1. A two-stroke engine concept was assumed which follows an idealized Otto cycle for its operation, i.e. instantaneous intake and exhaust at the innermost position and instantaneous heat release at the outermost position.

2. An idling case of operation with only a frictional force being encountered during the engine operation.

3. The heat input to the engine was used entirely for the work done to overcome the friction drag force acting on the piston (no heat loss).

The analysis was carried out on the idealized engine in a dimensionless form. Given these assumptions, an analytical solution in velocity versus position, velocity versus time and position versus time were obtained and are presented below.

\section{3.(4) MATHEMATICAL MODEL}

Consider a linear two stroke engine model.

We may specify, a priori, the following independent variables

The bore, $b$,

The maximum theoretical half-stroke length, $x_{m}$,

The friction force required to move the slider, $\mathrm{F}_{\mathrm{f}}$ : this was assumed in the simplified model to be constant throughout the stroke,

The mass of the slider, $\mathrm{m}_{\mathrm{s}}$,

The quantity of heat added to one cylinder during a cycle, $\mathrm{Q}_{\text {in, }}$ 
The midpoint pressure of the compression cylinder, $\mathrm{P}_{\mathrm{m}}$. In terms of constraint of the system, this is equivalent to defining the intake pressure at the beginning of the outward stroke.

The ratio of specific heats, $\mathrm{n}$, is assumed to be known.

These quantities reduce into the following independent dimensionless variables:

The friction work to heat ratio

$$
\frac{2 F_{f} x_{m}}{Q_{\text {in }}}
$$

The heat to pressure work ratio

$$
\frac{Q_{i n}}{2 P_{m} x_{m}\left(\frac{\pi b^{2}}{4}\right)}
$$

The compression ratio, $r$, also arises as a dependent variable, but in the data generated, $r$ was actually chosen so that $\mathrm{Q}_{\text {in }}$ became dependant.

The characteristic time

$$
t_{c}=\sqrt{\frac{2 m_{s} x_{m}}{P_{m}\left(\frac{\pi b^{2}}{4}\right)}}
$$

Now let us consider a force balance for a left-to-right stroke, with $x$ positive in the left-to-right direction. Then

$$
P_{l}(x) \frac{\pi b^{2}}{4}-P_{r}(x) \frac{\pi b^{2}}{4}-F_{f}-m_{s} \frac{d^{2} x}{d t^{2}}=0
$$

where, $P_{1}$ is instantaneous pressure in the left cylinder and $P_{r}$ is instantaneous pressure in the right cylinder. If $\mathrm{P}_{\mathrm{m}}$ is the midpoint pressure on compression, then when $x=0$ at the midpoint, assuming adiabatic compression and expansion behavior, we have

$$
P_{r}=\frac{P_{m} V_{m}^{n}}{V_{r}^{n}}
$$


where $V_{r}$ is the instantaneous volume of the right hand cylinder, and $V_{m}$ is the cylinder volume at the midpoint position, given by $\quad V_{m}=x_{m}\left(\frac{\pi b^{2}}{4}\right)$ But $\quad V_{r}=\left(V_{m}-x\left(\frac{\Pi b^{2}}{4}\right)\right)$ for the compression piston, so that

$$
P_{r}=P_{m} \frac{x_{m}^{n}}{\left(x_{m}-x\right)^{n}}
$$

The midpoint pressure for the left side, $\mathrm{P}_{\mathrm{U}}$, is unknown, but defines the pressure in the left cylinder for the expansion phase.

$$
P_{l}=\frac{P_{u} V_{m}^{n}}{V_{l}^{n}}
$$

but

$$
V_{l}=V_{m}+x\left(\frac{\Pi b^{2}}{4}\right)
$$

and so

$$
P_{l}=P_{u} \frac{x_{m}^{n}}{\left(x_{m}+x\right)^{n}}
$$

Hence

$$
\frac{\pi b^{2}}{4} P_{u}\left[\frac{x_{m}^{n}}{\left(x_{m}+x\right)^{n}}\right]-\frac{\pi b^{2}}{4} P_{m}\left[\frac{x_{m}^{n}}{\left(x_{m}-x\right)^{n}}\right]-F_{f}-m_{s} \frac{d^{2} x}{d t^{2}}=0
$$

Now the relationship between $\mathrm{P}_{\mathrm{U}}$ and $\mathrm{P}_{\mathrm{m}}$ depends upon the heat added, $\mathrm{Q}_{\text {in }}$, and the steady state stroke of the engine (half-stroke $=x_{s}$, so that engine oscillates between $x=-x_{s}$ and $x=+x_{s}$, where $-x_{s}<0<x_{s}$ and $0<x_{s}<x_{m}$ ). The minimum volume, during a particular cycle, for a cylinder of such an engine is $\frac{\pi b^{2}}{4}\left(x_{m}-x_{s}\right)$ and the 
maximum is $\frac{\pi b^{2}}{4}\left(x_{m}+x_{s}\right)$. Hence the compression ratio, $\mathrm{r}$, is given by $r=\frac{x_{m}+x_{s}}{x_{m}-x_{s}}$

The mechanical work done in one stroke is

$$
W_{f}=2 F_{f} x_{s}
$$

Invoking Otto cycle efficiency, $\quad \eta=1-\frac{1}{r^{n-1}}$,

one concludes that

$$
2 F_{f} x_{s}=Q_{i n}\left[1-\left(\frac{x_{m}-x_{s}}{x_{m}+x_{s}}\right)^{n-1}\right]
$$

Also, following an Otto cycle, assuming adiabatic compression and constant volume heat addition, one finds that

$$
\frac{P_{u}}{P_{m}}=\left[\frac{T_{m}\left(\frac{x_{m}}{x_{m}-x_{s}}\right)^{n-1}+\frac{Q_{i n}}{m_{f} C_{v}}}{T_{m}\left(\frac{x_{m}}{x_{m}-x_{s}}\right)^{n-1}}\right]
$$

Equations (1) and (3) may be solved mutually for a given input with the boundary conditions

$$
\begin{array}{ll}
x=-x_{s} ; & \frac{d x_{s}}{d t}=0 \\
x=+x_{s} ; & \frac{d x_{s}}{d t}=0
\end{array}
$$

provided that $x_{s}$ is known. However $x_{s}$ depends on $\mathrm{Q}_{\text {in }}$ and is best found using equation (2), which may be given in dimensionless form as 


$$
\frac{2 F_{f} x_{m}}{Q_{i n}}=\left(\frac{x_{m}}{x_{s}}\right)\left[1-\left(\frac{1-\frac{x_{s}}{x_{m}}}{1+\frac{x_{s}}{x_{m}}}\right)^{n-1}\right]
$$

We may graph the right hand side of equation (4), "the stroke function", against $\left(\mathrm{x}_{\mathrm{s}} / \mathrm{x}_{\mathrm{m}}\right)$, the "stroke ratio", as shown in Fig. 3., using values in Table 1. It is interesting to note that the graph has a minimum at a stroke ratio slightly more than 0.5 . One may also graph the stroke function against the compression ratio, $r$, as shown in Fig. 4. The plot shows a rapid decrease in the stroke function at low values of compression ratio and then a constant increase as the compression ratio rises. Note that for a fixed frictional force and maximum theoretical half-stroke length, the ideal fuel quantity $Q_{\text {in }}$ is tightly restricted within the constraint of commonly accepted compression ratios. Generally, $\mathrm{Q}_{\text {in }}$ decreases slowly with increasing stroke for this ideal model. Equation (3) may be re-written as

$$
\frac{P_{u}}{P_{m}}=\left[1+\left\{\frac{Q_{i n}\left(\frac{x_{m}}{x_{m}-x_{s}}\right)^{1-n}(n-1)}{P_{m} x_{m}\left(\frac{\pi b^{2}}{4}\right)}\right\}\right]
$$

So that the solution in dimensionless terms is

$$
\frac{P_{u}}{P_{m}}\left(\frac{1}{\left(1+\frac{x}{x_{m}}\right)^{n}}\right)-\left(\frac{1}{\left(1-\frac{x}{x_{m}}\right)^{n}}\right)-\frac{F_{f} x_{m}}{Q_{i n}} \cdot \frac{Q_{i n}}{P_{m} x_{m}\left(\frac{\pi b^{2}}{4}\right)}-\frac{1}{2} \frac{d^{2}\left(\frac{x}{x_{m}}\right)}{d t^{* 2}}=0
$$


where

$$
\begin{gathered}
t^{*}=\frac{t_{c}}{\sqrt{\frac{2 m_{s} x_{m}}{P_{m}\left(\frac{\pi b^{2}}{4}\right)}}} \\
\left(\frac{x}{x_{m}}\right)=\left(\frac{+x_{s}}{x_{m}}\right) ; \quad \frac{d\left(\frac{x_{s}}{x_{m}}\right)}{d t^{*}}=0 \\
\left(\frac{x}{x_{m}}\right)=\left(\frac{-x_{s}}{x_{m}}\right) ; \quad \frac{d\left(\frac{x_{s}}{x_{m}}\right)}{d t^{*}}=0
\end{gathered}
$$

where $\frac{P_{u}}{P_{m}}$ is found with knowledge of $\frac{F_{f} x_{m}}{Q_{i n}}$ and $\frac{Q_{\text {in }}}{P_{m} x_{m}\left(\frac{\pi b^{2}}{4}\right)}$

This equation is dependent on the dimensionless parameter, $\frac{F_{f}}{P_{m}\left(\frac{\pi b^{2}}{4}\right)}$, which may be termed the load ratio. Equation (6) proves intractable in seeking a solution for position versus time. However, it is possible to obtain an analytic solution for velocity versus position.

Setting $x^{*}=\frac{x}{x_{m}}$ and setting dimensionless velocity $v^{*}=\frac{d x^{*}}{d t^{*}}$

then

$$
\frac{d^{2} x^{*}}{d t^{* 2}}=v^{*} \frac{d v^{*}}{d x^{*}}
$$

Equation (6) may then be represented as

$$
\frac{1}{2} v^{*} \frac{d v^{*}}{d x^{*}}-\left(\frac{P_{u}}{P_{m}}\right)\left(\frac{1}{\left(1+x^{*}\right)^{n}}\right)+\left(\frac{1}{\left(1-x^{*}\right)^{n}}\right)+\frac{F_{f} x_{m}}{Q_{i n}} \cdot \frac{Q_{i n}}{P_{m} x_{m}\left(\frac{\pi b^{2}}{4}\right)}=0
$$


Therefore $\quad v^{*}=2\left[\frac{P_{u}\left(1+x^{*}\right)^{1-n}}{P_{m}(1-n)}+\frac{\left(1-x^{*}\right)^{1-n}}{(1-n)}-\frac{F_{f} x_{m}}{Q_{i n}} \cdot \frac{Q_{i n}}{P_{m} x_{m}\left(\frac{\pi b^{2}}{4}\right)}\left(x^{*}\right)+C^{*}\right]^{\frac{1}{2}}$

where

$$
C^{*}=\left\{-\frac{P_{u}}{P_{m}}\left[\frac{\left(1+x_{s}^{*}\right)^{1-n}}{(1-n)}\right]-\left[\frac{\left(1-x_{s}^{*}\right)^{1-n}}{(1-n)}\right]+\frac{F_{f} x_{m}}{Q_{i n}} \cdot \frac{Q_{i n}}{P_{m} x_{m}\left(\frac{\pi b^{2}}{4}\right)}\left(x_{s}^{*}\right)\right\}
$$

In the special case of frictionless steady-state case, no heat is added to the engine and the stroke is regulated by the initial condition at time of release of the piston-rod assembly.

$$
\frac{d x}{d t}=0 \quad \text { at } \quad x=-x_{s}
$$

if the system is released from rest with the piston initially at the left of its stroke.

At the midpoint position

$$
\begin{aligned}
& V_{l}=V_{r}=x_{m}\left(\frac{\pi b^{2}}{4}\right) \\
& P_{l}(0)=P_{r}(0)=P_{m}
\end{aligned}
$$

The cyclic motion for this special case is then given by

$$
\left[\frac{1}{\left(1+\frac{x}{x_{m}}\right)^{n}}\right]-\left[\frac{1}{\left(1-\frac{x}{x_{m}}\right)^{n}}\right]-\frac{1}{2} \frac{d^{2}\left(\frac{x}{x_{m}}\right)}{d\left[\frac{2 m_{s} x_{m}}{P_{m}\left(\frac{\pi b^{2}}{4}\right)}\right]}=0
$$




\section{3.(5) RESULTS}

The fundamental analysis provided an equation, which made it possible to obtain an analytic solution for piston velocity versus piston position in dimensionless parameters. It also permitted the calculation of heat input to the cylinders, ratio of midpoint pressures in the two cylinders, instantaneous piston velocity at a specified position and the time required for one stroke of the piston for a specified value of load ratio and compression ratio. The time required for one stroke was calculated numerically by using the relationship $v^{*}=\frac{d x^{*}}{d t^{*}}$ and integrating the time intervals required to constitute the travel of a full stroke. It was thus possible to plot the variation of time required for one stroke of the piston versus the piston position and the piston velocity in dimensionless parameters, for a given value of compression ratio and load ratio.

The graphs showing the above variations were plotted for different values of compression ratios and load ratios. In specifying realistic dimensionless parameters, the bore, $b$, of the engine cylinders was assumed to be $0.1 \mathrm{~m}$ (3.94in.), while the maximum theoretical half stroke length of the piston, $x_{m}$, was assumed to be $0.5 \mathrm{~m}$ (19.7in.). The piston velocity and stroke time were calculated for three different values of the compression ratio, $r$, that were realistically assumed to be 10,15 , and 20 . The frictional load encountered by the piston during its stroke was varied for a fixed value of compression ratio and the piston velocity variations and stroke time variations were plotted. The values of frictional load, $F_{f}$, used were $100 \mathrm{~N}$ (22.5lbf), $500 \mathrm{~N}$ (112.5lbf), $1000 \mathrm{~N}$ (225lbf), 10000N (2250lbf) and 15000N (3375lbf). 
The variation of the piston velocity $v^{*}$, with respect to the instantaneous piston position $x^{*}$, is plotted in Figs. 5 through 7. It was interesting to note that for a fixed compression ratio, the piston velocity, at low loads, was symmetric over the entire stroke. But at higher frictional loads, the piston accelerated rapidly at the beginning of the stroke and then decelerated slowly over the rest of the stroke. The reason for such behavior can be attributed to the fact that the mass of the piston remained constant, while the heat input to the system increased with increasing load. The difference between the expansion and compression pressures increased at high frictional loads. The Figs. 8 through 10, indicate the decrease in time $t^{*}$ required for one stroke of the engine, as the instantaneous piston velocity $v^{*}$ increased, due to the increased load encountered by the piston and the increase in heat input to the system. The piston position $x^{*}$, versus the stroke time $t^{*}$, is plotted in Figs. 11 through 13. The instantaneous piston position at any given time can be easily predicted with the help of these curves, for varying loads and a given value of compression ratio. The nature of the plot was once again symmetric for low loads and asymmetric for high loads. This was due to the rapid acceleration encountered by the piston at the beginning of the stroke at higher loads because of increase in heat input. The variation of in-cylinder pressures with respect to piston position is plotted in Fig. 14. The pressure variation within the cylinder due to change in compression ratio can be studied using similar plots. The change in the ratio of midpoint pressures within the cylinder $\frac{P_{u}}{P_{m}}$, with change in load ratio $\frac{F_{f}}{P_{m}\left(\frac{\pi b^{2}}{4}\right)}$, is shown in Fig. 15. Figure 16 shows the dimensionless piston velocity versus dimensionless piston position plot for one cycle. 


\section{3.(6) CONCLUSION FOR THE FUNDAMENTAL ANALYSIS}

Presented is a fundamental analysis for a linear two-cylinder internal combustion engine that follows the ideal air standard Otto cycle of operation. Dimensionless analysis was based upon a ratio of frictional work performed during the stroke, to the heat added in the thermodynamic cycle, which led in turn to the determination of the compression ratio. Under constraint of a midpoint compression stroke pressure and a characteristic time which considered the reciprocating mass, an analytic phase solution of velocity versus position was possible. Position and velocity versus time were then numerically accessible.

Decreasing compression ratio implies decreasing stroke for an engine of fixed geometry: this in turn implies poorer Otto cycle efficiency and less available mechanical energy. However, decreasing stroke also reduces the frictional energy loss over a cycle. The result is that engine behavior is highly sensitive to the quantity of heat added in the ideal model. Compression ratio must change violently with small changes in heat added. Also, for an engine with all independent variables held constant with the exception of heat addition, which may vary, there is a single maximum value of heat addition possible

(a minimum of $2 F_{f} x_{m} / Q_{i n}$ ) yielding a single possible compression ratio. Higher additions of heat are not theoretically possible. This is not the point of minimum engine efficiency, which would of necessity be at a compression ratio of 0 . At lower values of heat addition two solutions of compression ratio are possible. The lower value of compression ratio represents a short stroke with poor efficiency and little frictional work per cycle. The higher value represents a longer stroke with higher Otto cycle efficiency. This data suggests that in real terms an idling linear engine of this type will be difficult to control in 
terms of fuel quantity, although it will naturally find additional real inefficiencies (ring blowby at high pressures, poor scavenging at high speeds) to limit its behavior if it is overfueled. It is an interesting notion that compression ratio can increase as fueling is reduced, but conceptually it is credible that the piston will take a longer time to reverse its motion in the face of declining opposing in-cylinder pressures arising from reduced heat addition. Practical observations arise from this discussion. Firstly, compression ignition versions of a linear engine must achieve sufficient in-cylinder temperature, from compression, to ignite the fuel. Secondly, spark ignited engines must avoid excessive compression lest they knock. However, the analysis presented in this paper assumes ignition at the outermost piston position. This need not be the case in a real engine. Also, auto-ignition of the charge will be met only by reversible inertial resistance rather than the prescribed motion of a slider-crank engine, so that this additional degree of freedom may allow a more sympathetic interaction of thermodynamic and mechanical systems than in a conventional engine. The compression ratio will be determined by fuel cetane and octane ratios rather than just heat release in reality. 
TABLE 1

\begin{tabular}{|c|c|c|}
\hline$\left(\frac{x_{s}}{x_{m}}\right)$ & $r$ & {$\left[\frac{x_{m}}{x_{s}}\left[1-\left\{\frac{1-\frac{x_{s}}{x_{m}}}{1+\frac{x_{s}}{x_{m}}}\right)^{n-1}\right]\right.$} \\
\hline 0.1 & 1.22 & 0.7646 \\
\hline 0.2 & 1.50 & 0.7486 \\
\hline 0.3 & 1.86 & 0.7327 \\
\hline 0.4 & 2.33 & 0.7176 \\
\hline 0.5 & 3.00 & 0.7112 \\
\hline 0.6 & 4.00 & 0.7094 \\
\hline 0.7 & 5.67 & 0.7149 \\
\hline 0.8 & 9.00 & 0.7309 \\
\hline 0.85 & 12.33 & 0.7457 \\
\hline 0.9 & 19.00 & 0.7689 \\
\hline 0.95 & 39.00 & 0.8905 \\
\hline
\end{tabular}

TABLE 2

\begin{tabular}{|c|c|c|}
\hline Frictional Force $\mathrm{F}_{\mathrm{f}}$ & Heat Input $\mathrm{Q}_{\text {in }}$ & Ratio of midpoint pressures \\
$\mathrm{N}[\mathrm{lbf}]$ & $\mathrm{J}[\mathrm{ft}-\mathrm{lbf}]$ & $\mathrm{P}_{\mathrm{u}} / \mathrm{P}_{\mathrm{m}}$ \\
\hline Compression Ratio $\mathrm{r}=10$ & & \\
$100[22.5]$ & $13.59349[10.03]$ & 1.030719 \\
$500[112.5]$ & $67.96745[50.13]$ & 1.153597 \\
$1000[225]$ & $135.9349[100.26]$ & 1.307194 \\
$10000[2250]$ & $1359.349[1002.6]$ & 4.07194 \\
$15000[3375]$ & $2039.023[1503.9]$ & 5.60791 \\
\hline Compression Ratio $\mathrm{r}=15$ & & \\
$100[22.5]$ & $13.22759[9.76]$ & 1.024006 \\
$500[112.5]$ & $66.13795[48.78]$ & 1.120032 \\
$1000[225]$ & $132.2759[97.56]$ & 1.240064 \\
$10000[2250]$ & $1322.759[970.5]$ & 3.400637 \\
$15000[3375]$ & $1984.1385[1463.4]$ & 4.600955 \\
\hline Compression Ratio $\mathrm{r}=20$ & & \\
$100[22.5]$ & $12.95682[9.56]$ & 1.020632 \\
$500[112.5]$ & $64.7841[47.78]$ & 1.103158 \\
$1000[225]$ & $129.5682[95.56]$ & 1.206316 \\
$10000[2250]$ & $1295.682[955.6]$ & 3.063162 \\
$15000[3375]$ & $1943.523[1433.5]$ & 4.094743 \\
& & \\
\hline
\end{tabular}




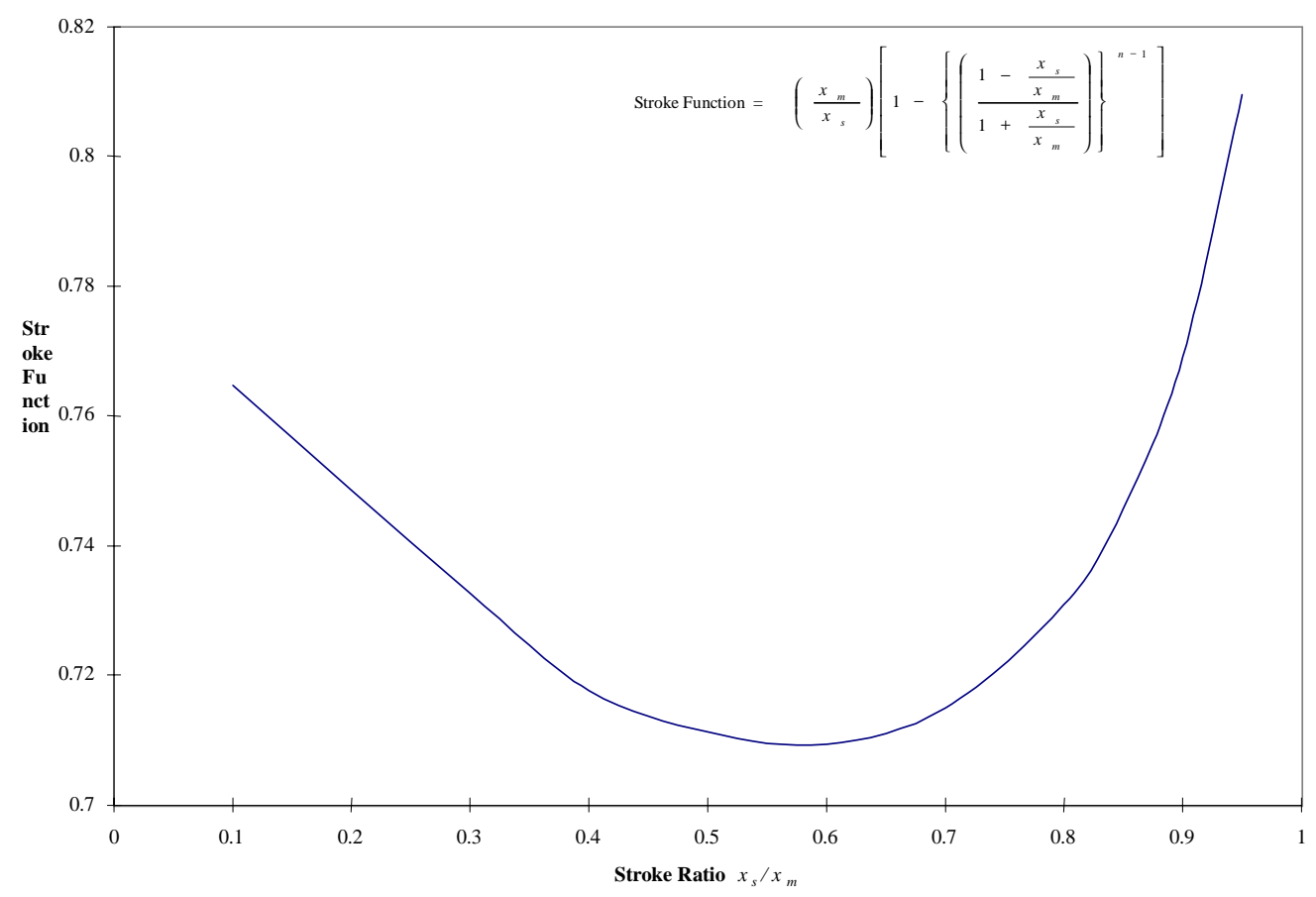

Figure 3 Plot of Stroke Function versus Stroke Ratio.

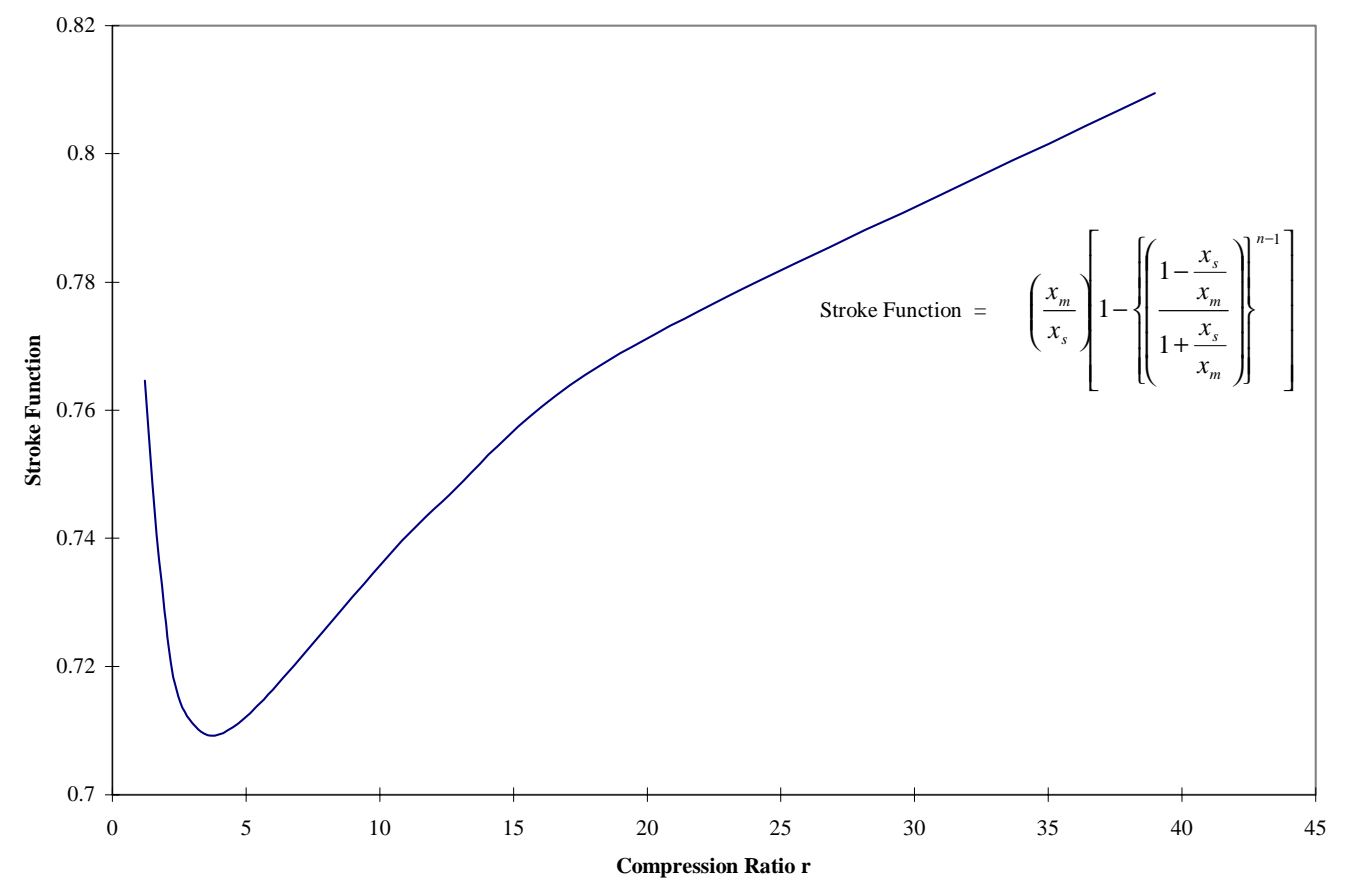

Figure 4 Plot of Stroke Function versus Compression Ratio r. 


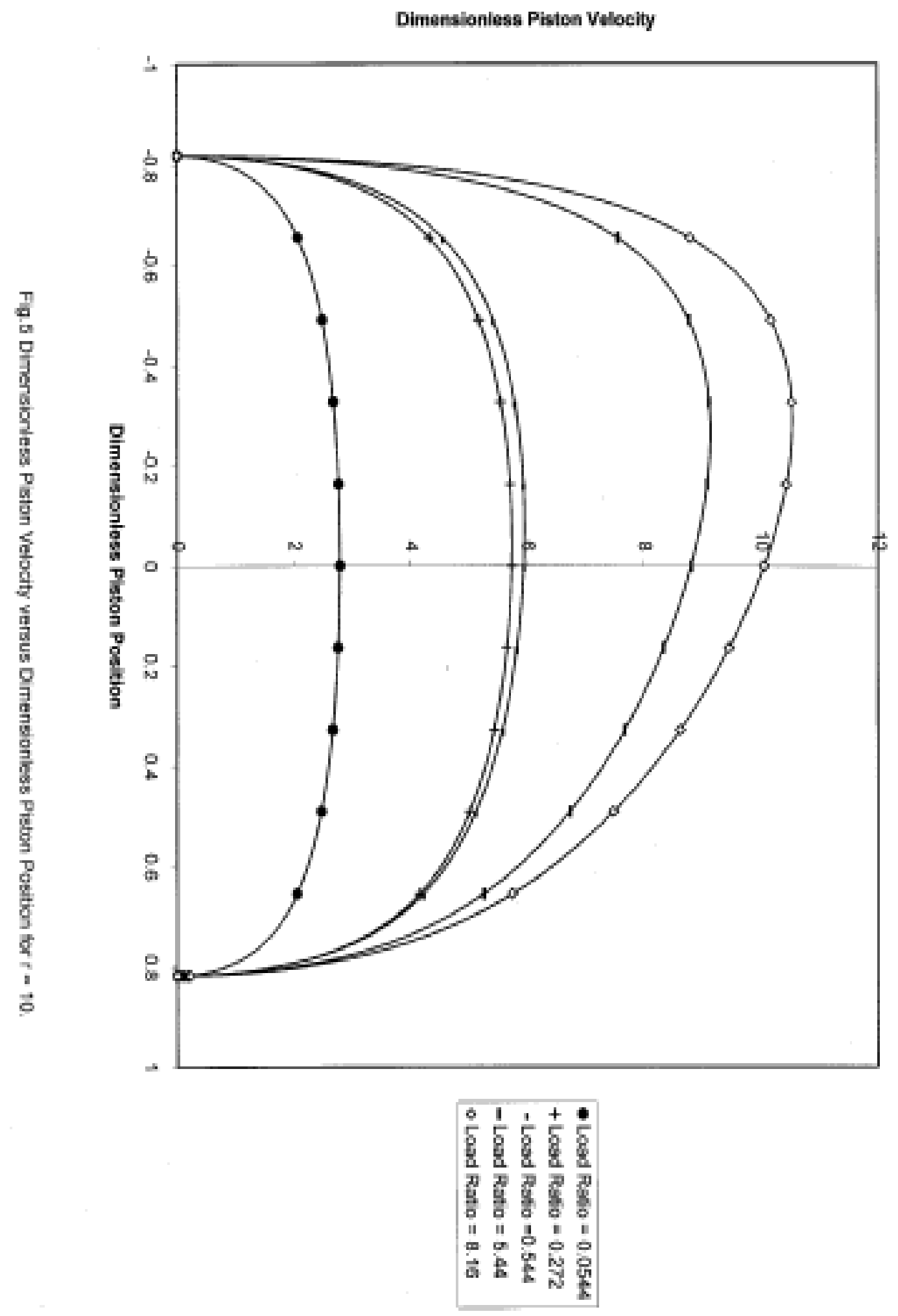




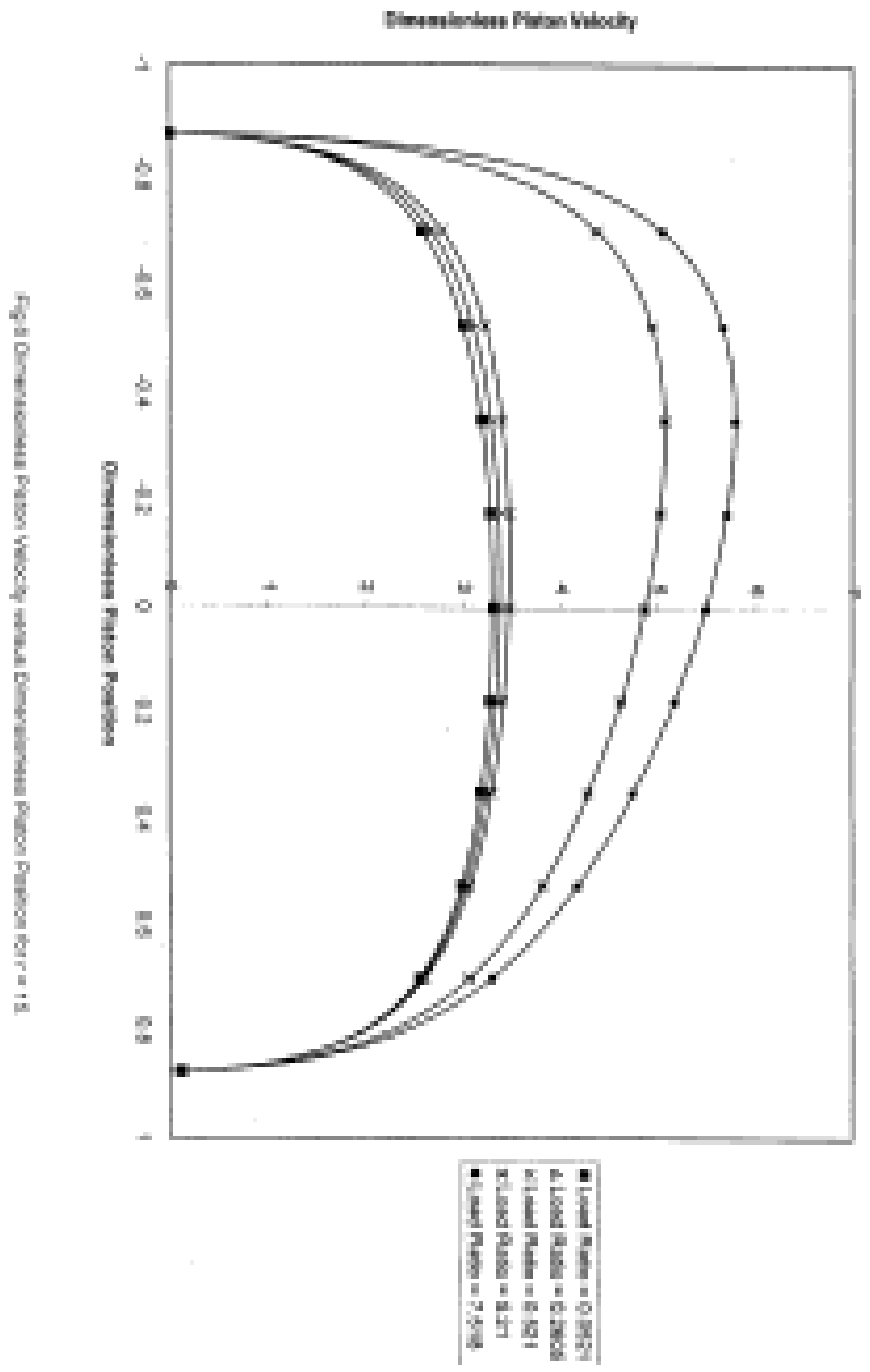




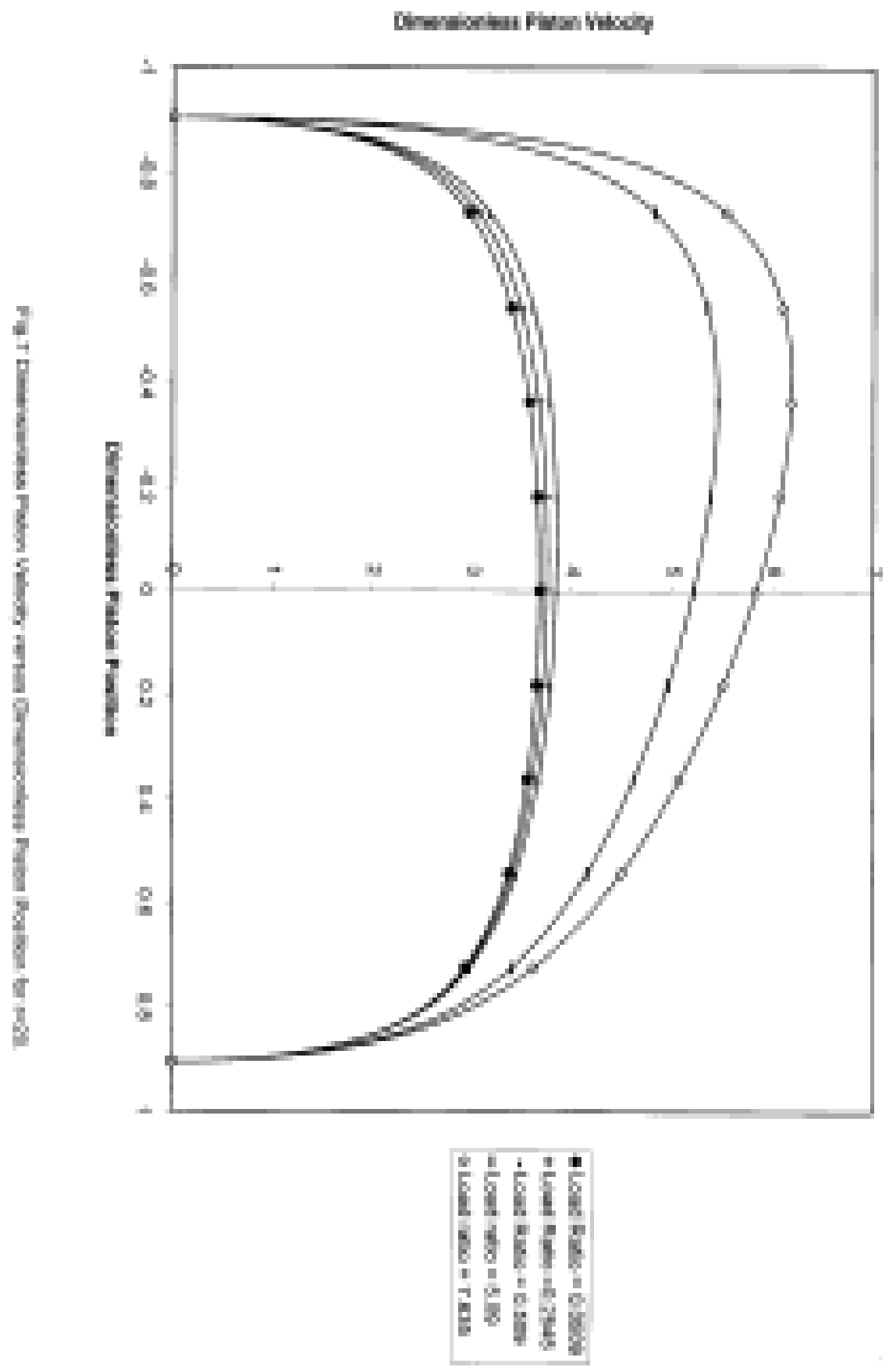




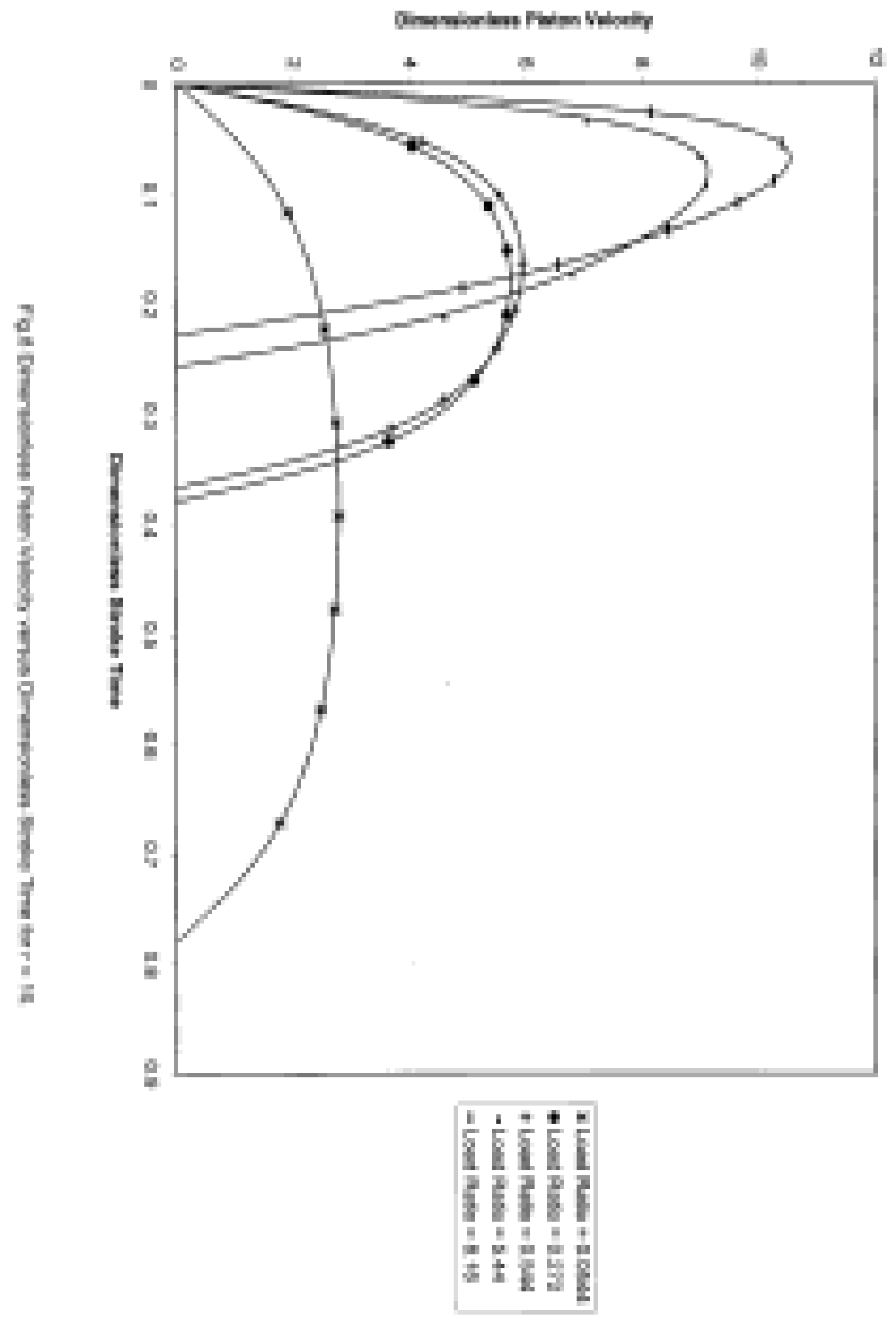




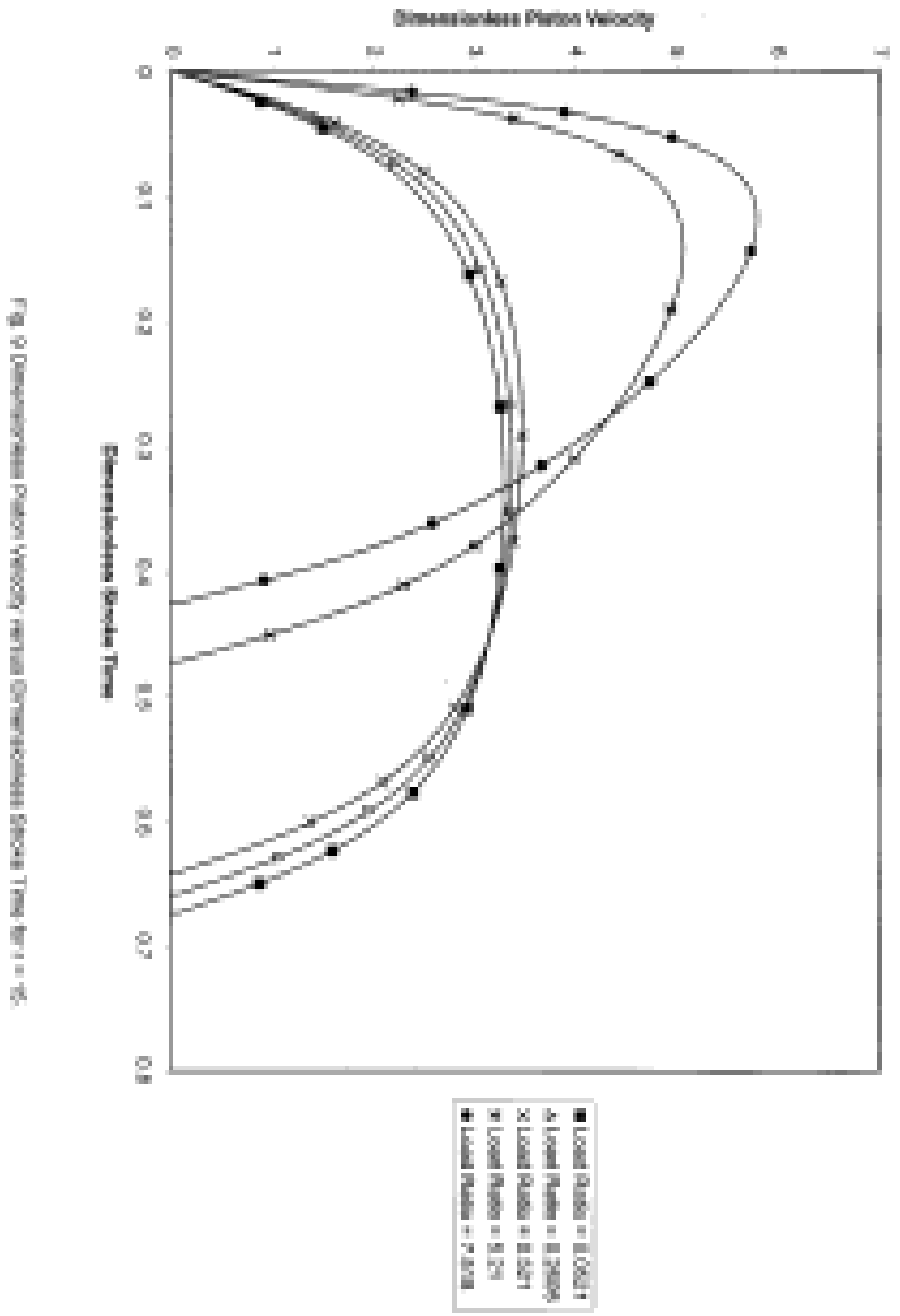




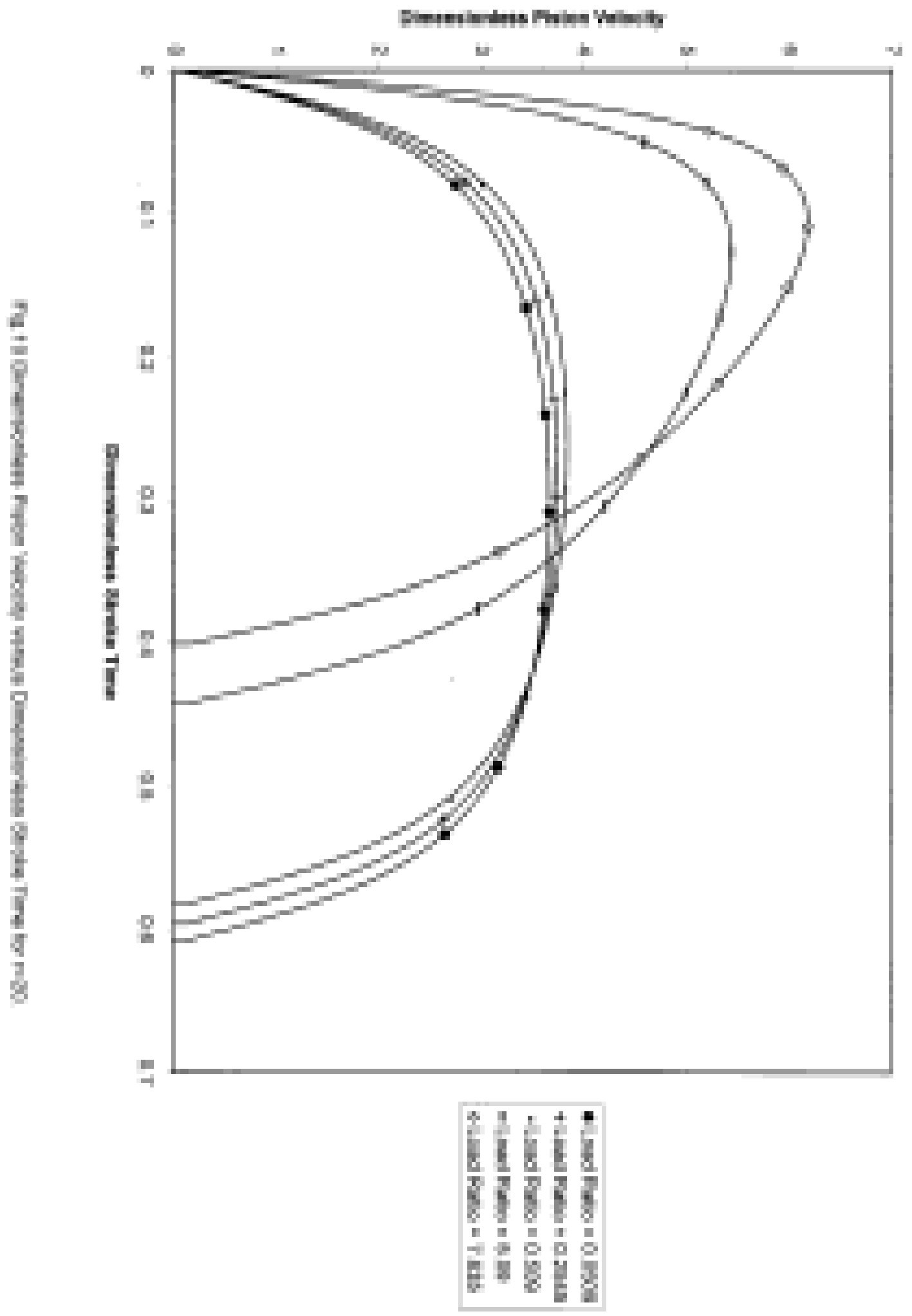




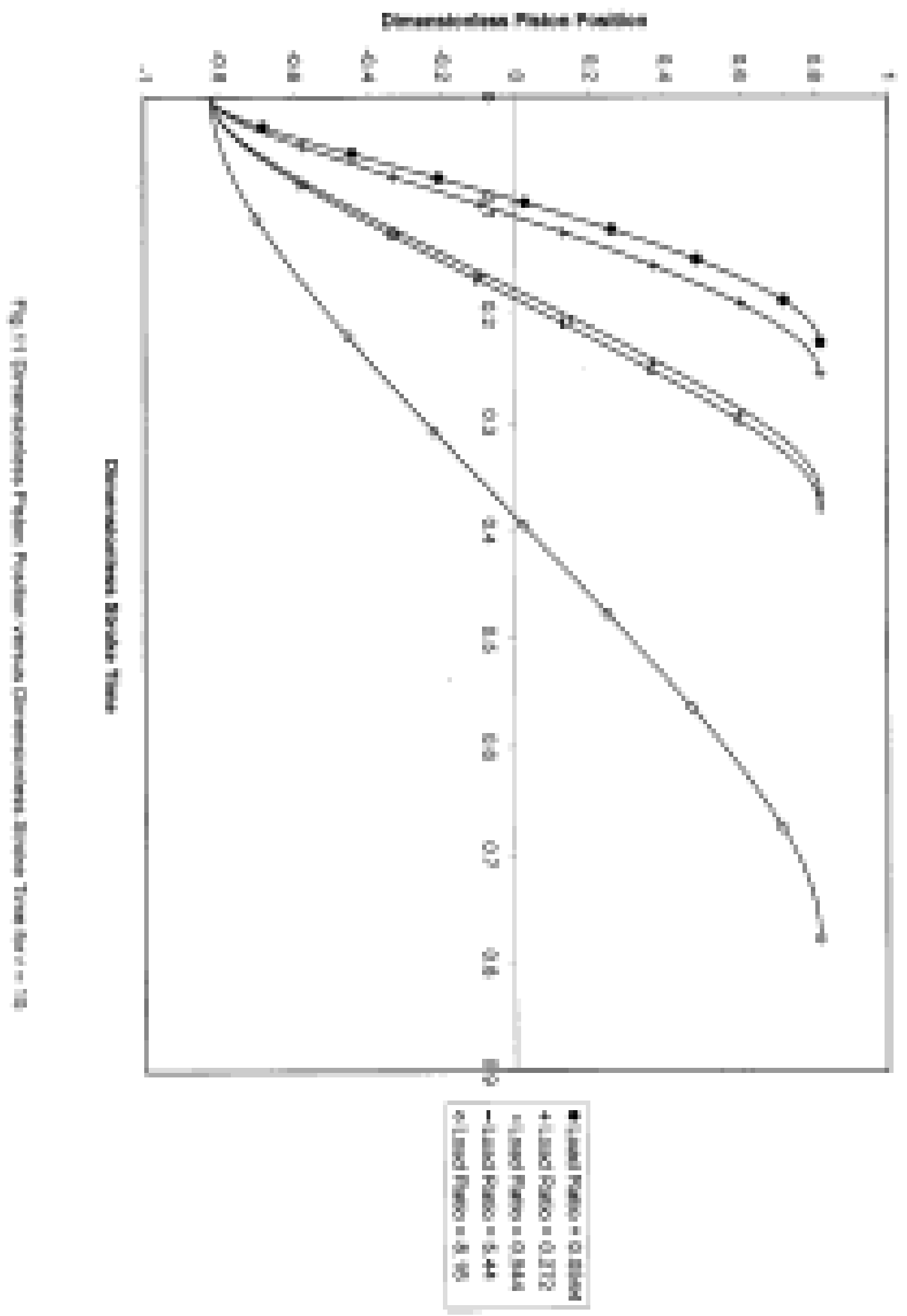




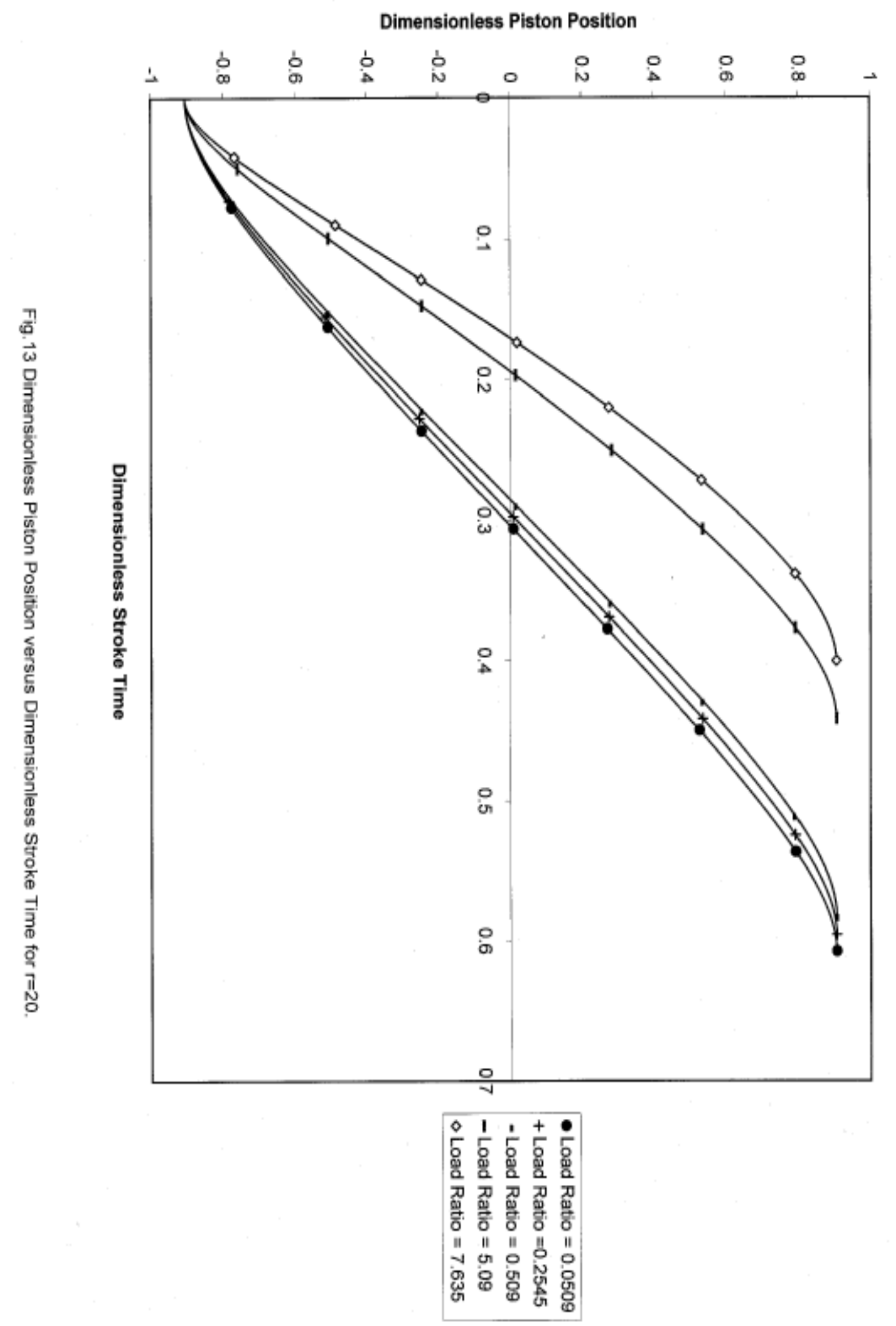




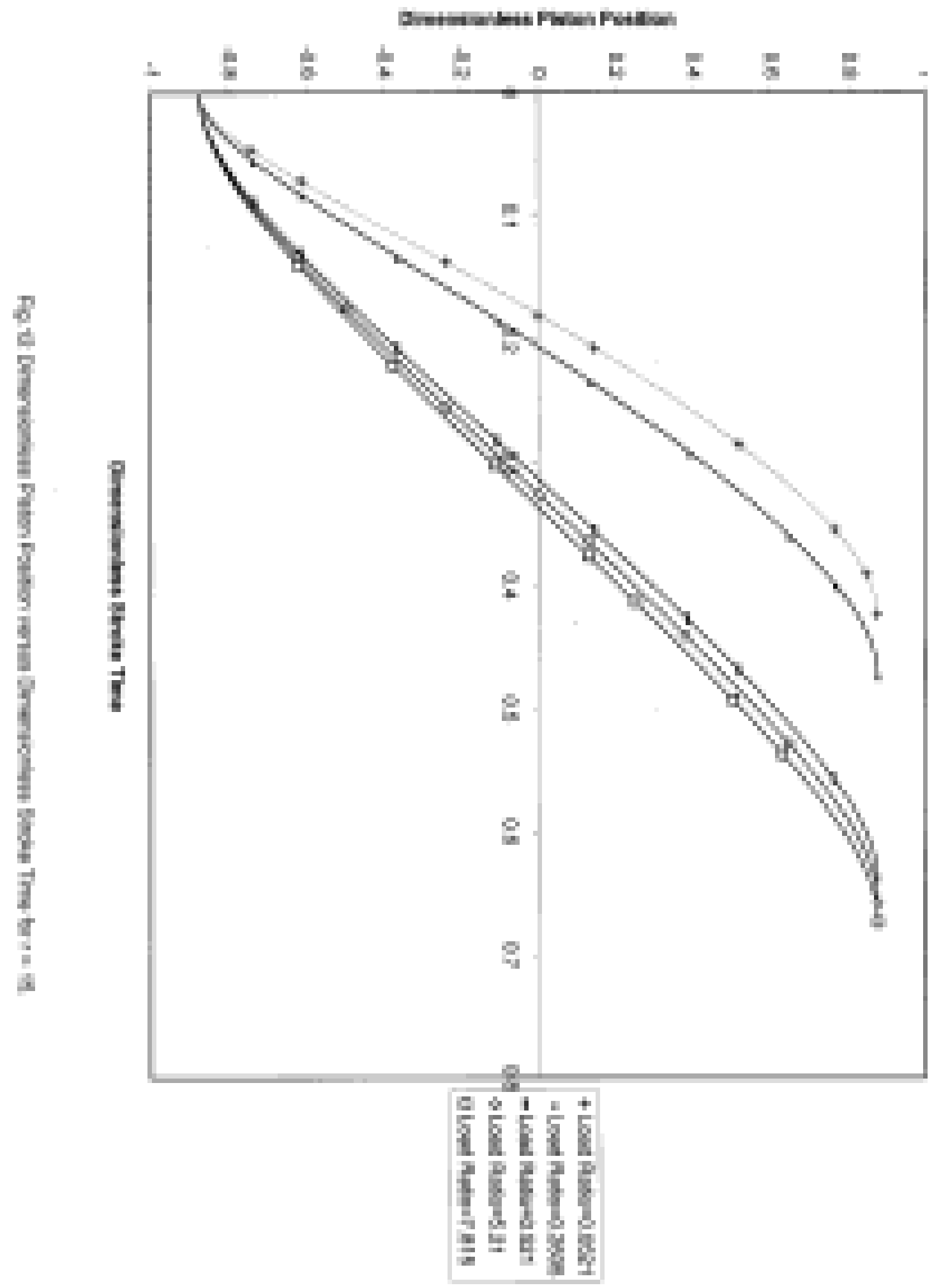




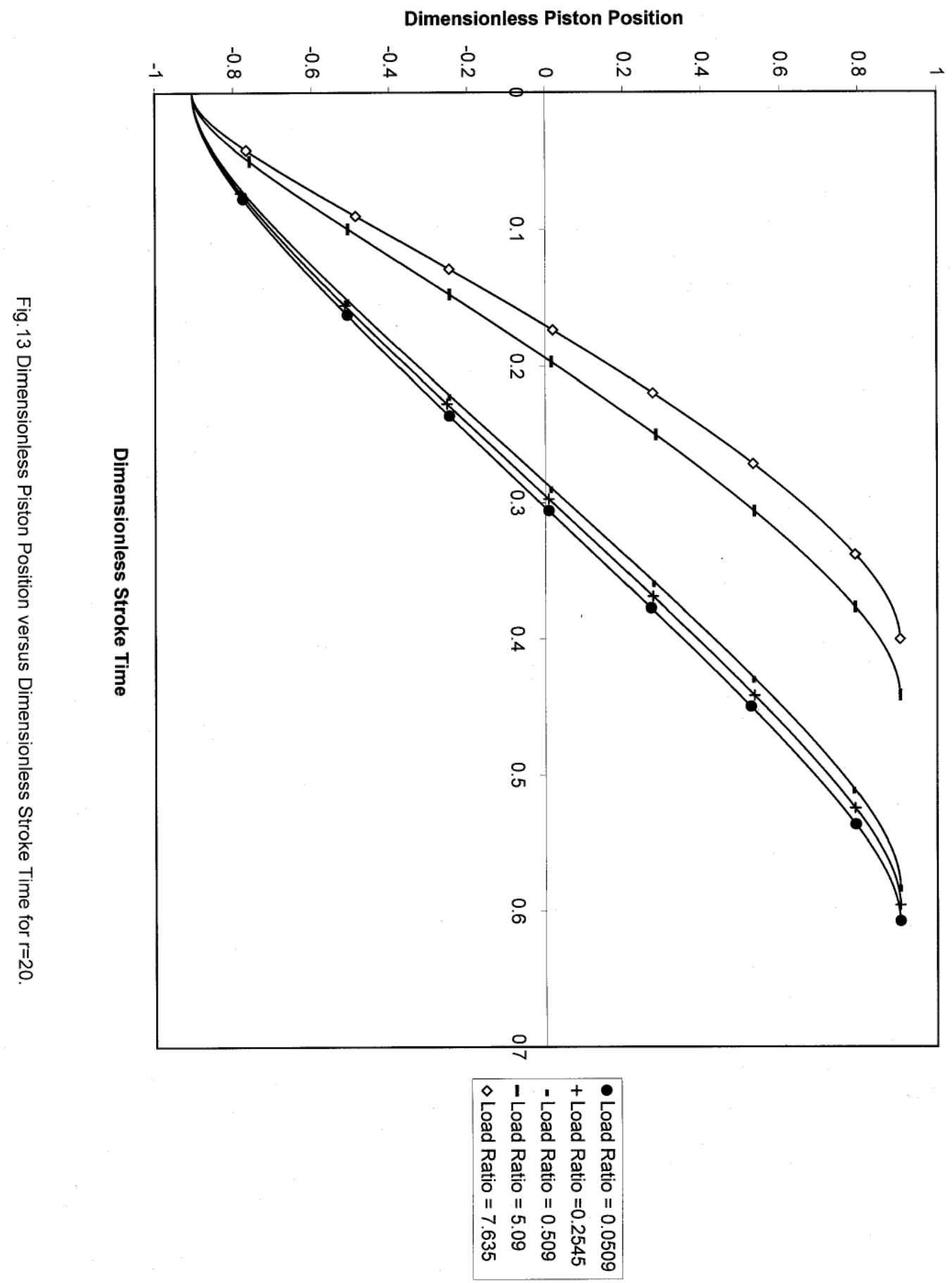




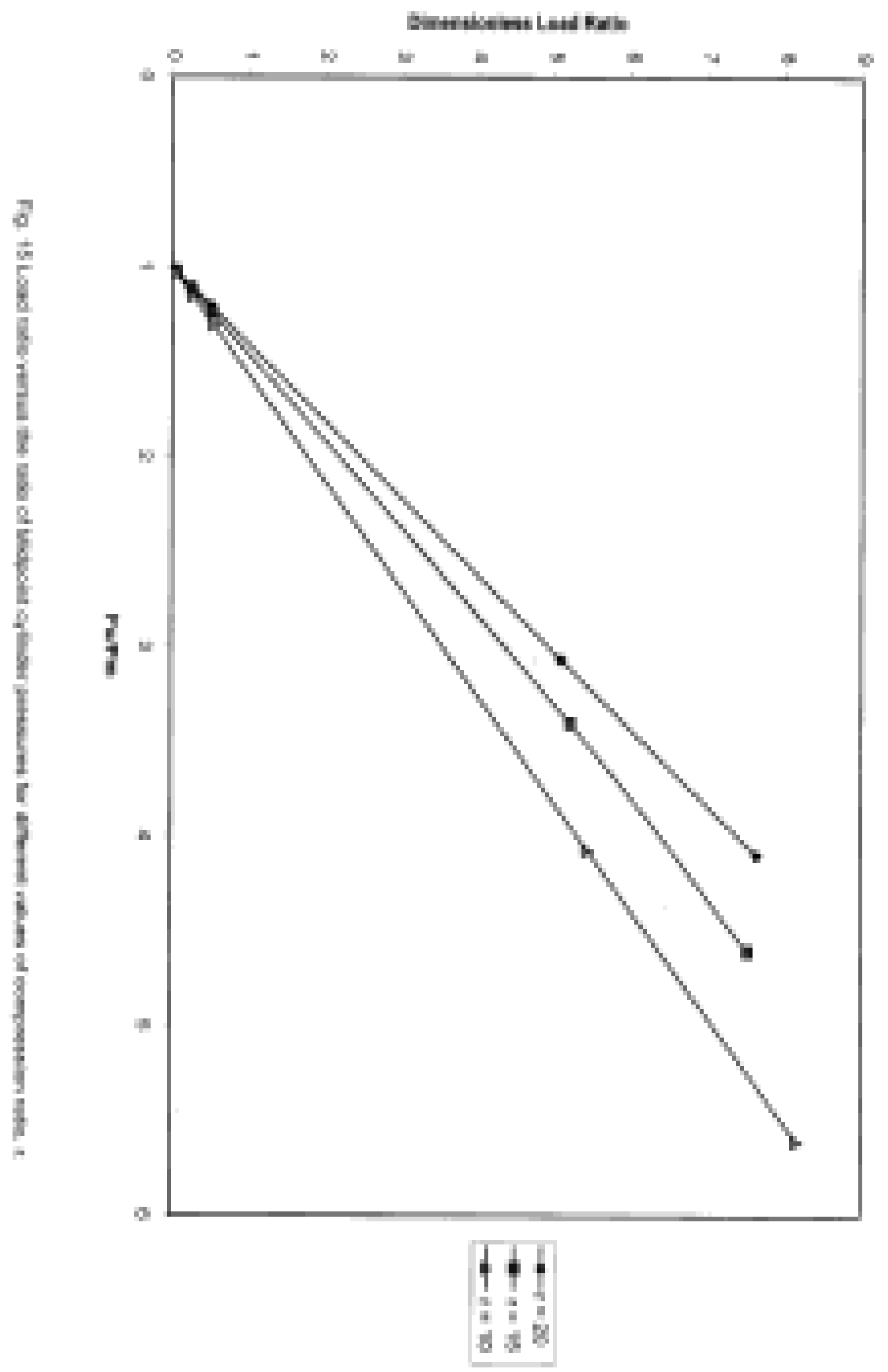




\section{ADDITIONAL ANALYSES USING IDEALIZED MODEL EQUATIONS}

The idealized mathematical model was utilized to provide an understanding of the effect of changes in engine bore dimensions, compression ratio and air-fuel ratio on the speed of the linear engine. These analyses were conducted using a few assumptions. The assumptions and results are presented in the following sections.

\subsection{EFFECT OF ENGINE BORE ON ENGINE SPEED}

Based on the mathematical model presented, in Chapter 3, analyses may be conducted to determine factors affecting the engine frequency of operation, assuming that the pressure in the left $\left(P_{l}\right)$ and right $\left(P_{r}\right)$ cylinders varies in the same way with respect to dimensionless time. Time is rendered dimensionless in this case with respect to the time period needed to complete a stroke, $\tau$. A simple force balance shows that

$$
\tau=\sqrt{\frac{8 m_{s} x_{m}}{\pi b^{2} k}}
$$

where $\mathrm{k}$ is a constant depending on the exact time-varying in-cylinder pressures. This equation shows us that piston speed will decrease as the square root of the reciprocating mass, but increase as the bore increases. The validity of this equation and the effect of bore on the engine speed were checked using the dimensionless relationship between velocity and position, and calculating the time required for one stroke numerically. The analysis was conducted for 3 different values of compression ratio, 10, 15 and 20. The bore was varied from $25.4 \mathrm{~mm}$ ( 1 in.) to $152.4 \mathrm{~mm}$ (6 in.). The reciprocating mass was assumed to be $5 \mathrm{~kg}(11 \mathrm{lbs})$. The engine was assumed to reciprocate freely (i.e. with its 
natural frequency) with no heat being added and no frictional load being encountered. The maximum permissible stroke of the engine (where the piston hits the head) was assumed to be $50 \mathrm{~mm}$ ( 2 in.). The numerical value of dimensionless time was converted into dimensional terms by using the following equation:

$$
t=t^{*} \times \sqrt{\frac{2 m_{s} x_{m}}{P_{m}\left(\frac{\pi b^{2}}{4}\right)}}
$$

where $t$ is in seconds. The engine speed in cycles per minute was thus calculated. The results of the analysis are tabulated below. The engine speed was found to increase with an increase in bore and an increase in compression ratio; as shown in Fig. 17. The analysis showed that the increase in engine bore was directly proportional to the engine speed.

TABLE 3

The effect of changing the engine bore for different compression ratios

\begin{tabular}{|c|c|c|c|}
\hline \multirow{2}{*}{$\begin{array}{c}\text { Bore } \\
\text { mm (in.) }\end{array}$} & $\mathbf{r = 1 0}$ & $\mathbf{r = 1 5}$ & $\mathbf{r = 2 0}$ \\
\cline { 2 - 4 } & speed (cpm) & speed (cpm) & speed (cpm) \\
\hline $25.4(1)$ & 751 & 915 & 965 \\
\hline $50.8(2)$ & 1499 & 1825 & 1938 \\
\hline $76.2(3)$ & 2249 & 2744 & 2900 \\
\hline $101.6(4)$ & 2998 & 3663 & 3860 \\
\hline $127.0(5)$ & 3748 & 4582 & 4837 \\
\hline $152.4(6)$ & 4511 & 5488 & 5798 \\
\hline
\end{tabular}




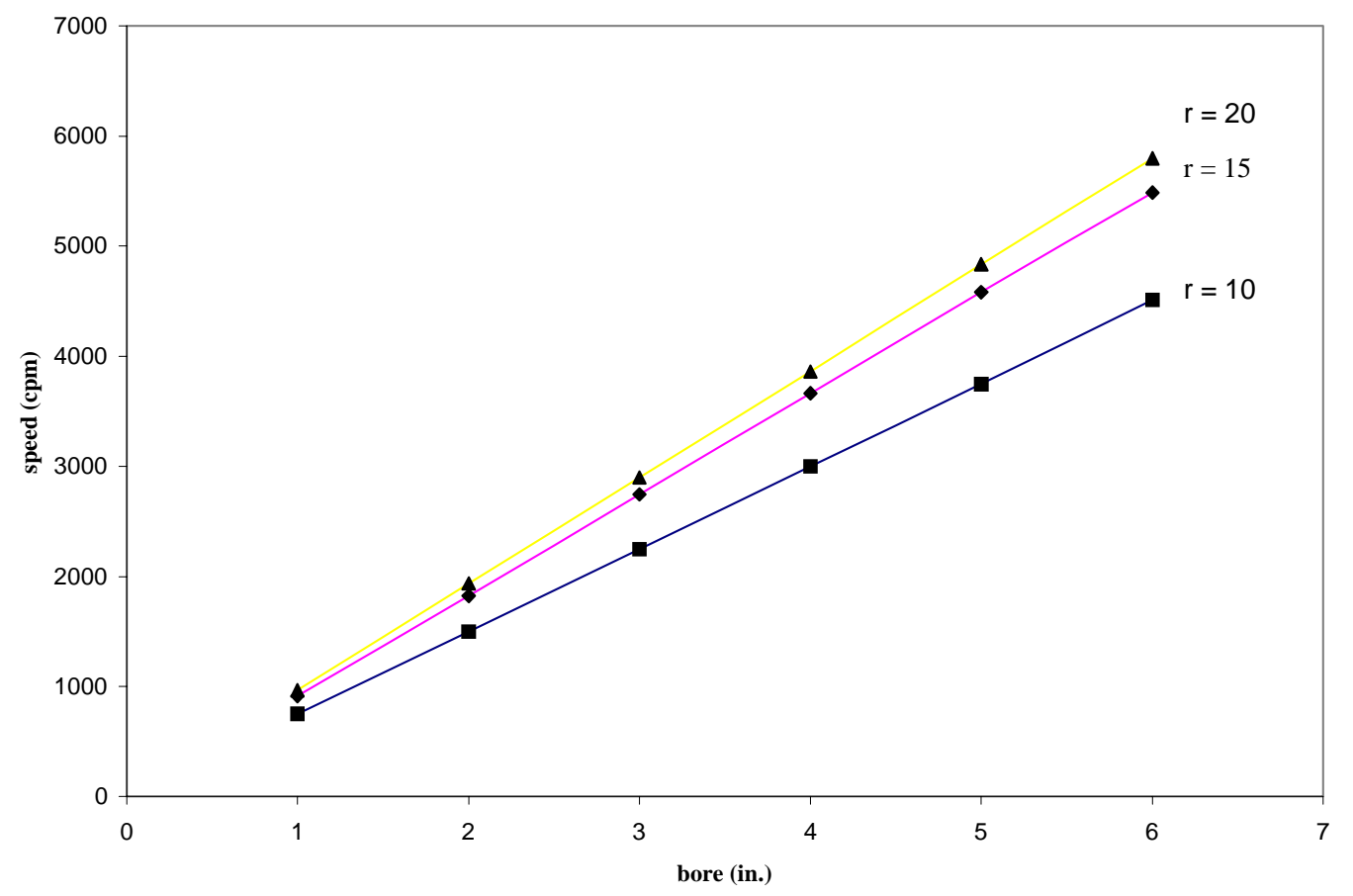

Figure 17 The engine speed plotted against the engine bore for different values of compression ratios. The increase in the engine speed with the increase in engine bore was as predicted.

\subsection{EFFECT OF AIR-FUEL RATIO ON ENGINE SPEED}

The power being extracted from the engine by the linear alternator is directly proportional to the speed of the engine. The speed of the engine would vary with the heat input (which is based on the air-fuel ratio) to the system and the engine size (stroke-tobore ratio). The effect of variations in air-fuel ratio for different stroke-to-bore ratios was analyzed to provide an insight into the effects on the engine speed. It was mooted that the required engine speed, for maximum chemical to electrical energy using the linear alternator, could be maintained constant by proper sizing of the engine and by varying the air-fuel ratio. The analysis was conducted on four different cases of stroke-to-bore ratios which were realistically assumed [17] to be $0.84,1,1.4$ and 3 . The air-fuel ratio was varied for each case from 12 to 50 , in order to cover a wide range of operation for both 
gasoline and diesel engines. The compression ratio of the engine was assumed to be 20 . The heat input to the engine was calculated by using the following equations:

Mass of air $(\mathrm{kg} /$ cycle $)=$ Displacement volume $*$ Density of air

Mass of fuel $(\mathrm{kg} /$ cycle $)=$ Mass of air per cycle $/$ Air-fuel ratio

Heat input $(\mathrm{kJ})=$ Mass of fuel $*$ Calorific Value of fuel

The heat input was then used to calculate the velocity and the displacement of the piston, which once again led to a numerical solution for time required for one stroke in dimensionless terms. The engine speed was then calculated by converting this dimensionless time into dimensional units, using equation 12 . The effect of varying the air-fuel ratio for different stroke-to-bore ratios is shown in Fig. 18. It was seen that the engine speed reduced with an increase in air-fuel ratio. This can be attributed to the fact that the idealized model does not take into consideration the combustion characteristics, heat transfer losses and fuel burning characteristics. As a result an increase in air-fuel ratio reflects in the model as a decrease in heat input and thereby a decrease in piston velocity. The analysis also showed an increase in the engine speed with a decrease in the stroke-to-bore ratio. The increase in bore increases the engine speed, as seen earlier in section 4.1. The results from the four different cases of stroke-to-bore ratios are shown in Table 4. It is seen that the small stroke and large bore combination $(\mathrm{L} / \mathrm{b}=0.84)$ shows the maximum engine speed while the large stroke small bore combination $(\mathrm{L} / \mathrm{b}=3)$ shows the lowest engine speeds. Since the final electrical output from the linear alternator is directly proportional to the speed of the engine, it is desirable to increase the engine speed. The analysis shows that the engine should have a short stroke and a large bore in order to increase the engine speed. The analysis presented provides a means of predicting the 
behavior of a linear engine with regards to engine speed for different combinations of stroke length and bore, and also in studying the effects of changes in air-fuel ratios.

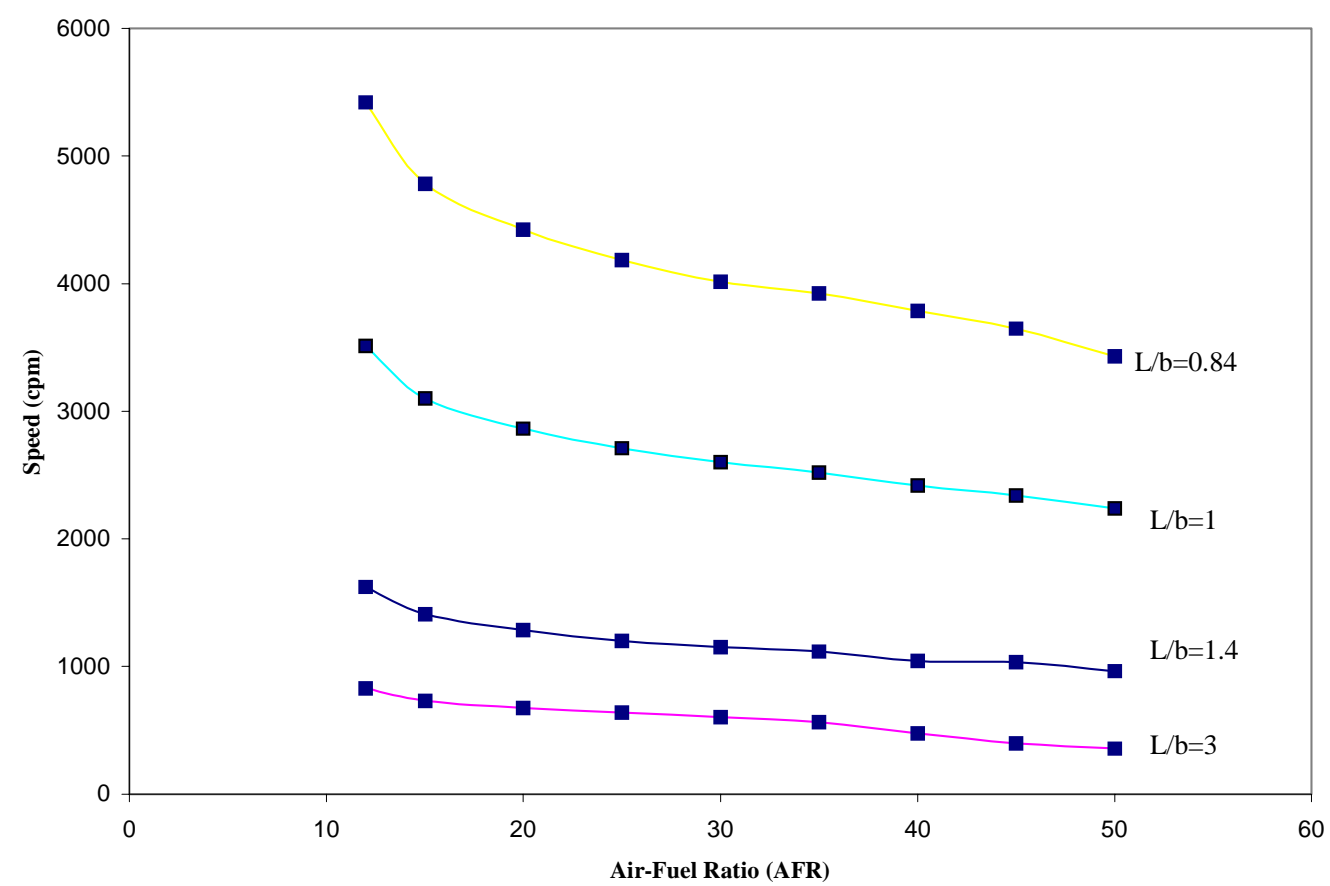

Figure 18 The engine speed is plotted against the air-fuel ratio (AFR), for different L/b ratios.

TABLE 4

Effect of varying the air-fuel ratio(AFR) for different stroke-to-bore (L/b) ratios.

\begin{tabular}{|c|c|c|c|c|}
\hline \multirow{2}{*}{ AFR } & $\mathbf{L} / \mathbf{b}=\mathbf{3}$ & $\mathbf{L} / \mathbf{b}=\mathbf{1 . 4}$ & $\mathbf{L} / \mathbf{b}=\mathbf{1}$ & $\mathbf{L} / \mathbf{b}=\mathbf{0 . 8 4}$ \\
\cline { 2 - 5 } & Speed (cpm) & Speed $(\mathbf{c p m})$ & Speed $(\mathbf{c p m})$ & Speed (cpm) \\
\hline 12 & 827.8 & 1624.2 & 3513.1 & 5420.0 \\
\hline 15 & 730.5 & 1407.5 & 3099.6 & 4783.1 \\
\hline 20 & 675.2 & 1284.1 & 2865.1 & 4420.5 \\
\hline 25 & 638.8 & 1200.0 & 2710.5 & 4182.6 \\
\hline 30 & 604.5 & 1151.2 & 2601.3 & 4013.1 \\
\hline 35 & 561.3 & 1115.9 & 2520.2 & 3925.5 \\
\hline 40 & 476.8 & 1042.6 & 2417.9 & 3785.78 \\
\hline 45 & 395.5 & 1032.5 & 2339.6 & 3645.1 \\
\hline 50 & 355.3 & 965.0 & 2235.6 & 3430.6 \\
\hline
\end{tabular}




\subsection{ENERGY ANALYSIS}

The working of the linear engine results from the conversion of heat energy released during combustion of fuel into kinetic energy of the piston and potential energy stored in the compressed gases. The conversion of potential energy to kinetic energy and back to potential energy, if not efficient can lead to an inefficient system. The energy analysis was conducted to study the amount of potential and kinetic energy present in the system and the rate of change of energy in the system. The transient energy analysis for a steady state operation of the engine was conducted. The analysis was carried out on the same assumptions as the engine bore effect analysis. The engine was assumed to be moving at its natural frequency without addition of heat or encountering any frictional load. The engine was assumed to start at atmospheric pressure and the compression and expansion strokes were assumed to be polytropic $(\mathrm{n}=1.4)$. Using the relation

$$
P_{1} V_{1}^{n}=P_{2} V_{2}^{n}
$$

the pressures in the cylinder during compression and expansion strokes of the respective pistons were calculated. The potential energy in the system is the energy stored in the working fluid (air in this case), by the piston during its motion. This is equal to the pressure work done by the piston during the compression stroke. The work done by the working fluid on the piston is converted into the kinetic energy of the piston and into potential energy of the compressed gases in the other cylinder. The analysis was conducted to measure the amount of potential energy converted to kinetic energy and the amount of potential energy stored in the working fluid as positive work energy. The 
compression ratio was once again chosen realistically to be 20 and the analysis was carried out for a bore of $25 \mathrm{~mm}$ ( $1 \mathrm{in}$.). The kinetic energy was measured by the equation

$$
K E=\frac{1}{2} m_{s} v^{2}
$$

The reciprocating masses were assumed to be $5 \mathrm{~kg}(11 \mathrm{lbs})$ and the velocity was measured by the fundamental equation and converted to dimensional form. The result of the energy analysis is shown in Fig. 19. The kinetic energy of the system goes from zero to a maximum at the center and back to zero, at the other end where reversal of motion takes place. The potential energy has a minimum at the center and a maximum at the ends. The combined energy $(\mathrm{KE}+\mathrm{PE})$ is also shown in Fig. 19. As expected, for the steady state operation of the engine the total energy $(\mathrm{KE}+\mathrm{PE})$ in the system remains a constant. Figure 20 shows the plot of change in potential energy in the left and right cylinders, versus the piston displacement. The analysis was carried out for a left to right expansion stroke and as seen in the plot, the potential energy in the left cylinder decreases as the displacement increases. This shows the work done by the fluid on the piston during the expansion stroke. This energy is converted to the piston kinetic energy and also into potential energy being stored in the compressed gases in the right cylinder. As seen in the figure, the potential energy in the right cylinder increases and reaches a maximum as all the work done in compressing the gases is stored as potential energy in it. The potential energy in converted to kinetic energy stored in the piston and potential energy in the compressed air in the other cylinder. The efficient conversion of energy in an actual working model of a linear engine would provide stable operation. 


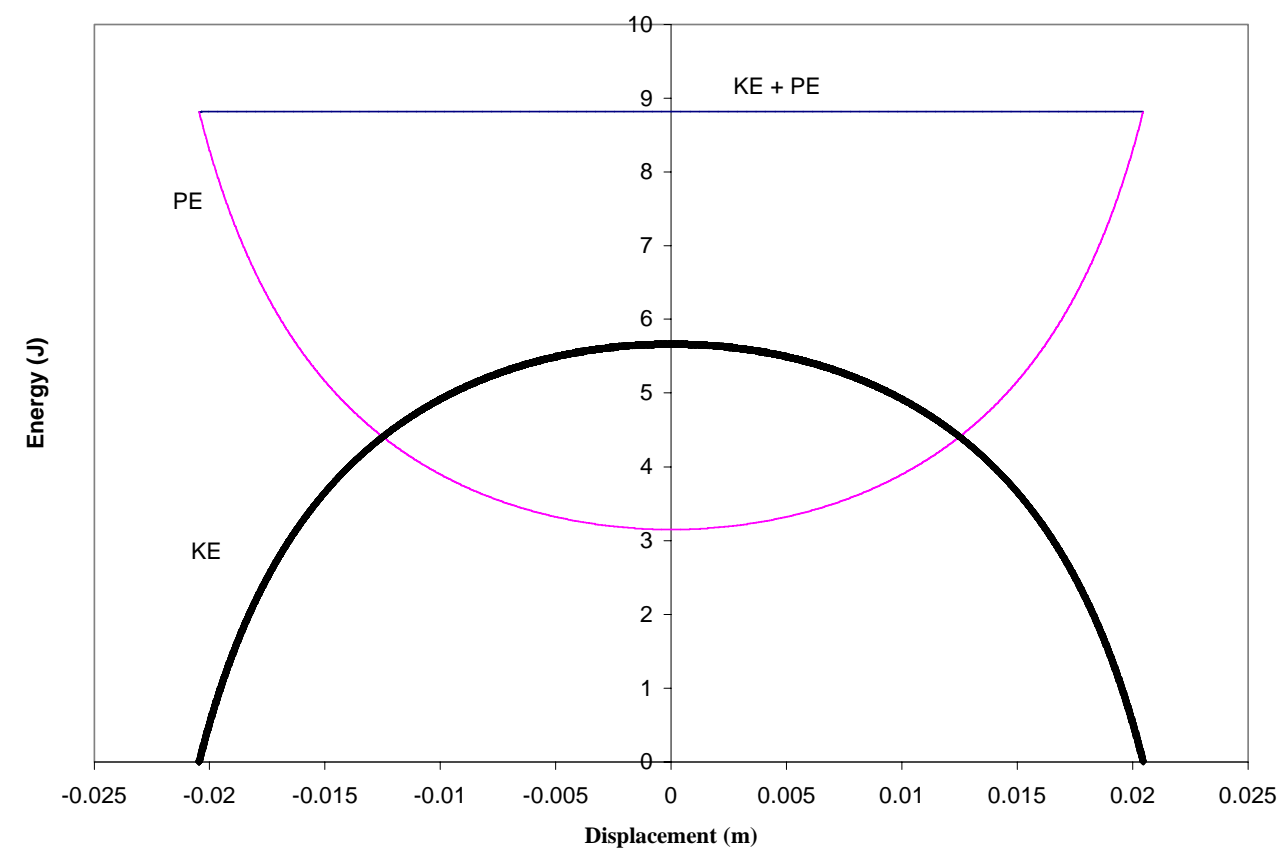

Figure 19 The potential and kinetic energy plotted versus piston displacement. The total energy in the system is seen to be constant, as expected.

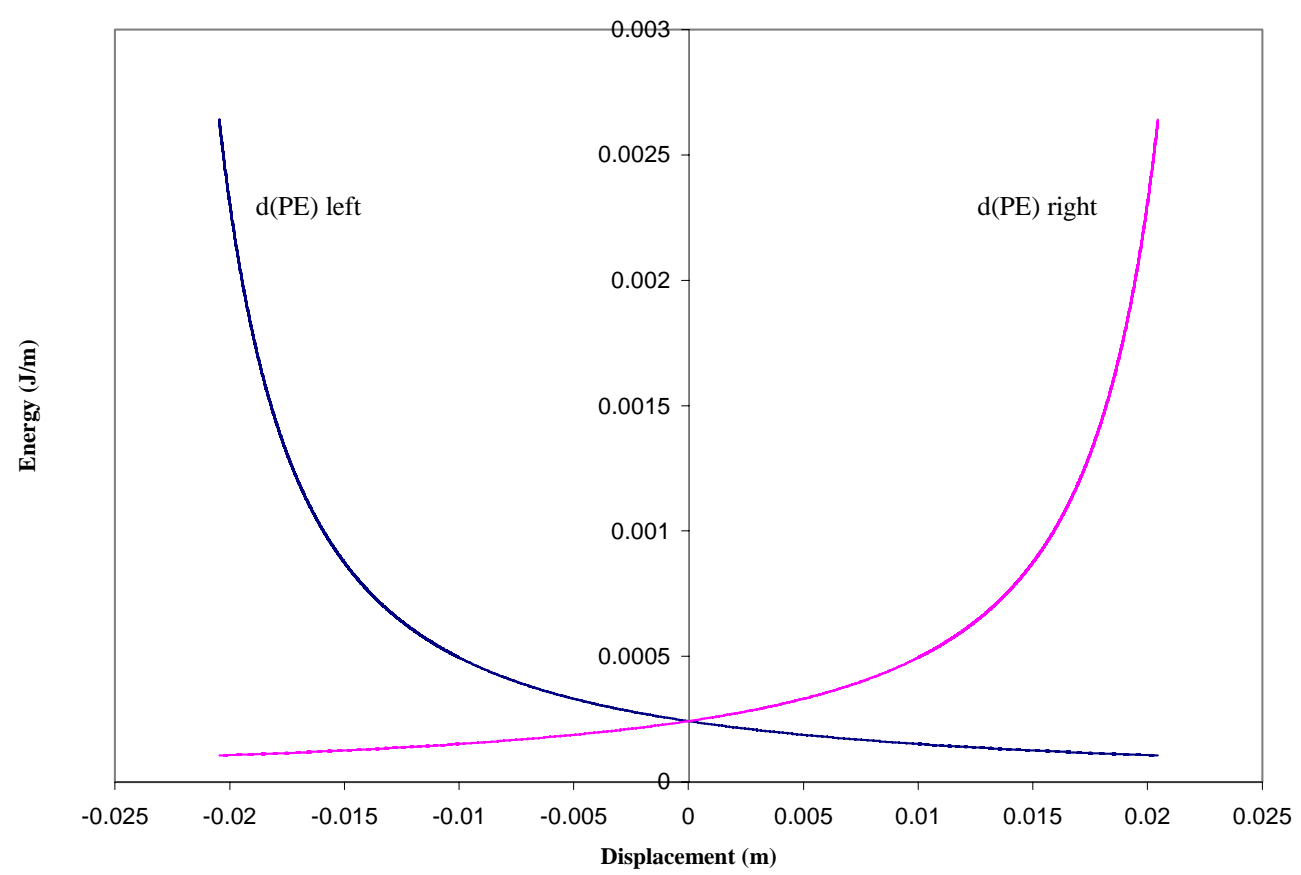

Figure 20 The change in potential energy in the two cylinders is plotted against the piston displacement. 


\section{ENGINE PROTOTYPE}

So little is known of linear engine behavior, that in light of the complexity of engine modeling, a benchtop model was constructed on an ad hoc basis. It was hypothesized that this approach would prove inexpensive, yet yield data that would provide insight into the modeling and further development.

\subsection{Description}

Following the initial design, construction and operation of a $29 \mathrm{~mm}(1.125 \mathrm{in}$. bore model, the $36.5 \mathrm{~mm}$ (1.4335 in.) bore model, described below, was constructed. A sketch of major engine components is shown in Fig. 21.

The benchtop model was sized to use 2-stroke chainsaw (Homelite Classic 180 Chainsaw) engine components to reduce development time and cost. The chainsaw heads/cylinders were the first to see sustained operation in an idle mode, but they were soon replaced with heads/cylinders of new design that allowed water cooling. The pistons remain a commercially available item. The benchtop engine used a two-stroke cycle, to insure sustainable motion without intervention because each stroke is a power stroke. This also allowed a simple port configuration by drilling holes in the cylinder, eliminating the need to develop a camless valve control system. Spark-ignited operation was used to allow low-pressure port fuel injection, eliminating the need to adapt a highpressure in-cylinder injection system to the engine. Fueling was originally accomplished using carburetors matched to the engine providing the heads. After some experience trying to balance operation on each cylinder, a port fuel injection system replaced the carburetors for more precise control of fuel flow. The fuel injection used a fuel pump 
(Holley Automotive) to maintain a common rail at a constant pressure of $103 \mathrm{kPa}$ (gauge) (15 psig). Fuel flow rate was controlled by adjusting the fuel injector pulse width (time the injector is held open). Fuel injectors (GM Part \# 17109448F) were pulsed once every two strokes, or every complete cycle. Compressed (house) air at the intake ports was used to improve scavenging. Airflow was controlled to each cylinder by individual manually operated valves. Generic automotive ignition coils, were selected to provide the necessary voltage for the spark, generated by the original spark plugs for the cylinder heads. Coolant water was forced through the heads from the house water supply. Off-theshelf components were used extensively to keep development time short and cost low. A simple dimensional sketch of the engine cylinder and port locations is shown in Fig. 22.

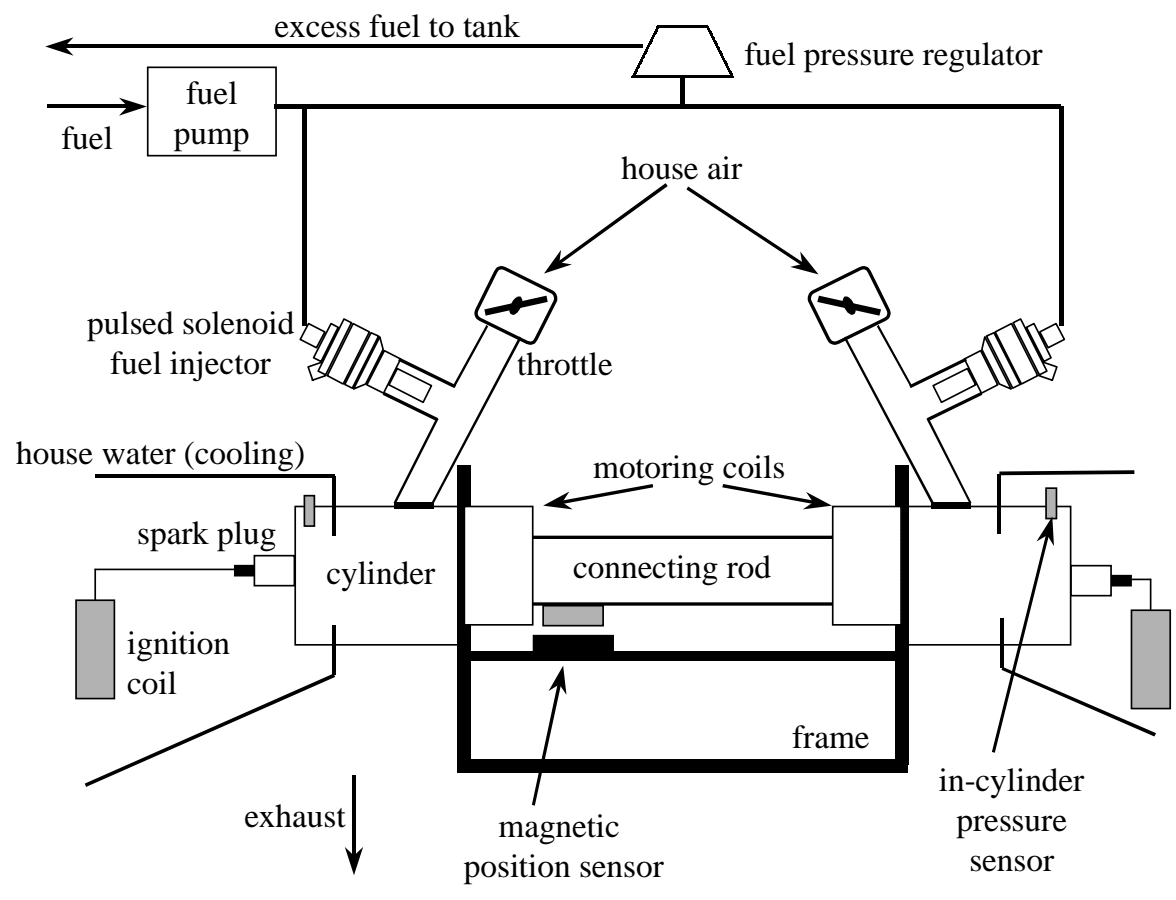

Figure 21 Benchtop Model. 
A simple I-beam frame provided support for each cylinder. To provide the motoring force for the engine, two starter solenoid coils from a heavy-duty engine were adapted to act directly on the connecting rod. Motoring coil operation was automatically disengaged when the shaft speed exceeds a preset value, inferring that the engine has started. The port locations (Fig. 22) were not optimized. Because the stroke of the engine was not mechanically constrained and therefore allowed to vary during normal operation, optimum port location could vary with each cycle. Another variable dependent on the stroke was the compression ratio, which had a theoretical maximum, for this particular engine of approximately 8:1. This wa found using an oil displacement method and was limited by the volume where the shaft hits a stop that prevents piston contact with the head. Spark plug dead volume accounted for much of the clearance volume at the outermost position.

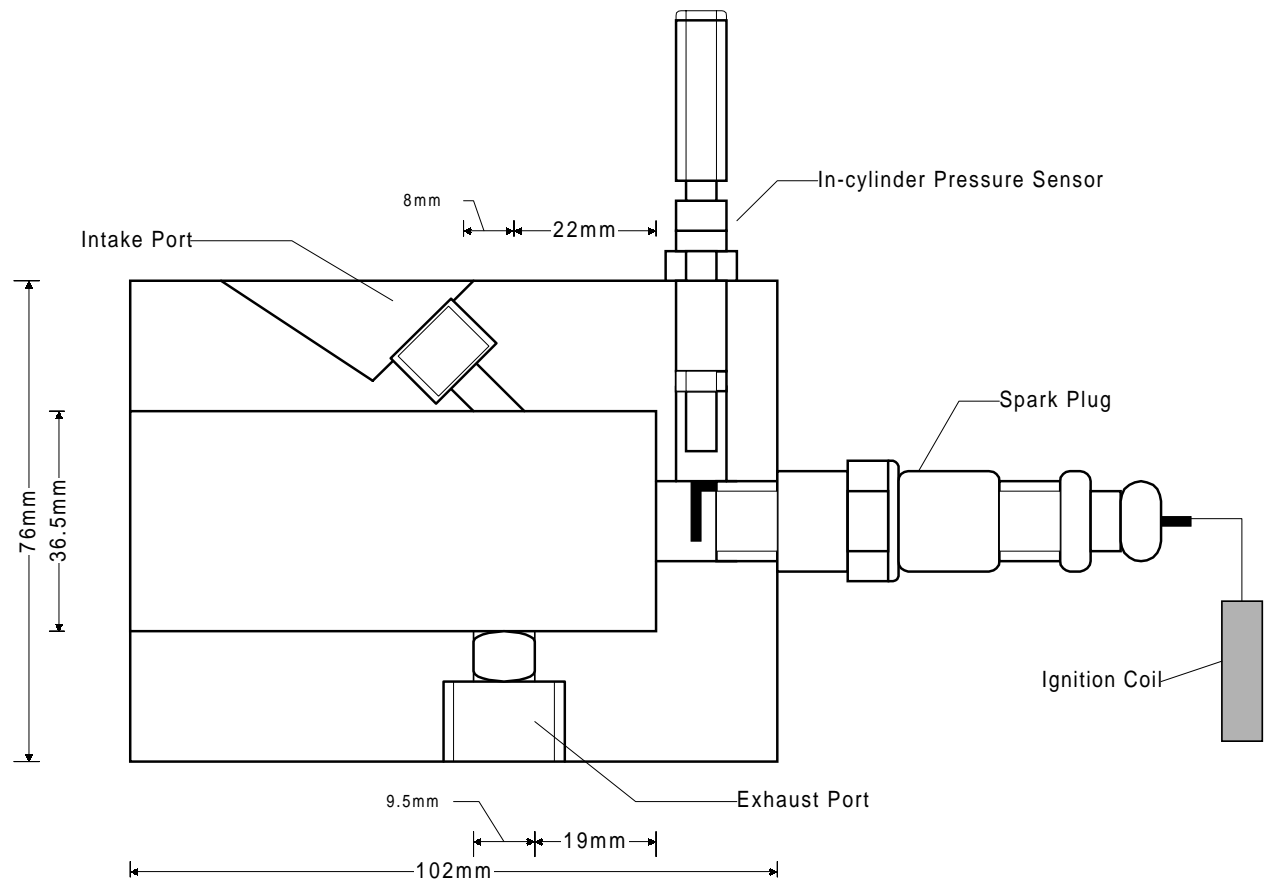

Figure 22 Simple Dimensional Sketch of Engine Cylinder. 


\subsection{Engine Controller}

An engine controller was constructed by Richard Atkinson, of West Virginia University, to fire the motoring coils, as well as control spark timing and fuel injection pulse width. A block diagram of the controller is shown in Fig. 23. A Hall-effect linear position sensor was designed and constructed, and was the only sensor input to the controller. In order to directly observe the nature of combustion in this novel engine, piezoelectric in-cylinder pressure transducers [PCB Part \#501 and Part \#509] were mounted with direct access to the combustion chamber. Pressure data, along with linear position data, were captured with a DAS-58 [Keithley-Metrabyte] A/D Board at 8889 samples/sec.

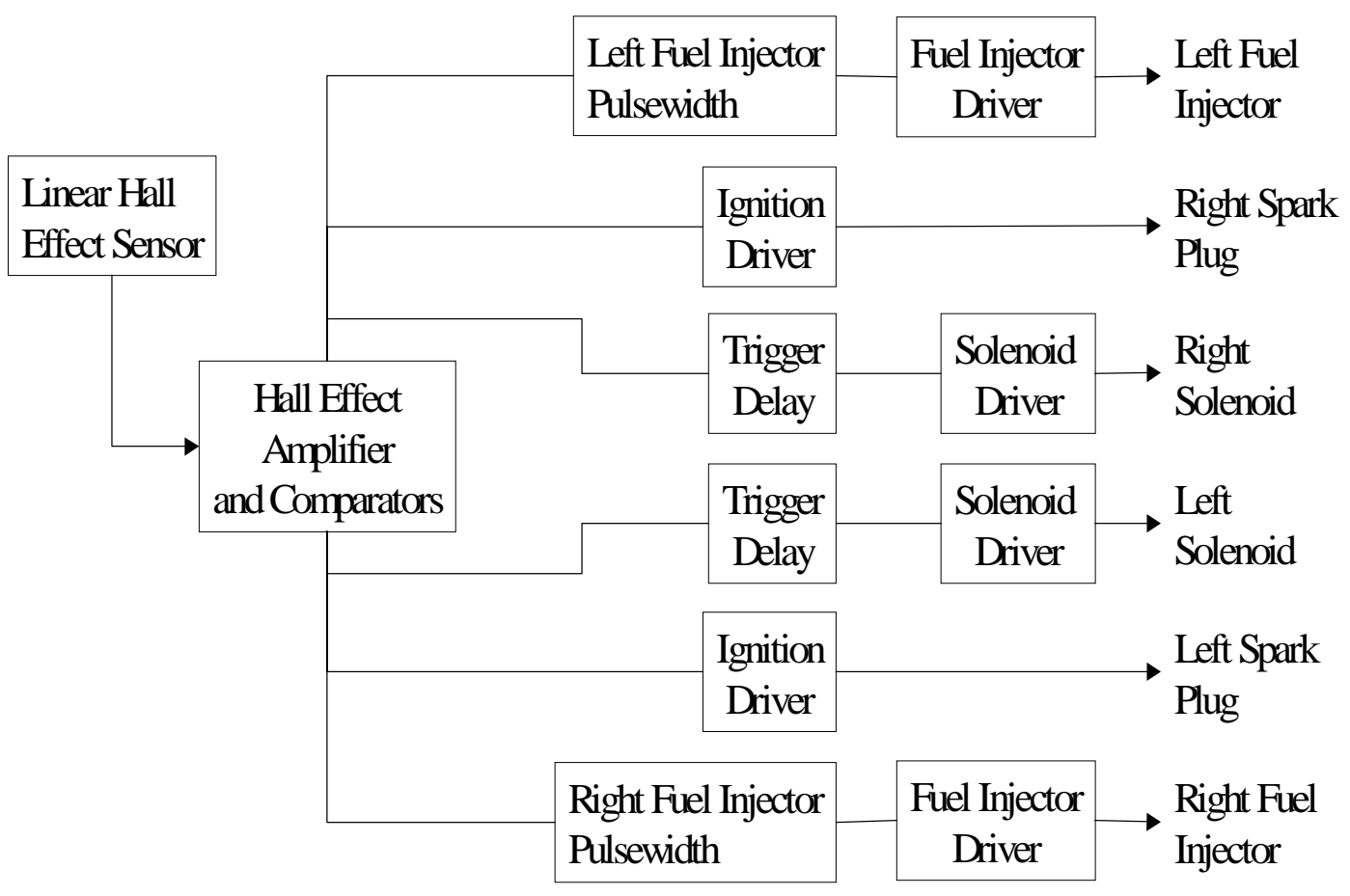

Figure 23 Benchtop Model Controller Block Diagram. 


\subsection{Simulation of Alternator Load}

In order to provide a resistance to the shaft, as an approximate simulation of the load that a linear alternator will apply, a simple friction brake was constructed. The brake used sections of ordinary automotive brake pad to apply a frictional resistance to the shaft. The pads were held by metal plates fixed to the bed of the engine, but were free to rotate so that load could be applied by the operator by pressing the plates together at the top of the shaft. While this method did not allow precise load control or precise knowledge of the load applied, it allowed the qualitative investigation of how the ignition timing must change in response to engine power demand. Load was measured using a static pull to impose a frictional drag of about $133 \mathrm{~N}$ (30 lbf) on the shaft.

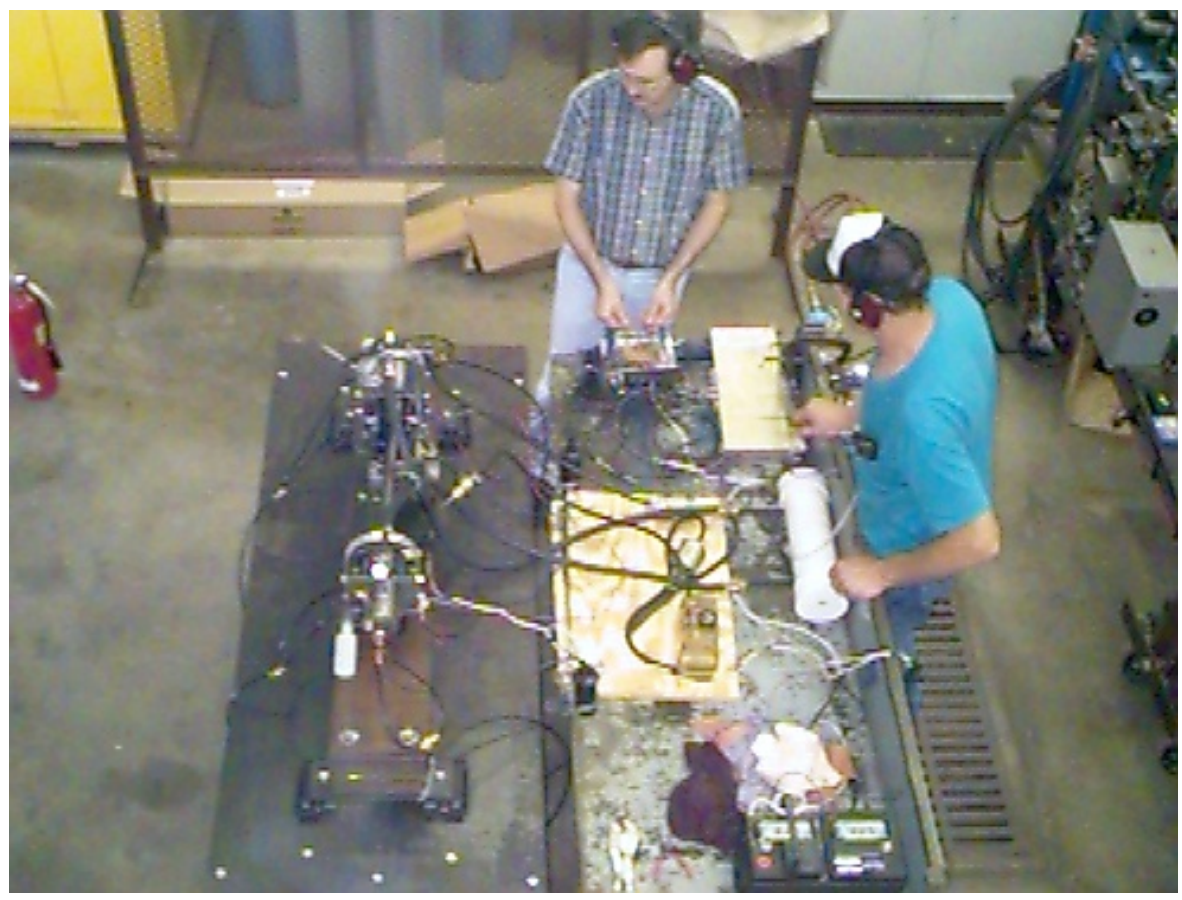

Figure 24 Richard Atkinson (top) and Tom McDaniel (right) performing a test of the benchtop model. 


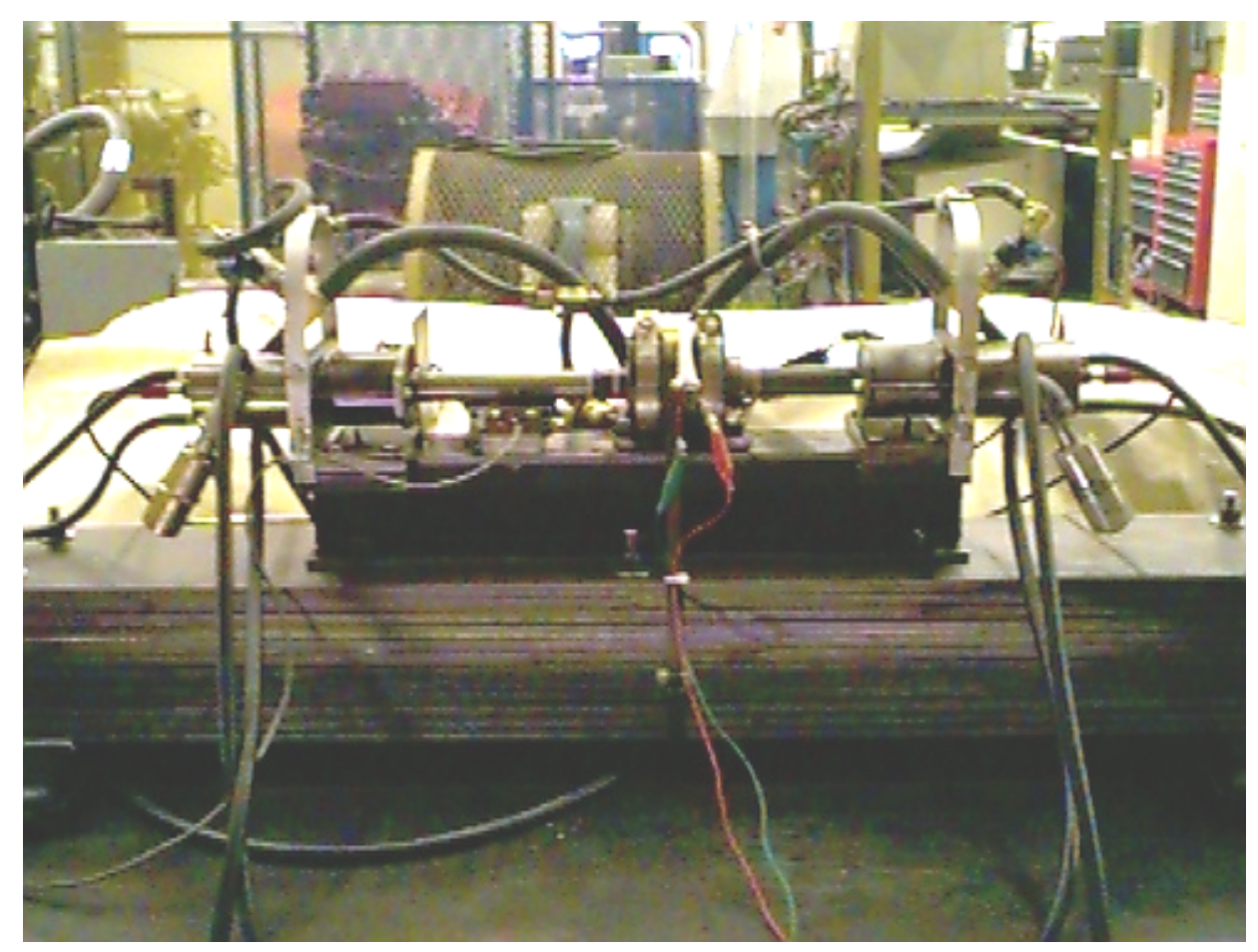

Figure 25 The benchtop model is shown with the steel plate bed to reduce the severity of vibrations. Tuning success after the construction of this table has dramatically reduced the vibration.

Table 5

Benchtop Model Component Descriptions

\begin{tabular}{|c|c|}
\hline Component & Description \\
\hline cylinder/head & $\begin{array}{l}\text { OD: } 76 \mathrm{~mm}(3 \mathrm{in} .) \\
\text { Length: } 102 \mathrm{~mm}(4 \mathrm{in} .) \\
9.5 \mathrm{~mm}(0.375 \text { in. }) \text { exhaust port } 19 \mathrm{~mm}(0.75 \mathrm{in} .) \text { from end of piston stroke; } 8 \\
\mathrm{~mm}(0.3125 \text { in. }) \text { intake port } 22 \mathrm{~mm}(0.87 \text { in. }) \text { from end of piston stroke }\end{array}$ \\
\hline pistons & $36.5 \mathrm{~mm}$ (1.4335") Homelite Classic 180 Chainsaw \\
\hline $\begin{array}{l}\text { connecting rod } \\
\text { assembly }\end{array}$ & $\begin{array}{l}\text { piston-to-main: } 102 \mathrm{~mm}(4 \mathrm{in} .) \text { length, } 13 \mathrm{~mm}(0.5 \mathrm{in} .) \text { diameter steel grade } 8 \\
\text { main shaft: } 508 \mathrm{~mm}(20 \text { in.) length, } 29 \mathrm{~mm}(1.125 \text { in.) diameter mild steel }\end{array}$ \\
\hline frame & $\begin{array}{l}\text { bottom beam: I-beam: } 100 \mathrm{~mm}(4 \mathrm{in} .) \text { wide, } 105 \mathrm{~mm} \text { (4.1 in.) high, } 600 \mathrm{~mm}(24 \\
\text { in.) long, web thickness } 7.2 \mathrm{~mm}(0.3 \mathrm{in} .) \\
\text { head supports: angle iron: } 102 \mathrm{~mm} \text { (4 in.) sides, } 153 \mathrm{~mm} \text { (6 in.) long, } 18.5 \mathrm{~mm} \\
\text { (0.7 in.)thick }\end{array}$ \\
\hline throttles & brass gas valves \\
\hline motoring coils & $\begin{array}{l}\text { adapted from a generic starter pull-in solenoid for a heavy duty automotive } \\
\text { engine }\end{array}$ \\
\hline fuel injectors & GM Part \# 17109448F \\
\hline fuel pump & Holley Automotive \\
\hline ignition coils & standard automotive \\
\hline
\end{tabular}


The experimental engine designed and developed in-house, with the engine controller, was successfully tested under different operating conditions. Figure 24 shows a test run in progress. Figure 25 shows another view of the engine prototype and the dedicated bench of steel plates weighing about $600 \mathrm{lbs}$., constructed to reduce the severity of vibrations during early engine operation. The experimental results and conclusions have been presented in the next chapter. 


\section{ANALYSIS OF DATA}

\subsection{OPERATING CONDITIONS}

The engine prototype was tested under four different operating conditions. The first mode of operation was the no-load (idling) case, with highly advanced ignition timing. Advanced timing was a requirement to cause early burn and return the piston before the stop was contacted. A friction braking load was then added and kept constant by means of a friction braking pad and the ignition timing was maintained the same in the second case. The ignition timing was then advanced in the remaining two test runs. The piston position and in-cylinder pressure data were documented for 1.125 seconds (20 cycles). Initially a single cycle was analyzed to provide a thorough understanding of the engine working. The left cylinder pressure data could not be recorded due to a malfunction in the in-cylinder pressure transducer used.

\subsection{EXPERIMENTAL RESULTS}

The $36.5 \mathrm{~mm}$ (1.4335 in.) bore engine model was operated successfully on gasoline with a lubrication oil mix of 50:1 to preserve and seal the rings. Fuel delivery was electronically metered but controlled manually, and was typically rich to ensure combustion. It was found, as expected, that ignition timing control was crucial to the successful operation of the engine. For example, under no load conditions, there was a tendency for the assembly to hit the stops before motion was reversed, unless timing was advanced so far that adverse work was done in slowing the piston. Figure 26 shows the pressure-volume diagram for the right cylinder under no load (idle) conditions, with the engine operating at 2914 strokes/min (1457 cycles/min). In Fig. 26 some high frequency 
components can be seen in the traces: this is because the shaft had some small freedom to rotate, which led to variations in the Hall effect output of up/to 5 ADC codes in a total of 787 ADC codes for the digital position measurement. Since there was no load applied to the rod and piston assembly, it was evident that the only forces slowing the assembly to the point of reversal were the relatively minor ring and rod friction, and the pressure in the cylinder at its outermost point. To prevent slapping of the stops, the timing must be highly advanced to occur just after port closing. This would prove less critical with engines of a higher compression ratio. It was evident from the P-V diagram that there are three distinct regions of work, namely a small (lower) area associated with gas exchange, a region of positive work at low compression, and a region of adverse work at high compression. It was this adverse work that was primarily responsible for opposing the stroke energy and it can be attributed to the high heat loss (high surface area to volume ratio) and high mass loss (single ring, high ring length to volume ratio) found near the outermost point. Figure 27 shows the effect of adding load through friction braking of the rod, with an apparent, measured friction force of approximately $133 \mathrm{~N}$ (30 lbf). The application of the frictional force was quite crude, but it offered an excellent basis for comparison of the calculated net power output of the engine, from the P-V diagram. Although the spark timing was the same as in the no load case (Fig. 26), the positive work done was significantly increased, and the adverse work reduced. This was in sympathy with the reduction in stroke from $42.5 \mathrm{~mm}$ (1.67 in.) (Fig. 26) to $40 \mathrm{~mm}$ (1.57 in.). Engine speed was reduced to 1361 cycles/min. Neglecting pumping work done, the net indicated power output of the engine was $264 \mathrm{~W}(195 \mathrm{ft} \mathrm{lbf} / \mathrm{s})$, from an analysis of the P-V diagram. Assuming that the applied drag was 133 N (30 lbf), as measured, and from 
the known stroke and engine speed, the power output was calculated to be $242 \mathrm{~W}$ (178.5 $\mathrm{ft} \mathrm{lbf} / \mathrm{s})$. The indicated power output of the engine was calculated by estimating that the same amount of power is being developed in the left cylinder. The indicated power output of the right cylinder, calculated from the figure, was doubled in order to compare it with the net brake power output. Figure 28 shows the effect of retarding the timing while maintaining the load. The adverse work done was reduced significantly, as shown in Table 6, because pressure rise occurred late in the stroke. In this case the indicated power output was $437 \mathrm{~W}$ (322 ft lbf/s) while the measured brake power was $208 \mathrm{~W}$ (153.5 ft lbf/s). When timing was retarded further under load, the stroke increased, thus increasing the net mechanical work per stroke, and the adverse work was entirely eliminated. Figure 29 shows this trace, which resembles that from a conventional slidercrank engine: indicated power output was $782 \mathrm{~W}(577 \mathrm{ft} \mathrm{lbf} / \mathrm{s})$ while the measured brake power was $298 \mathrm{~W}$ (220 ft lbf/s). Figure 30 compares the data in Figures 26 and 29 as plots of instantaneous indicated power, $\mathrm{P} \mathrm{dV/dt}$, versus time. It was evident that in the high load, late ignition case (Fig. 29), work done on the inward stroke was far greater than work on the outward stroke, whereas in the light load case, the outward stroke work and inward stroke work were of similar magnitude. Figure 31 shows the actual position of the piston assembly, at conditions corresponding to Fig. 26, with respect to time: it is evident that the piston motion deviates significantly from a sinusoid, with long periods of near constant velocity over much of the stroke. Figure 32 shows a phase plot of the actual piston velocity versus position. 


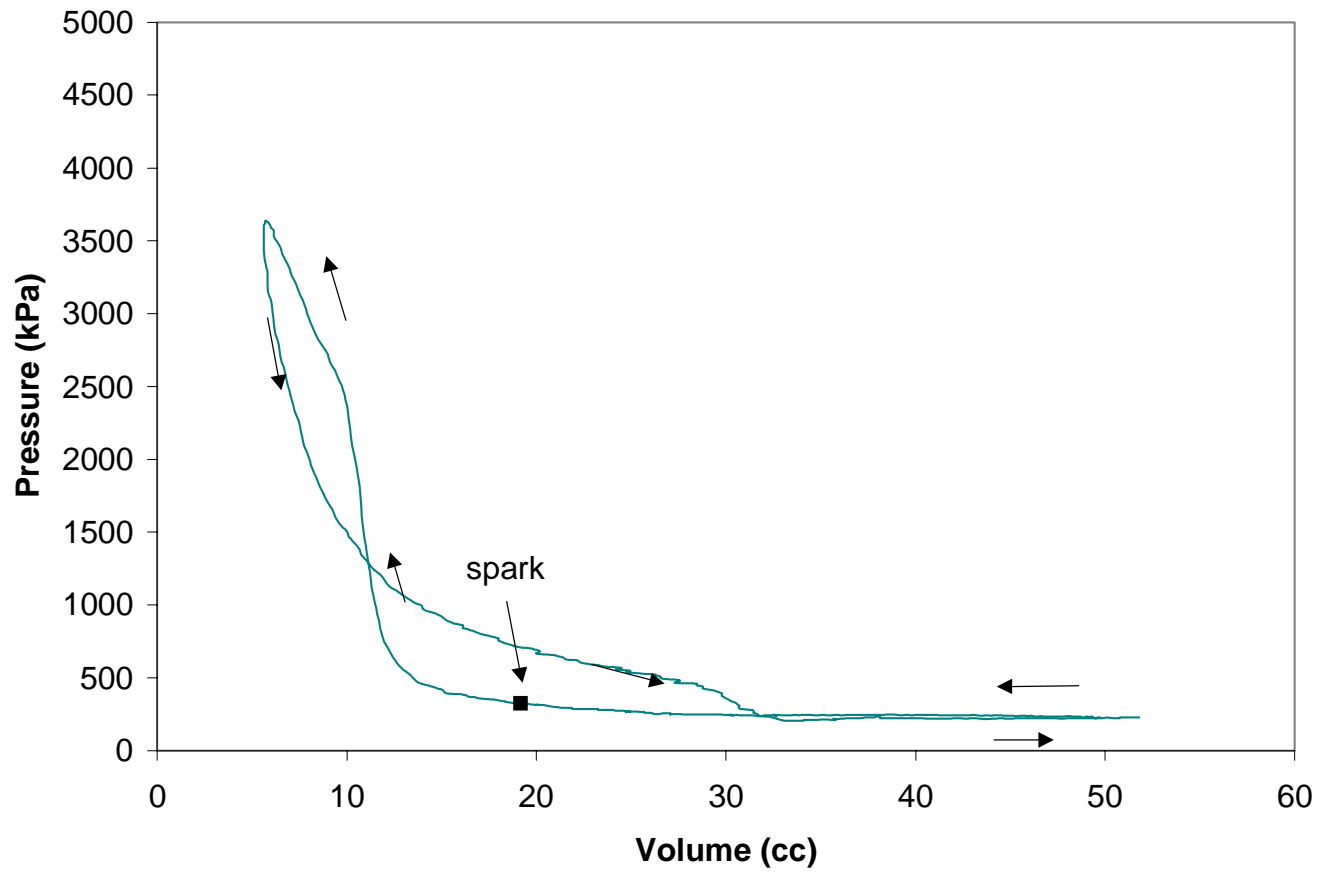

Figure 26 The P-V diagram for the right cylinder under no load (idle) condition is shown here. The box symbol denotes the point of spark ignition.

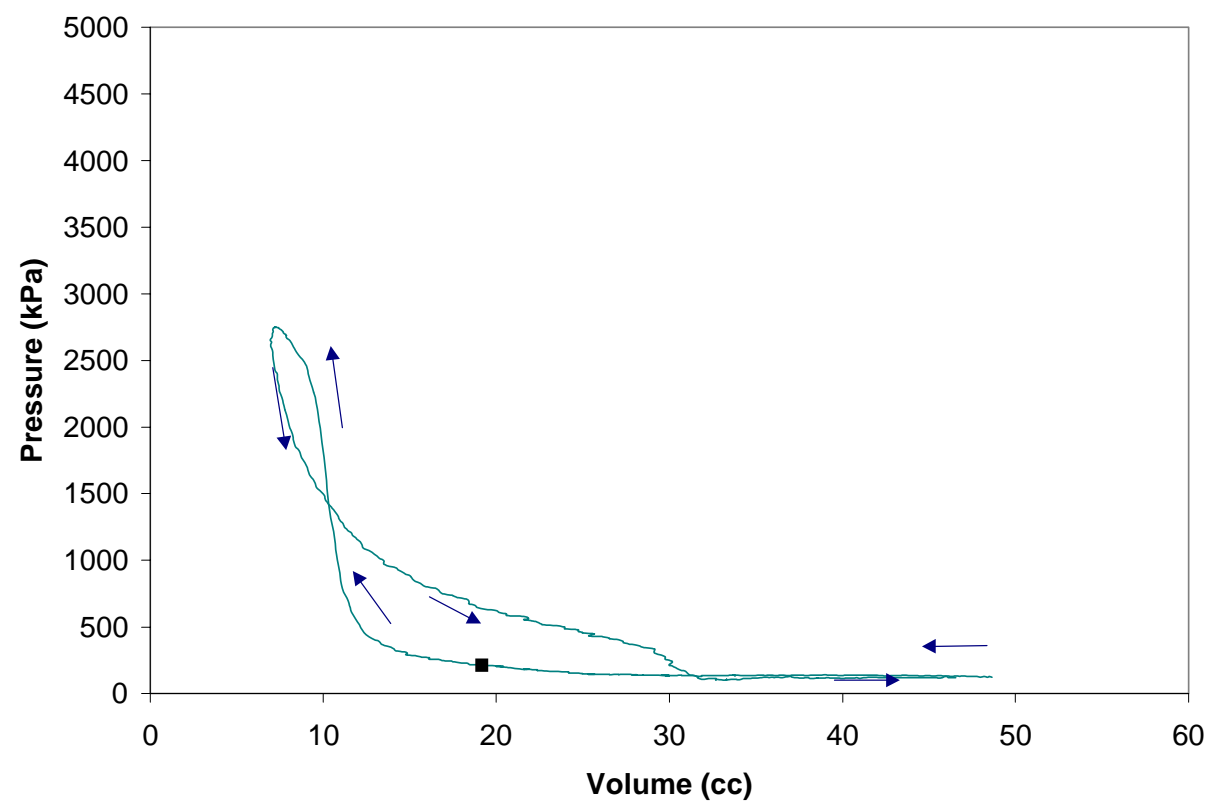

Figure 27 The P-V diagram for the right cylinder under load due to friction braking. 


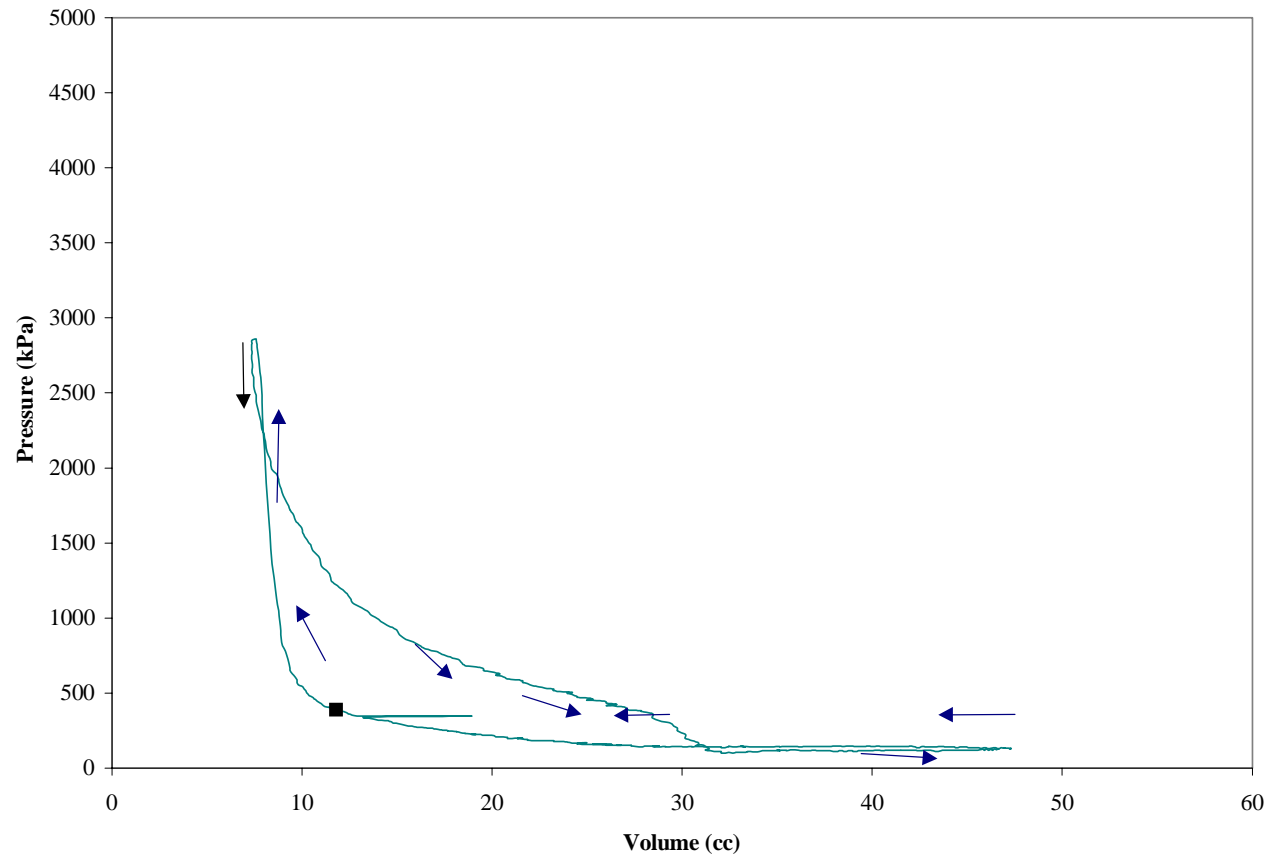

Figure 28 The effect of retarding the timing for the same load is seen here.

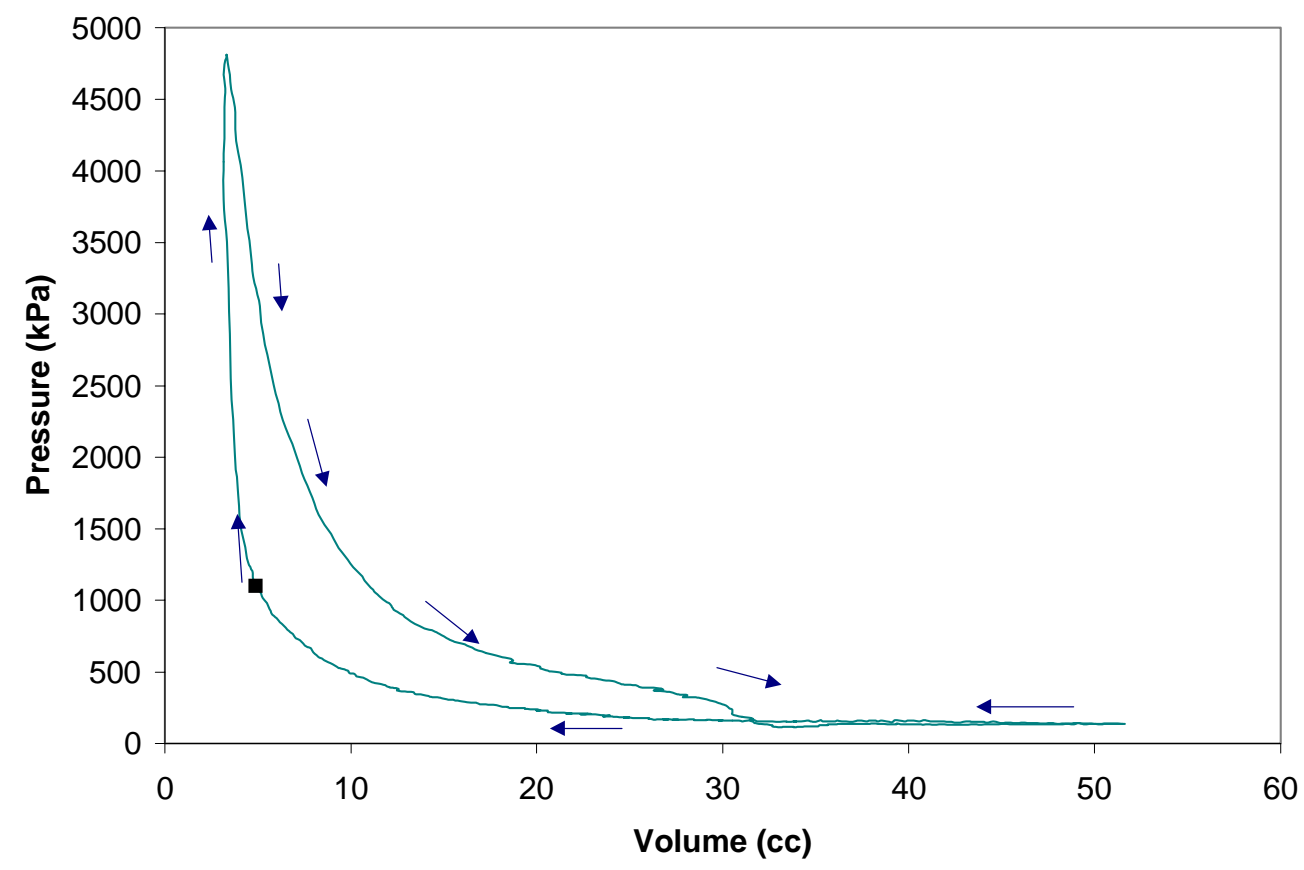

Figure 29 A plot resembling the conventional slider-crank engine is obtained by highly retarding the timing under the same load condition. 


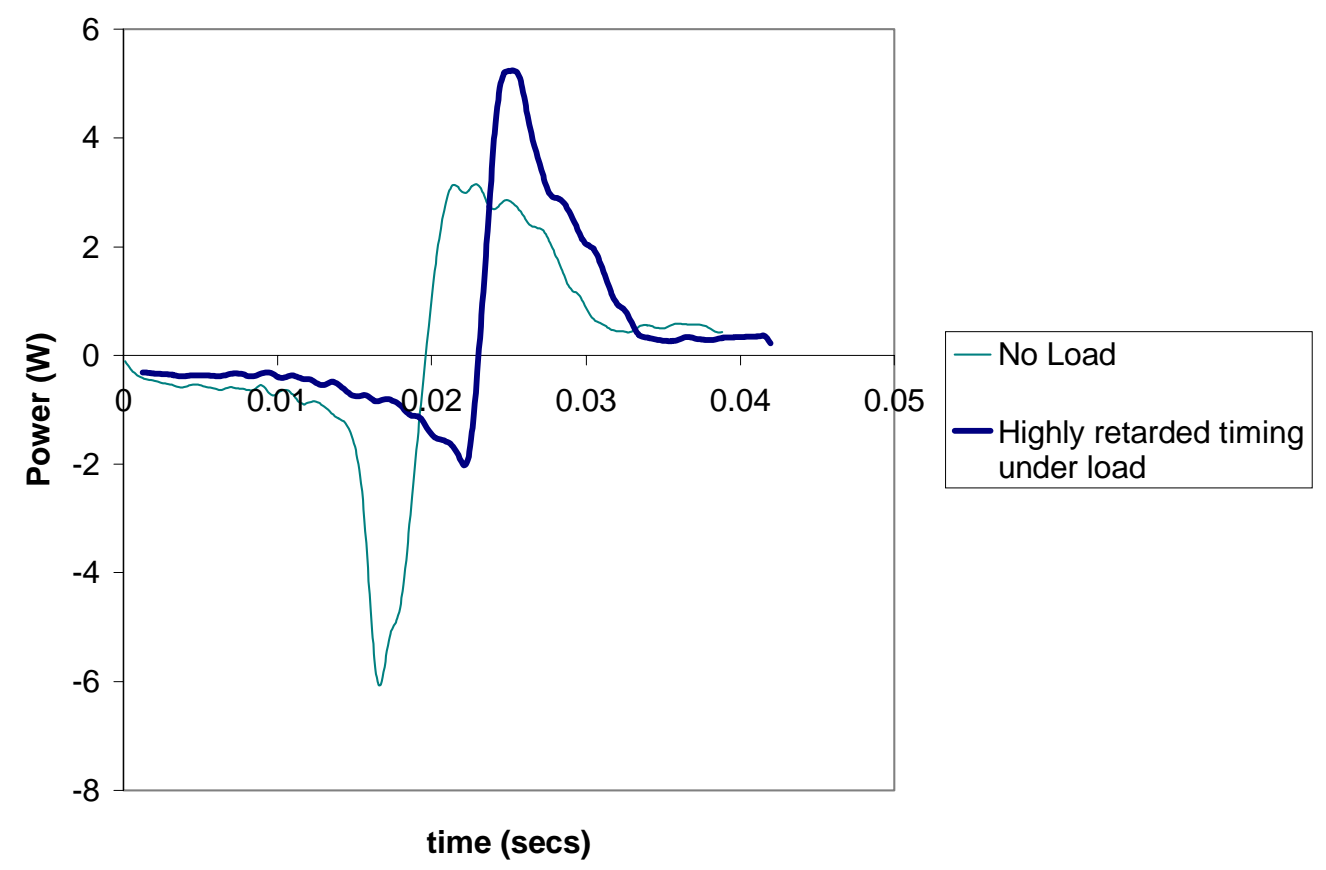

Figure 30 A comparison between the instantaneous indicated power vs time, for the no load condition and highly advanced timing under load condition.

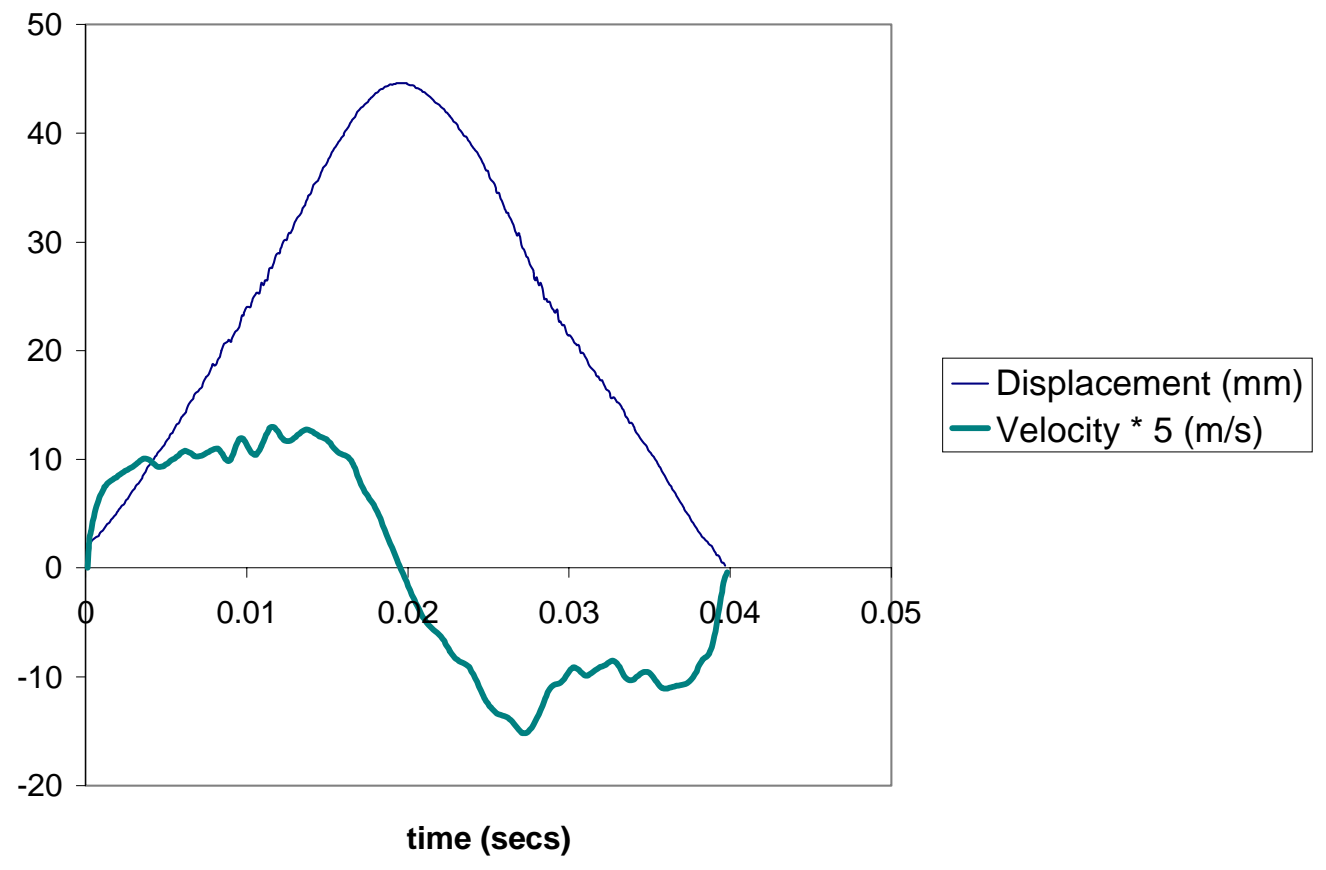

Figure 31 The piston position and piston velocity plotted against time; the piston velocity has been magnified to improve clarity. 


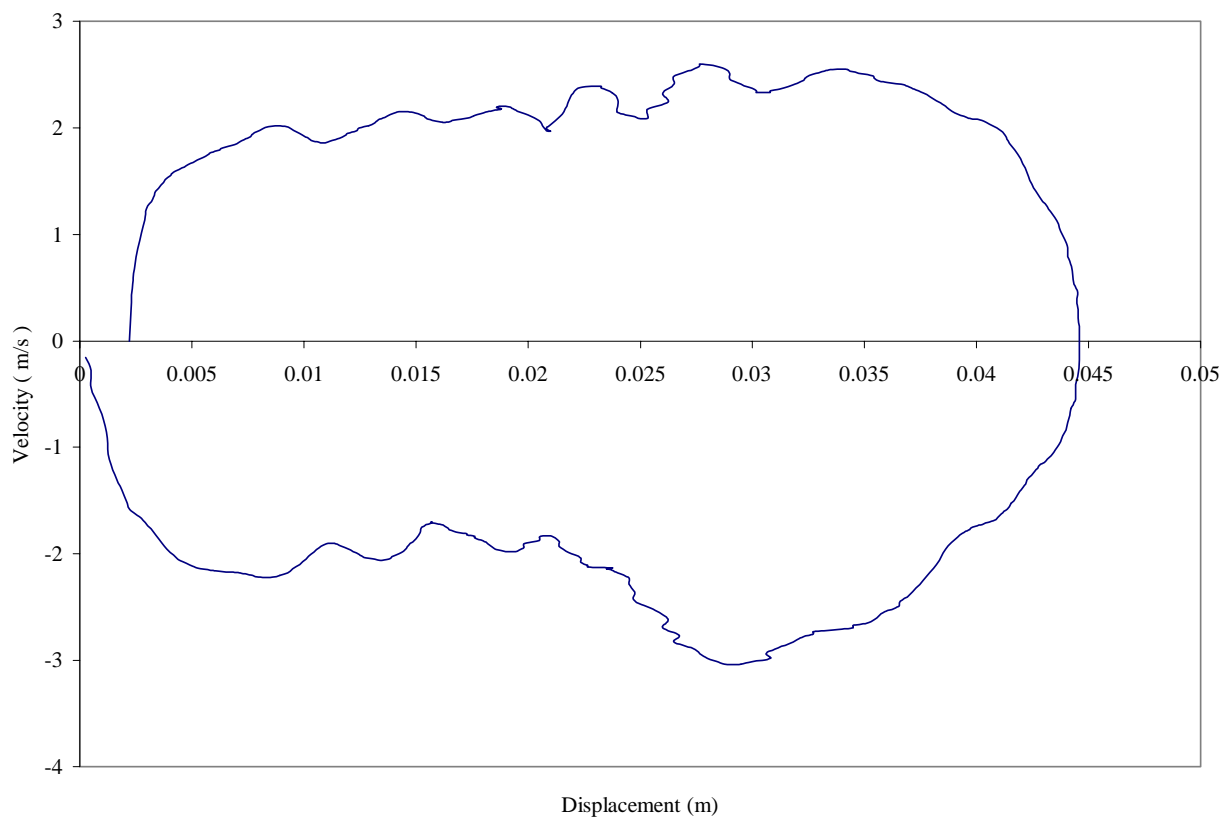

Figure 32 The piston velocity when plotted against the piston displacement is seen to be similar to the idealized motion described earlier.

Table 6

Experimental Data from Benchtop Engine.

\begin{tabular}{|l|l|l|l|l|l|l|}
\hline Figure & Load & $\begin{array}{l}\text { Timing } \\
\text { (from center position) } \\
\text { mm (in.) }\end{array}$ & $\begin{array}{l}\text { Positive Work } \\
\text { per stroke } \\
\text { J (ft lbf) }\end{array}$ & $\begin{array}{l}\text { Adverse Work } \\
\text { per stroke } \\
\text { J (ft lbf) }\end{array}$ & $\begin{array}{l}\text { Stroke } \\
\text { Length } \\
\text { mm (in.) }\end{array}$ & $\begin{array}{l}\text { Speed } \\
\text { cycles/min }\end{array}$ \\
\hline 7 & No & $\mathbf{6 . 1}(\mathbf{0 . 2 4})$ & $7.232(5.3)$ & $4.562(3.4)$ & $42.5(1.67)$ & 1457 \\
\hline 8 & Yes & $\mathbf{6 . 1}(\mathbf{0 . 2 4})$ & $\mathbf{7 . 1 8 9}(5.3)$ & $1.376(1.0)$ & $40(1.57)$ & 1361 \\
\hline 9 & Yes & $\mathbf{1 3 . 5}(\mathbf{0 . 5 3})$ & $\mathbf{1 0 . 8 5 0}(\mathbf{8 . 0})$ & $\mathbf{0 . 0 9 7 5}(\mathbf{0 . 0 7})$ & $\mathbf{3 8 . 5}(\mathbf{1 . 5 )}$ & 1218 \\
\hline 10 & Yes & $\mathbf{2 0 . 3 5}(\mathbf{0 . 8 0})$ & $\mathbf{1 6 . 4 5 5 ( 1 2 . 1 )}$ & $\mathbf{0}$ & $\mathbf{4 7}(\mathbf{1 . 8 5})$ & 1426 \\
\hline
\end{tabular}

\subsection{EXPERIMENTAL RESULTS (20 cycles of operation)}

Following the analysis of a single cycle of operation under different operating conditions, the data acquired over 20 successive cycles of operation, for each mode, was analyzed. The pressure-volume diagrams for 20 cycles of operation for the no-load (idling) case are shown in Figure 33. The spark timing was the same, with the ignition 
timed to occur when the piston assembly was $6.1 \mathrm{~mm}$ from its center position. Figure 34 shows the pressure-volume diagram for the same ignition timing with load case. Further retarding of the ignition timing, for the same applied load reduced the adverse work area in the pressure-volume plot shown in Fig. 35. The highly retarded timing case, resembling the pressure-volume relationship expected from a conventional two-stroke slider-crank engine, is shown in Fig. 36.

The pressure-volume diagrams provided insight into the working of the engine and the importance of timing control with regards to improvement in the engine efficiency. The experimental data also showed significant cycle-to-cycle variations in the in-cylinder pressures. The cycle-to-cycle variations have been quantified and are presented in the following section.

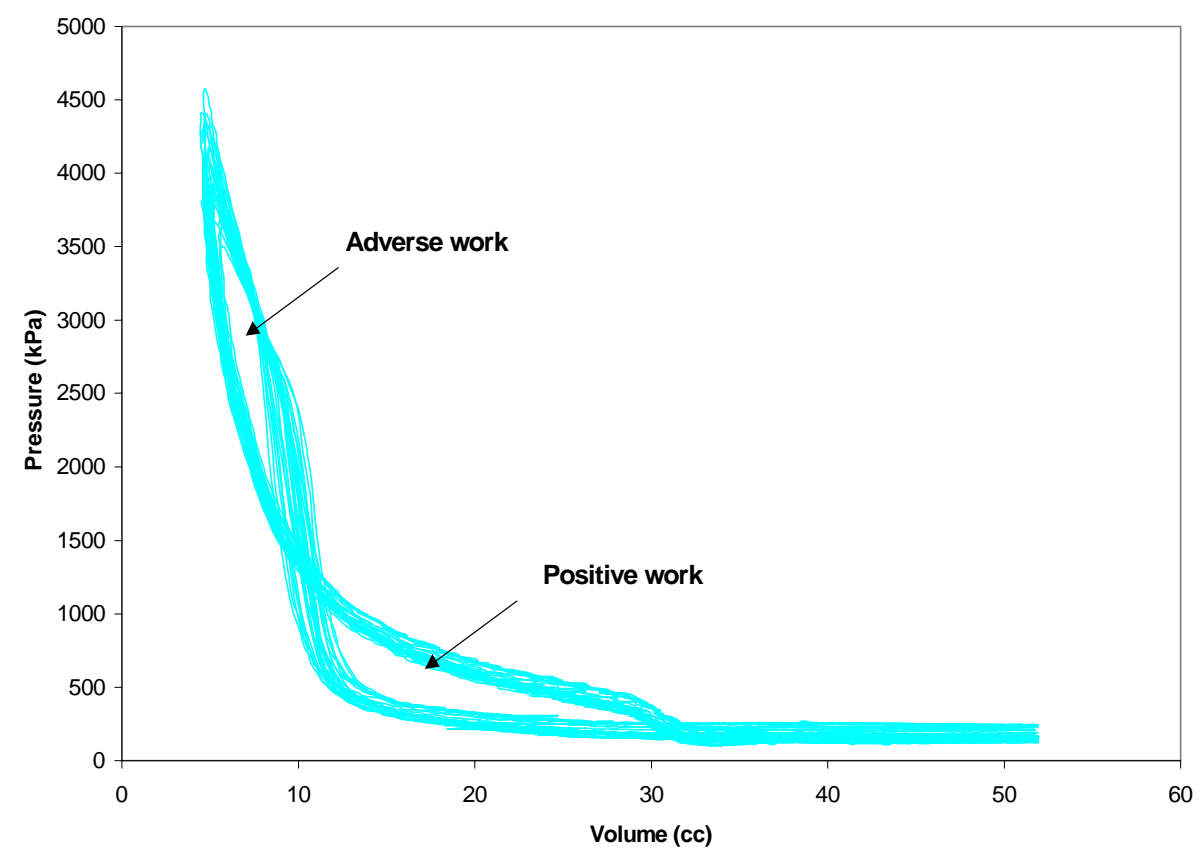

Figure 33 The pressure-volume traces for the no-load (idle), highly advanced ignition timing case for the right cylinder, over 20 successive cycles of operation. 


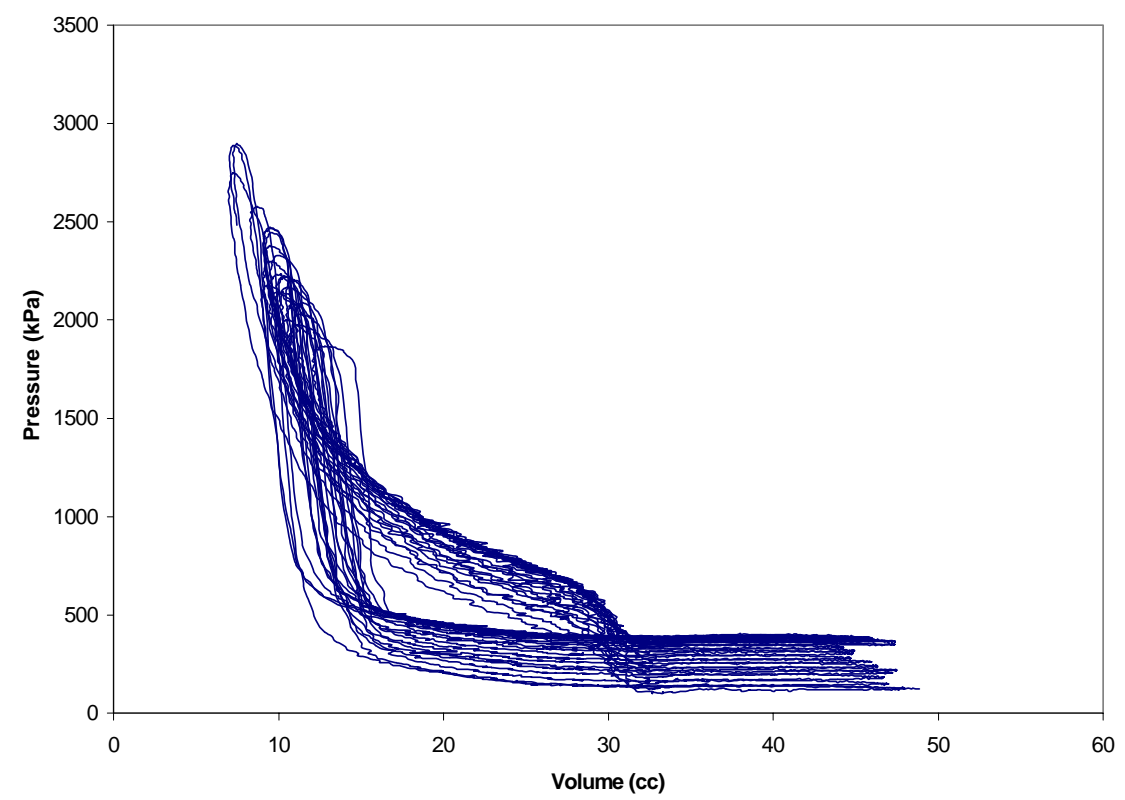

Figure 34 The pressure-volume diagram for the loaded case with highly advanced ignition timing for the right cylinder (for 20 successive cycles). The adverse work area has been reduced by the application of load.

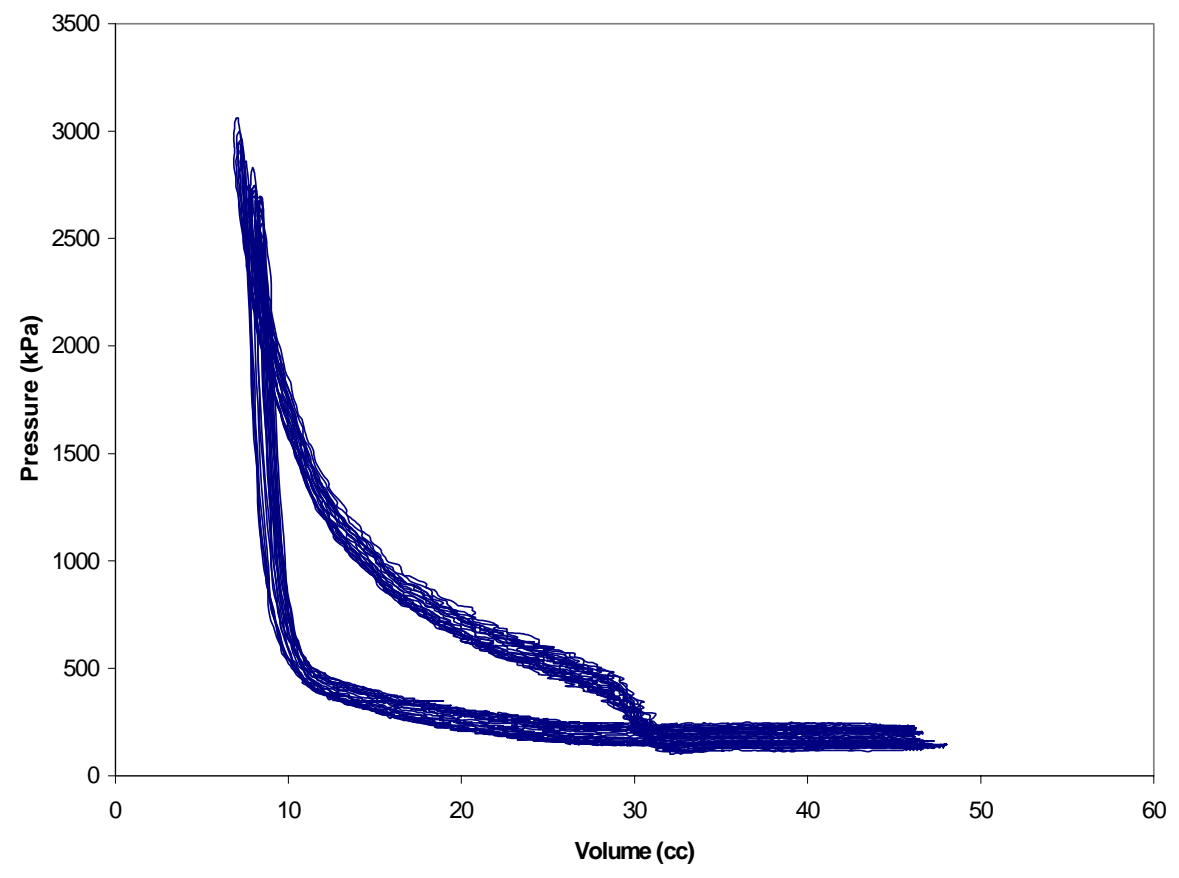

Figure 35 The pressure-volume diagram for 20 cycles of operation, for the loaded condition with retarded timing, is shown here. 


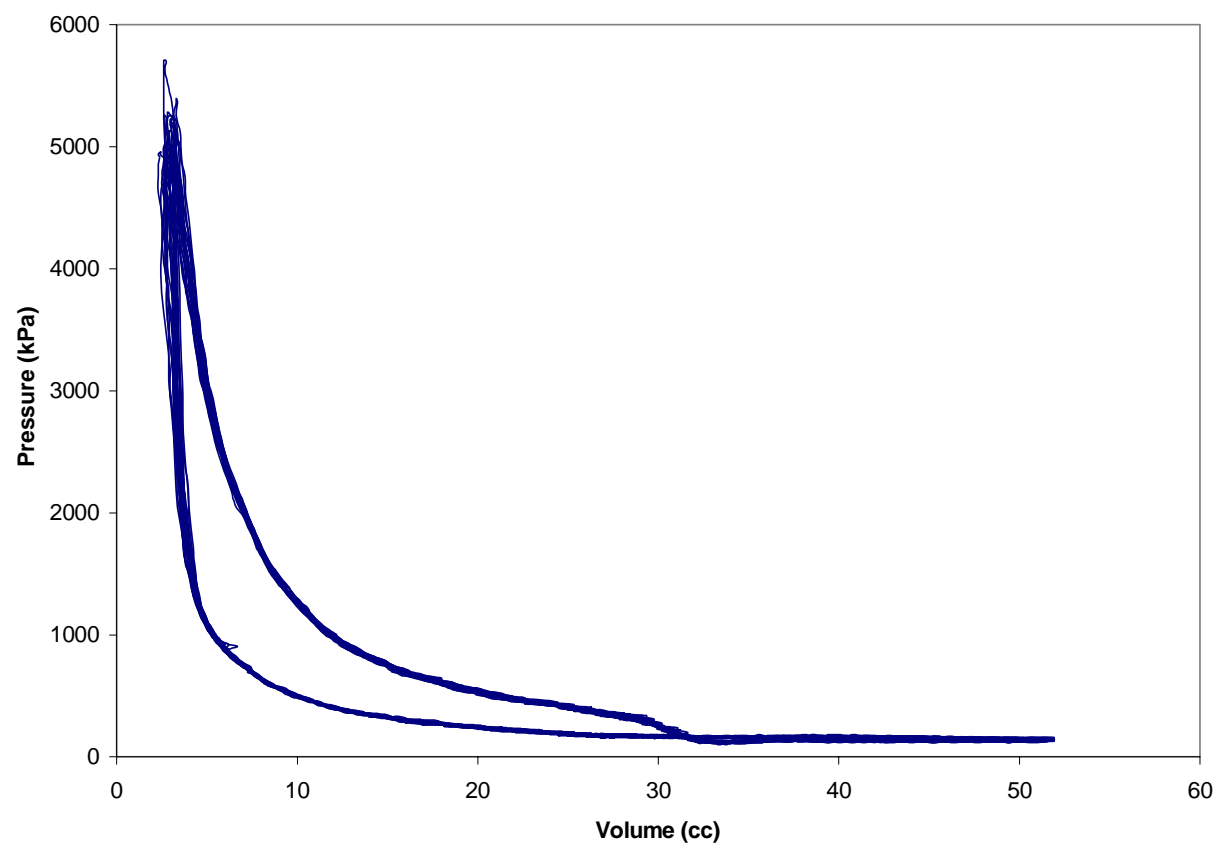

Figure 36 Pressure-volume relationship for the linear engine obtained by varying the ignition timing for the same load. This plot resembles the trace that would be expected from a conventional two-stroke slider-crank engine.

\section{6.(4) CYCLE-TO-CYCLE VARIATIONS}

An analysis of the in-cylinder pressure-time profile allows the calculation of the gross indicated mean effective pressure $\left(\mathrm{IMEP}_{\mathrm{g}}\right)$, peak pressure and an inference of the ignition timing. The spark timing has been found to be crucial in the location of the peak pressure in relation to the piston position, which directly affects the work output of the engine. Heywood [1] has attributed cycle-to-cycle variations in the in-cylinder pressure of an engine to variations in the combustion process from cycle to cycle due to changes in mixture strength, variations in mixture motion within the cylinder and variations in mixing of fresh mixture and residual gases within the cylinder during each cycle. The cycle-to-cycle variations are especially important with regard to spark-timing and the scavenging efficiency of a two-stroke engine. 
The gross indicated mean effective pressure $\left(\mathrm{IMEP}_{\mathrm{g}}\right)$ is the measure of work done by the piston during the entire cycle of an engine (during both the compression and expansion strokes) and is related to the piston displacement and instantaneous cylinder volume. The $\mathrm{IMEP}_{\mathrm{g}}$ has units of force per unit area and is indicative of the work done by an engine regardless of engine size. The work done during an entire cycle, $\mathrm{W}$, can be calculated by performing a numerical integration of the differential change in pressure and the relevant change in volume over the entire cycle,

$$
W=\oint P d V
$$

The IMEP $_{\mathrm{g}}$ is then calculated by dividing the cyclic work done, W, by the total displacement volume of the cylinder. The coefficient of variation $(\mathrm{COV})$ of the $\mathrm{IMEP}_{\mathrm{g}}$ is used as a standard measure of the cyclic variability. It is defined as the standard deviation in the $\mathrm{IMEP}_{\mathrm{g}}$ (over a number of operating cycles: 20 cycles in this case) divided by the mean $\operatorname{IMEP}_{\mathrm{g}}$ (for the same number of operating cycles), and is usually expressed as a percentage:

$$
\operatorname{COV}(I M E P g)=\frac{\sigma(I M E P g)}{\text { mean }(I M E P g)} \times 100
$$

This defines the cyclic variability in indicated work per cycle, and it has been found that in automotive applications, vehicle driveability problems result when this value exceeds 10\% (Heywood, 1988).

Experimental data were collected for each test condition for a period of approximately 1.2 seconds. The pressure-volume plot for the no-load highly advanced timing condition is shown in Figure 33. The average positive indicated work done was found to be $1.55 \mathrm{~J}$ while the average stroke displacement was found to be $44.3 \mathrm{~mm}$. The average speed of 
the engine was found to be $1574 \mathrm{cpm}$, where a cycle refers to a single left-to-right-back to left motion of the piston assembly. In contrast, a stroke refers to a single left-to-right or right-to-left movement of the piston assembly. Figure 37 shows the plot of pressure versus time for the no-load (idle) case. Since the linear engine does not have a fixed displacement, it does not have a fixed top dead center (TDC) or bottom dead center (BDC) position. Each stroke displays an innermost piston position (the beginning of compression stroke for the right piston) and an outermost piston position (beginning of expansion stroke for the right piston). The innermost piston position of the right cylinder piston has been used as the arbitrary datum or starting point (time $=0$ seconds) for all of the pressure-time plots.

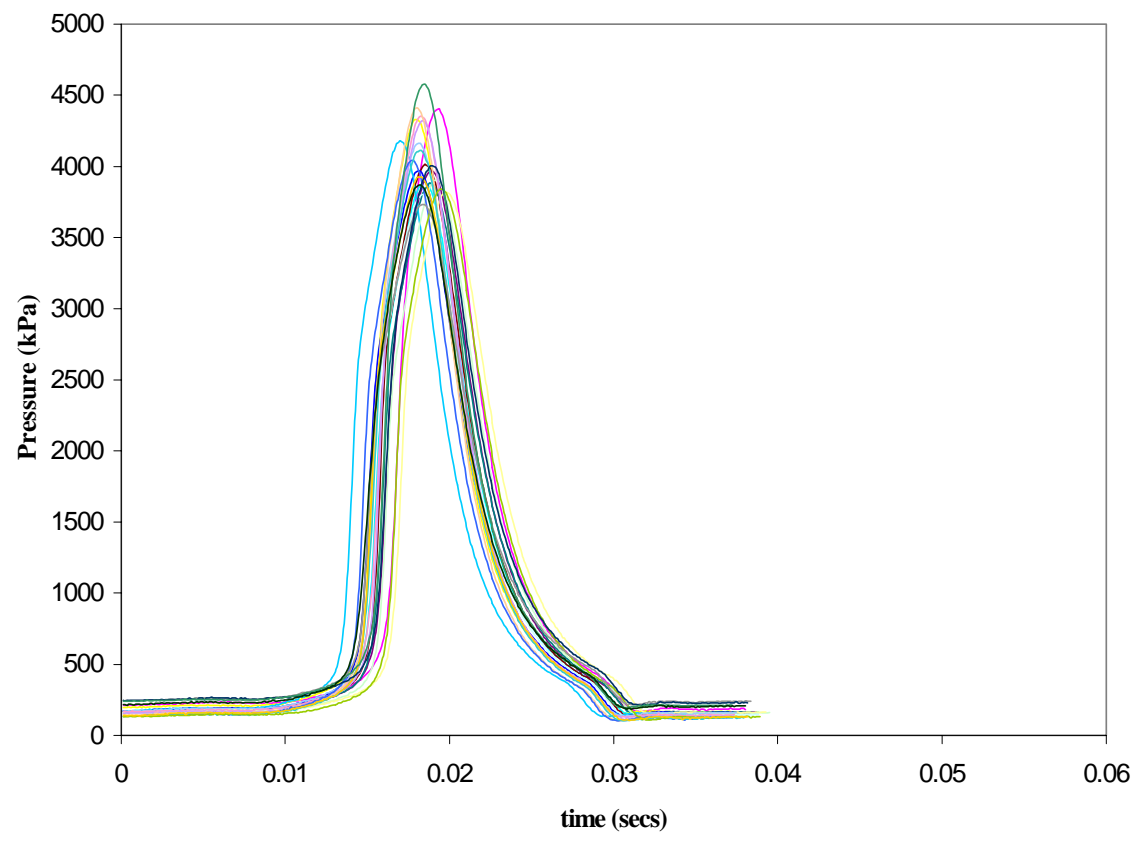

Figure 37 Pressure - time trace for the no load, highly advanced ignition timing case. 
The COV ( $\mathrm{IMEP}_{\mathrm{g}}$ ) was calculated to be $51.3 \%$ for the no load (idling) case. The relatively high value of the $\mathrm{COV}$ in the no load case can be attributed to the fact that small differences in the quality of the combustion in a particular cylinder have a distinct effect on the next combustion event in the opposing cylinder. In addition, the relatively small sample size of only 20 cycles of data could have contributed to the high COV value, but as can be seen later, the COV is reduced significantly for the higher load cases implying that the sample size was adequate. In addition, the gross indicated mean effective pressure $\left(\mathrm{IMEP}_{\mathrm{g}}\right)$ was derived from the work done by the engine over the same set of cycles. Since the average net positive indicated work output of the engine in the no load case was very small (Table 7), the value of coefficient of variation can be comparatively high. The pressure-volume diagrams for the highly advanced timing with load case, was shown in Figure 34. The average stroke was found to be $35.3 \mathrm{~mm}$ and the average speed was $1260 \mathrm{cpm}$. However, the average net positive indicated work output from the analysis of the pressure-volume diagrams was found to be $6.25 \mathrm{~J}(262.5 \mathrm{~W})$.

The application of load resulted in the decrease of adverse work done and a decrease in the stroke. The peak pressure, as a result of application of load, was found to occur closer to the end of the compression stroke than in the no load case and the net positive work output was higher than in the no load case. The $\operatorname{COV}\left(\mathrm{IMEP}_{\mathrm{g}}\right)$ was reduced to $19.9 \%$. The pressure-time trace for this condition is seen in Figure 38.

Retarding of the spark-timing for the same applied load led to a delay in the occurrence of the peak pressure with respect to the compression stroke of the engine and thereby an increase in the net positive work output of the engine. The analysis of the pressure-volume diagram (Figure 35) provided an average net positive work output value 
for the indicated work as $10.79 \mathrm{~J}(438 \mathrm{~W})$. The average stroke in this case was $37.6 \mathrm{~mm}$ while the average speed was $1197 \mathrm{cpm}$. Figure 39 shows the pressure versus time plot for the retarded timing under load condition over 20 cycles of operation. The occurrence of the peak pressure further towards the end of the compression stroke resulted in a reduction in the amount of work done by the piston in compressing the gases, thereby increasing the net indicated work output. The $\operatorname{COV}\left(\operatorname{IMEP}_{\mathrm{g}}\right)$ was calculated to be $5.9 \%$.

The COV value was seen to be comparatively low in this case. Further retarding of the ignition timing showed a trace that was similar to that from a conventional slidercrank engine. The pressure-volume diagrams for 20 cycles (Figure 36) had no adverse work region (except for the gas exchange region, which had been neglected in all cases). The average net indicated work output in this case was $16.4 \mathrm{~J}(804 \mathrm{~W})$ and the average stroke was $47 \mathrm{~mm}$. The average engine speed was $1470 \mathrm{cpm}$. The increase in the value of the gross indicated mean effective pressure can be attributed to the stroke timing being retarded thereby increasing the net positive work done by the engine. The COV was found to be $2.61 \%$ (Figure 40 ) as a result of increase in stroke and the occurrence of peak pressure at the optimum time in the stroke thereby eliminating the negative work done on the piston completely.

The analysis of in-cylinder pressures for different test conditions has shown that the COV ( IMEP $_{\mathrm{g}}$ ) had a very high value for the no-load (idle) case and a very low value for the highly advanced load condition. The peak pressure and the stroke were increased and the engine stability improved significantly through proper ignition timing control. 


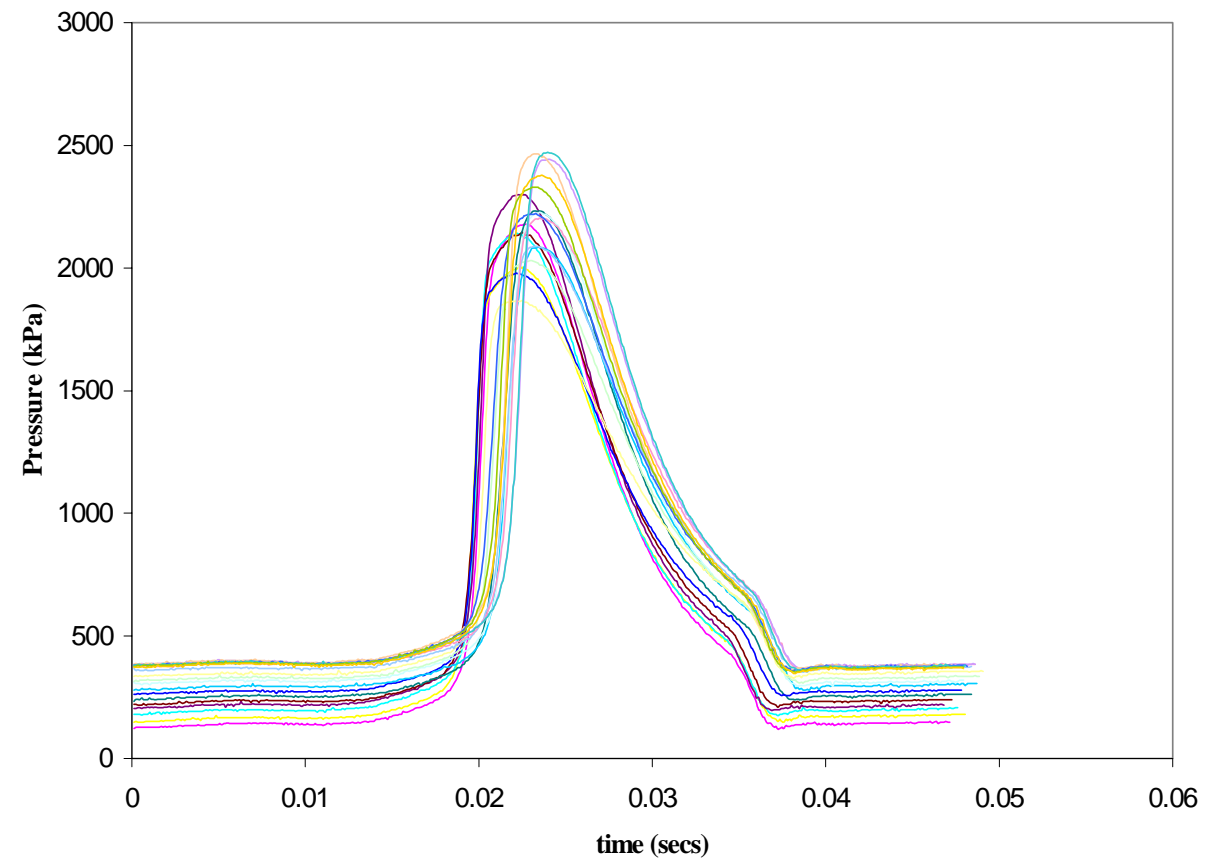

Figure 38. The application of load, for the same ignition timing as in figure 33, increased the average net positive work done and reduced the value of $\mathrm{COV}$.

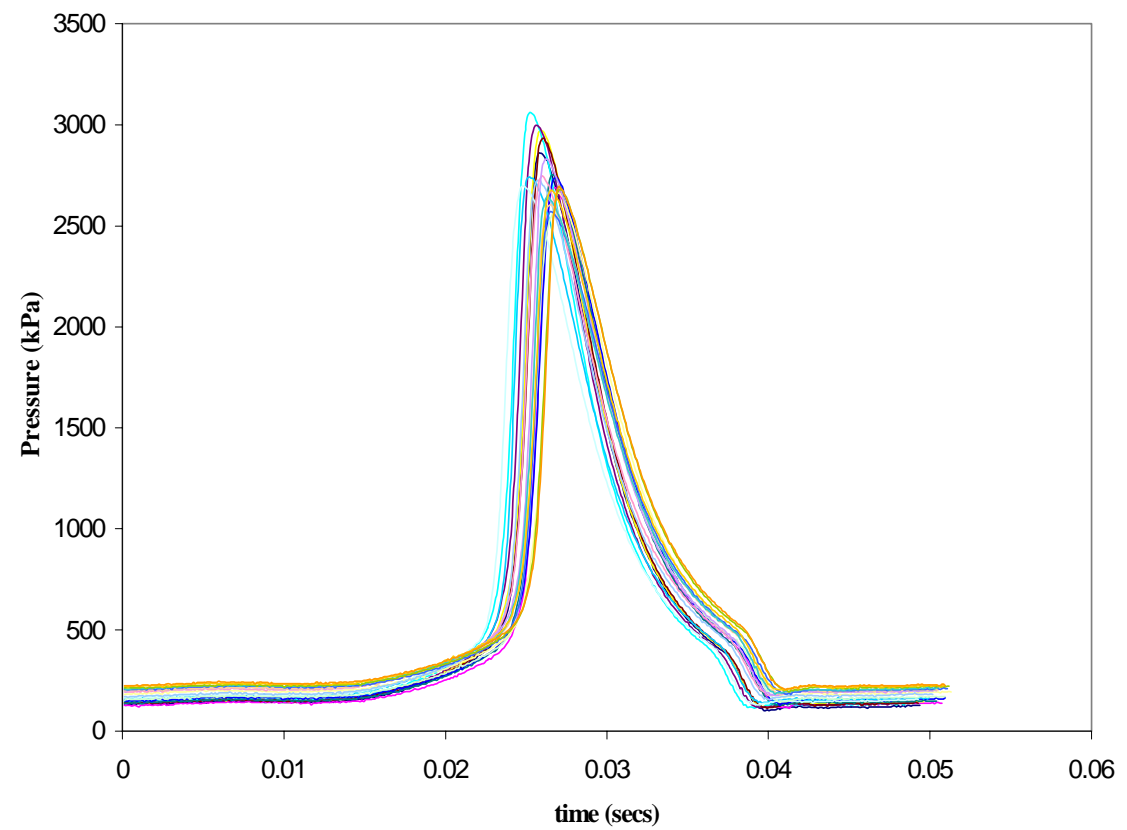

Figure 39 Retarding the timing for the same load increased the net positive work output and reduced the COV significantly. 


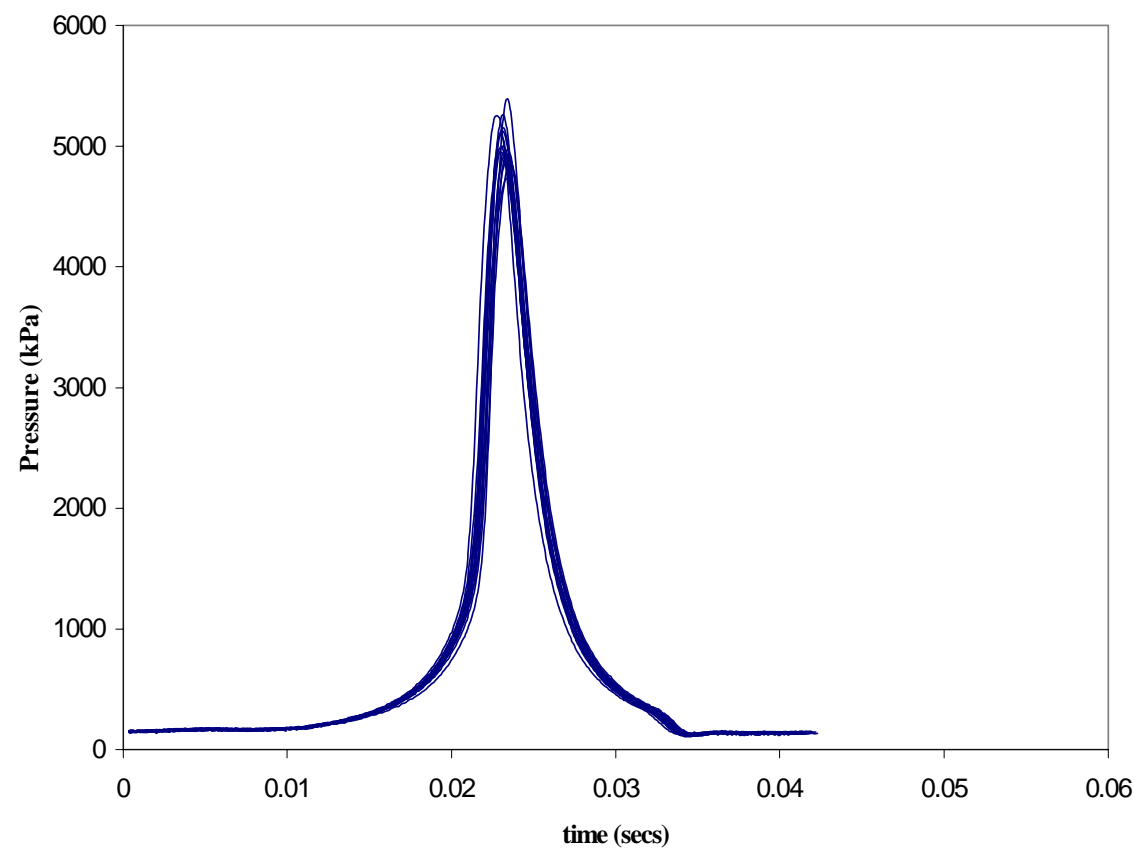

Figure 40 Further retarding of ignition timing, increased the peak pressure and the stroke of the engine. The variations in pressures from cycle to cycle were reduced significantly.

Table 7

Average Data over 20 Cycles of Operation.

\begin{tabular}{|c|c|c|c|c|}
\hline Load & $\begin{array}{c}\text { Average positive } \\
\text { indicated Work output } \\
\text { per stroke J }\end{array}$ & $\begin{array}{c}\text { Average positive } \\
\text { Power output W }\end{array}$ & $\begin{array}{c}\text { Average Stroke } \\
\text { mm (in.) }\end{array}$ & $\begin{array}{c}\text { Average Frequency } \\
\text { (cycles/min.) }\end{array}$ \\
\hline No & 1.55 & 81.3 & 44.3 & 1574 \\
\hline Yes & 6.25 & 262.5 & 35.3 & 1260 \\
\hline Yes & 10.79 & 438.0 & 37.6 & 1197 \\
\hline Yes & 16.40 & 804.0 & 47.0 & 1470 \\
\hline
\end{tabular}

\subsection{HEAT RELEASE RATE CALCULATIONS}

The heat release rate was calculated using the instantaneous piston pressure and the corresponding instantaneous cylinder volume data, both of which are known explicitly as a function of time. Rassweiler and Withrow presented a simplified heat release rate calculation theory, which was referenced by Blair [18] and is given by 


$$
\delta Q_{R}=\left[p_{2}-p_{1}\left(\frac{v_{1}}{v}\right)^{n}\right]\left(\frac{v_{2}}{\gamma-1}\right)
$$

A plot showing the heat release curve and the pressure variation with respect to time, for one cycle of the no-load (idle) case, is shown in Fig. 41. The highly advanced timing leads to the combustion process and the heat release to occur before the end of the compression stroke. This increases the compression stroke work transfer (from the piston to the cylinder gases), thereby preventing the slapping of the piston on the cylinder head. The positive work done by the piston is reduced in this case. The heat release versus time curve, shown in Fig. 42, shows the heat release to occur at the optimum time with respect to the compression stroke, thereby reducing the compression stroke work transfer and increasing the expansion stroke work transfer (from the cylinder gases to the piston). The positive work done is increased substantially as a result of retarding the spark timing.

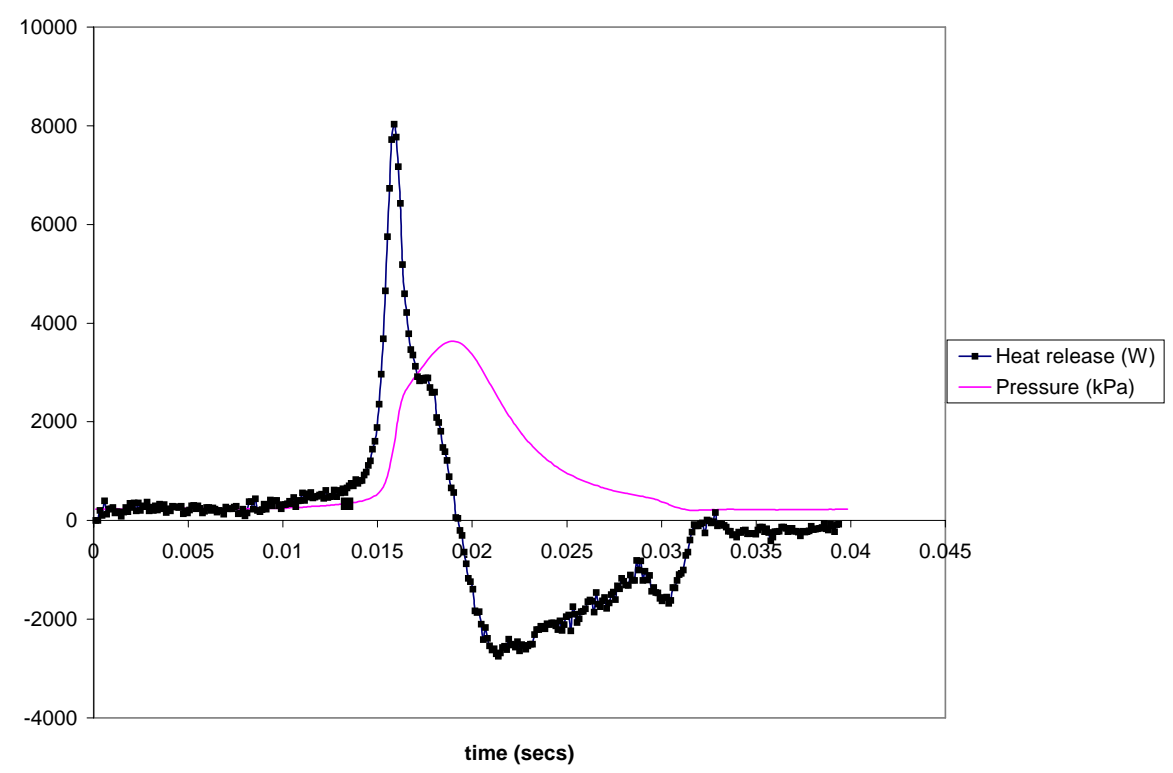

Figure 41 The heat release and in-cylinder pressure versus time plot for the no-load (idle) case, shows the large amount of compression stroke work done by the piston on the gases. 


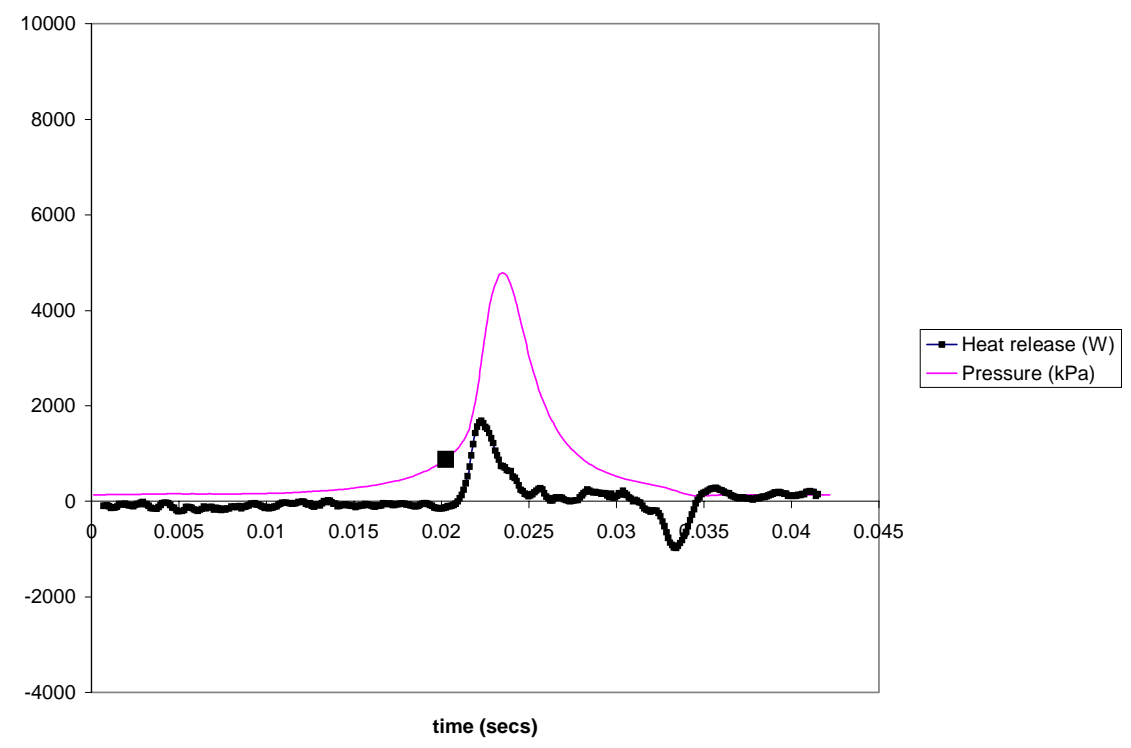

Figure 42 The trace showing the occurrence of heat release and peak pressure at the optimum time in the compression stroke is seen here (highly retarded timing under load case). 


\section{CONCLUSIONS}

Linear engines offer the potential to provide power without the conversion of linear to rotary motion. An idealized model of a linear engine, consisting of two pistons linked by a solid rod, has revealed the relationship between stroke, compression ratio and operating parameters. Also, a benchtop model of the engine was constructed (by Tom McDaniel and Richard Atkinson of West Virginia University) and used to provide twostroke, port injected, spark ignited operating data. Pressure-volume diagrams for no load conditions, and loaded conditions, with advanced timing, showed adverse work where pressure in the latter part of the outward stroke exceeded that at the beginning of the inward (expansion) stroke. This adverse work was eliminated at high loads with retarded spark timing. The engine has produced approximately $780 \mathrm{~W}$ of net positive power output in sustained operation. The cycle-to-cycle variations of pressure were studied and led to the conclusion that the addition of load and retarding of timing would be highly beneficial in improving the engine driveability. The heat release rate calculations for the highly advanced ignition timing case with no applied load on the piston, showed significant compression stroke work transfer (from the piston to the cylinder gases),

thereby preventing the slapping of the piston on the cylinder head. This reduced the positive work output of the engine. The positive work output of the engine was significantly increased as compared to the no-load highly advanced case with the addition of load and retarding of ignition timing, which effectively increased the expansion stroke work transfer (from the cylinder gases to the piston). The occurrence of peak pressure was also found to be nearer to the end of the stroke as opposed to being earlier in the stroke for the no-load case. The effect of varying the engine bore on the engine speed, for 
different values of compression ratios, was also studied using the idealized mathematical model for a two-stroke linear engine. The increase in engine bore was found to increase the engine speed (the reciprocating mass remaining constant). The effect of altering the air-fuel ratio for different stroke-to-bore ratios was also analyzed. This provided an insight into the correct engine sizing required to provide maximum engine speed output. The transient energy analysis conducted showed the importance of the conversion of potential energy to kinetic energy and back to potential energy for efficient working of a linear engine.

PRESENT AND FUTURE WORK: The experimental linear engine was integrated with a permanent magnet alternator, and successful operation was achieved at an electrical output of $316 \mathrm{~W}$ at $23.1 \mathrm{~Hz}$ (1386 cycles/minute). The maximum measured power produced by the engine-alternator combination was found to be less than the power produced by the engine alone under friction braking (by about 60\%). This is readily explained by the electrical alternator efficiency, as well as by the differences in engine operation between the two tests. While the present engine does not represent an optimal design, it has provided an advanced platform to demonstrate the feasibility of the concept and technology, and to formulate a coherent design approach for future versions. Based on the experimental results provided it is clear that throttled operation is undesirable and compression ignition operation is desirable. Also a large bore engine is recommended, as this would provide ample bounce energy for reversal of piston motion without depending on the combustion of gases to do the same. The construction of a diesel-fueled two-stroke linear engine model is currently under way. The engine would use a Bosch high-pressure common-rail fuel injection system. 


\section{REFERENCES}

[1] Heywood, J. B., Internal Combustion Engine Fundamentals, McGraw-Hill Inc., New York, 1988.

[2] Cleveland Diesel Engine Division, 1957, "History and Description of the Free Piston Engine-Gas Turbine Power", (authors unknown to GM).

[3] Achten, A. J., "A Review Of Free-Piston Engine Concepts", International offHighway \& Powerplant Congress \& Exposition, SAE 941776, 1994.

[4] Underwood, A. F., “ The GMR 4-4 "Hyprex” Engine-A Concept Of the Free-Piston Engine For Automotive Use”, SAE Transactions, Vol. 65, 1957, pp 377- 391.

[5] Flynn, G. Jr., "Observations on 25,000 Hours of Free-Piston-Engine Operation", SAE Transactions, Volume 65, 1957, pp 508-515.

[6] Frey, D. N., Klotsch, P., Egli, A., "The Automotive Free-Piston-Turbine Engine”, SAE Transactions, Volume 65, 1957, pp 628-634.

[7] Widener, S. K., Ingram, K., “ Free-Piston Engine Linear Generator Technology Development", Final Report, Under Contract to U.S. Army TARDEC, Mobility Technology Center-Belvoir, Fort Belvoir, Virginia, January 1995.

[8] Galitello, K. A. Jr., "Two Stroke Cycle Engine”, U.S. Patent Application No. 281,530, Application filed December 8, 1988; U.S. Patent No. 4,876,991, Patent Issued October 31, 1989.

[9] White, M. A., Colenbrander, K., Olan, R. W., Penswick, L. B., "Generators that won't wear out”, Mechanical Engineering, February 1996, pp 92-96.

[10] Bock, R., "Gas Cushioned Free Piston Type Engine”, U.S. Patent Application No. 809,999, Application filed June 24, 1977; U.S. Patent No. 4,128,083, Patent issued December 5, 1978.

[11] Kos, F. J., "Computer Optimized Hybrid Engine”, U.S. Patent Application No. 556,872, Application filed July 20, 1990; U.S. Patent No. 5,002,020, Patent Issued March 26, 1991.

[12] Deng, Y. A., Deng, K., "Free-Piston Engine Without Compressor", U.S. Patent Application No. 154,145 (RDG Inventions Corporation), Application filed February 
9, 1988; U.S. Patent No. 4,924,956 (RDG Inventions Corporation), Patent Issued May 15, 1990.

[13] Nerstrom, J. S., "Two-Cycle Internal Combustion Engine Including Means For Varying Cylinder Port Timing", U.S. Patent Application No. 376,705 (Outboard Marine Corporation), Application filed May 10, 1982; U.S. Patent No. 4,516,540 (Outboard Marine Corporation), Patent Issued May 14, 1985.

[14] Iliev, M. D., Kervanbashiev, S. S., Karamanski, S. D.,Makedonski, F. M., "Method And Apparatus For Producing Electrical Energy From A Cyclic Combustion Process Utilizing Coupled Pistons Which Reciprocate In Unison", U.S. Patent Application No. 431,119 (CUV "Progress"), Application filed September 30, 1982; U.S. Patent No. 4,532,431 (CUV "Progress"), Patent Issued July 30, 1985.

[15] Allais, E., "Free-Piston Engine With Operatively Independent Cam", U.S. Patent Application No. 416,959, Application filed September 9, 1982; U.S. Patent No. 4,480,599, Patent issued November 6, 1984.

[16] Heintz, R. P., "Free-Piston Engine Pump", U.S. Patent Application No. 150,390, Application filed May 16, 1980; U.S. Patent No. 4,369,021, Patent Issued January $18,1983$.

[17] Rittmaster, P. A., Booth J. L., "Hydraulic Engine", U.S. Patent Application No. 110,771, Application filed January 9, 1980; U.S. Patent No. 4,326,380, Patent Issued April 27, 1982.

[18] Blair, G. P., Design and Simulation of Two-Stroke Engines, SAE Inc., Warrendale, PA, 1996. 


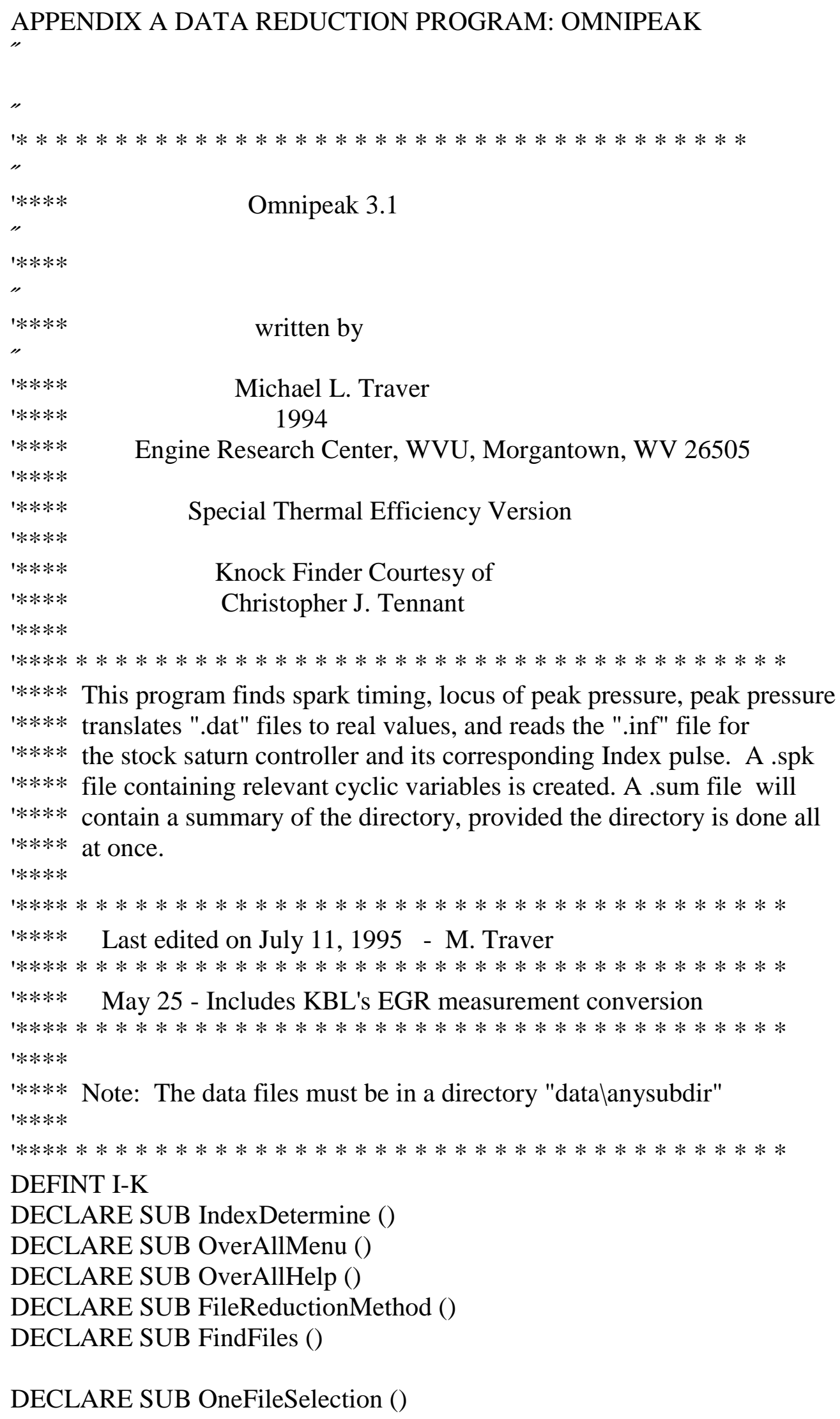


DECLARE SUB ProgramEnding ()

DECLARE SUB ReadInfFile ()

DECLARE SUB InitialValues ()

DECLARE SUB ConvertDataFiletoReal ()

DECLARE SUB TransducerTranslation ()

DECLARE SUB WriteAveragestoFile ()

DECLARE SUB AdjustedMean (iTotal\%, VarValSum!, VarVal() AS SINGLE)

DECLARE SUB FindTDCandIgnitionPoints ()

DECLARE SUB FindPeaketc ()

DECLARE SUB ParsePressureTraces ()

DECLARE SUB PressureRelatedCalculations ()

DECLARE SUB MassFractionBurn ()

DECLARE SUB KnockFinder ()

DECLARE SUB IMEPGenerator ()

DECLARE SUB InitializeArrays ()

DECLARE SUB Progress ()

COMMON SHARED PI\#, dec $\$$, iCyls

COMMON SHARED iSparkHi, iSparkLow, iTDCLine

COMMON SHARED Index Var\$, iFlagVal, subdirec\$

COMMON SHARED iNumberofFiles, iFileFlag, iSlowTotal

COMMON SHARED filename\$, iNumberofCylChannels, igain

COMMON SHARED transcyl\#, iOffset, iRevLength

COMMON SHARED iSparkOffset, TPSAvg, UEGOAvg

COMMON SHARED Indexchn\$, FuelFlow, TorqueAvg

COMMON SHARED RPMAvg, FIPWAvg, ALPM

COMMON SHARED ExTemp1Avg, ExTemp2Avg, ExTemp3Avg, ExTemp4Avg

COMMON SHARED MATAvg, MapAvg, CLTAvg

COMMON SHARED BSHC, BShCO, BSICO, BSCO2, BSNOx

COMMON SHARED VTempAvg, VPresAvg, Maxx\&

COMMON SHARED VARAvg, iVarRej, init

COMMON SHARED iAverageFlag, iParseFlag, newdirec\$

COMMON SHARED PistonVar\$, iM, iHighSpeedStart

COMMON SHARED increment, iiCounter2

COMMON SHARED CombustionDuration, LMFB50, MFBStart

COMMON SHARED MaxMassBurnLocation, MaxMassBurninRealTime

COMMON SHARED iTraceNumber, TorqueMaxAngle, TorqueMax

COMMON SHARED EquivRatio, BMEP, VolEff, BSFC, BThermEff

COMMON SHARED iMapVal, drivepath\$

'\$DYNAMIC

DIM SHARED FileArray\$(60), Parameter\&(15)

DIM SHARED Coef\#(6, 4), StaticVariable(3), Channel\$(8)

DIM SHARED Emiszero\&(7), TDCPoint\&(275), spark\&(550)

DIM SHARED MaxBurnLocAvg(4), PresValSum(0)

DIM SHARED Pr(0), MFB(0), RPM(0) 
DIM SHARED Pressure(0), noklow(0), IMEP\#(0)

DIM SHARED PeakAvg(4), LPPAvg(4), IMEPAvg\#(4)

DIM SHARED TorqueMaxAvg(4), COVPeak(4), COVLPP(4)

DIM SHARED COVIMEP(4), COVTorqueMax(4), SparkPtAvg(4)

DIM SHARED BurnDelayAvg(4), CombustionDurationAvg(4), LMFB50Avg(4)

DIM SHARED MaxMassBurninRealTimeAvg(4), MaxMassBurnLocationAvg(4)

DIM SHARED noklowAvg(4), TorqueMaxAngleAvg(4)

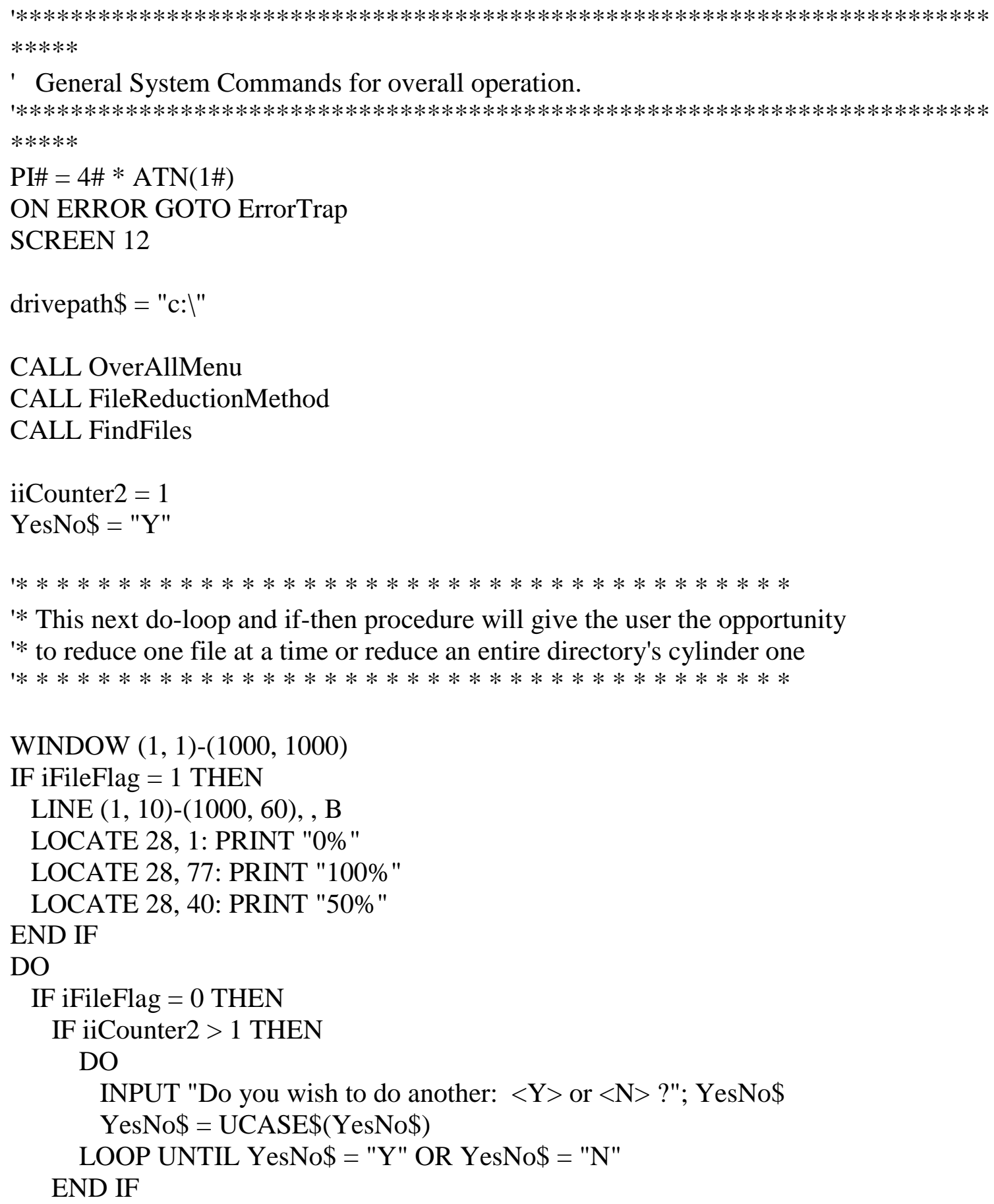

WINDOW $(1,1)-(1000,1000)$

IF iFileFlag $=1$ THEN

LINE $(1,10)-(1000,60)$, , B

LOCATE 28, 1: PRINT "0\%"

LOCATE 28, 77: PRINT "100\%"

LOCATE 28, 40: PRINT "50\%"

END IF

DO

IF iFileFlag $=0$ THEN

IF iiCounter2 > 1 THEN

DO

INPUT "Do you wish to do another: $\langle$ Y $>$ or $<\mathrm{N}\rangle$ ?"; YesNo\$

YesNo\$ = UCASE\$(YesNo\$)

LOOP UNTIL YesNo\$ = "Y" OR YesNo\$ = "N"

END IF 
IF YesNo\$ = "Y" THEN

CALL OneFileSelection

ELSE CALL ProgramEnding: END

END IF

ELSEIF (iFileFlag = 1) AND (iiCounter2 <> (iNumberofFiles + 1)) THEN

filename\$ = LEFT\$(FileArray\$(iiCounter2), 8)

END IF

CALL InitializeArrays

' CALL ReadInfFile

' CALL InitialValues

' CALL ConvertDataFiletoReal

' CALL TransducerTranslation

OPEN drivepath $\$$ + "datal" + subdirec $\$$ + filename $\$$ + ".pr1" FOR BINARY AS \#11

OPEN drivepath\$ + "datal" + subdirec\$ + filename\$ + ".pr2" FOR BINARY AS \#12

OPEN drivepath\$ + "datal" + subdirec\$ + filename\$ + ".pr3" FOR BINARY AS \#13

OPEN drivepath\$ + "datal" + subdirec\$ + filename\$ + ".pr4" FOR BINARY AS \#14

OPEN drivepath\$ + "datal" + subdirec\$ + filename\$ + ".pr5" FOR BINARY AS \#15

' CALL IndexDetermine

' CALL FindTDCandIgnitionPoints

CALL ParsePressureTraces

CLOSE

LOCATE 14, 10

PRINT "Completed Cylinder: "; Channel\$(iCyls)

IF iFileFlag $=1$ THEN

CALL Progress

END IF

IF iAverageFlag = 1 THEN

CALL WriteAveragestoFile

END IF

iiCounter $2=$ iiCounter $2+1$

LOOP UNTIL iiCounter2 $=$ iNumberofFiles +1

CALL ProgramEnding

END

ErrorTrap: 


\section{SELECT CASE ERR}

CASE 76: CHDIR drivepath\$

MKDIR drivepath $\$$ + "datal" + subdirec $\$$ + "I" + newdirec\$

RESUME

CASE 62: CLS

LOCATE 10, 5

PRINT "Error has occurred"

LOCATE 15, 5

PRINT "The .inf file has not been updated"

END

CASE 6: CLS

LOCATE 10, 5

PRINT "Error has occurred"

LOCATE 15, 5

PRINT "Are you using the proper version? Try using Omnipktb." END

CASE ELSE: ON ERROR GOTO 0

\section{END SELECT}

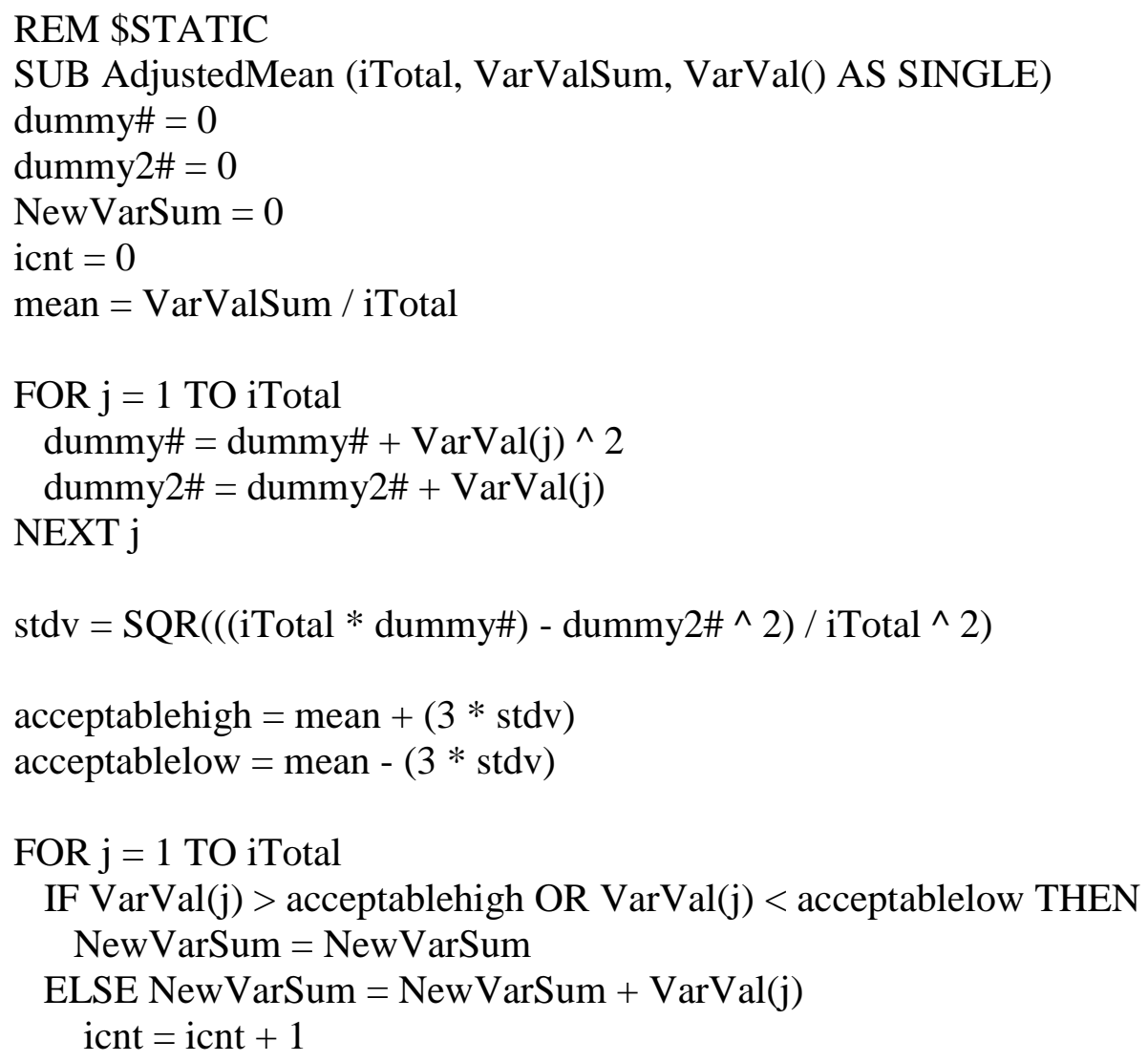




\section{END IF \\ NEXT $j$}

VARAvg $=$ NewVarSum $/$ icnt

iVarRej $=$ iTotal - icnt

\section{END SUB}

SUB ConvertDataFiletoReal

$\mathrm{DIM}$ a $\$(21)$

DIM modenum(iSlowTotal)

DIM MAT(iSlowTotal), CLT(iSlowTotal), UEGO(iSlowTotal)

DIM FIPW(iSlowTotal)

REDIM RPM(iSlowTotal)

DIM Torque(iSlowTotal), MAP(iSlowTotal)

DIM HC(iSlowTotal), hCO(iSlowTotal), 1CO(iSlowTotal)

DIM CO2(iSlowTotal), NOx(iSlowTotal)

DIM VTemp(iSlowTotal), Vpres(iSlowTotal)

iTempArray $=$ INT $($ iSlowTotal $/ 4)+1$

DIM ExTemp1(iTempArray), ExTemp2(iTempArray), ExTemp3(iTempArray),

ExTemp4(iTempArray)

time $\&=$ PrevTime $\&=0$

SUB FileReductionMethod

$\mathrm{DIM} B$ \$(100)

DO

LOCATE 10, 10

PRINT "Specify your choice for file reduction"

LOCATE 14, 10

PRINT " $<\mathrm{O}>$ ne file at a time for the given subdirectory"

LOCATE 16, 10

PRINT " $<\mathrm{C}>$ ontinuous reduction of a subdirectory."

DO

choice $\$=$ INKEY\$

LOOP WHILE choice $\$=" "$

choice $\$$ = UCASE $\$($ choice $\$$ )

LOOP UNTIL choice $\$=$ "O" OR choice $\$=$ " $\mathrm{C} "$

IF choice $\$=$ "O" THEN

iFileFlag $=0$ 


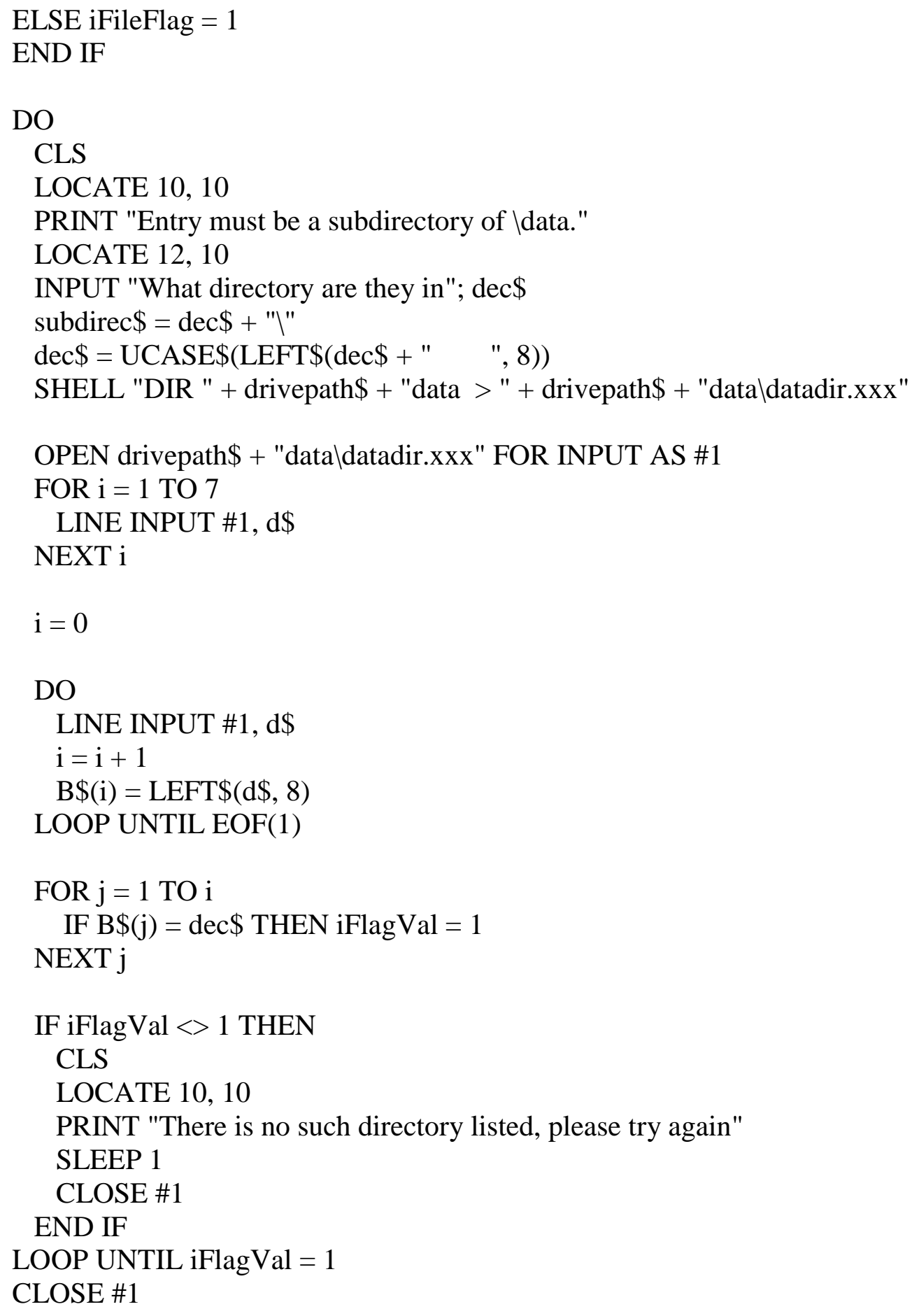


SHELL "DEL " + drivepath $\$+$ "ddt.xxx"

SHELL "DIR " + drivepath\$ + "datal" + subdirec $\$+$ "*.pr1 > " + drivepath\$ + "ddt.xxx" OPEN drivepath\$ + "ddt.xxx" FOR INPUT AS \#1

FOR $\mathrm{i}=1$ TO 5

LINE INPUT \#1, d\$

NEXT i

$\mathrm{i}=0$

DO

$\mathrm{i}=\mathrm{i}+1$

LINE INPUT \#1, d\$

FileArray $\$(i)=d \$$

LOOP UNTIL EOF(1)

iNumberofFiles $=\mathrm{i}-2$

END SUB

SUB ParsePressureTraces

iTraceNum $=0$

LOCATE 10, 10

newdirec\$ = "pars" + RIGHT\$(filename\$, 4)

presfile $\$=$ filename $\$+$ "." + "red"

OPEN drivepath $\$+$ "datal" + subdirec\$ + newdirec $\$+" \backslash "$ + presfile $\$$ FOR OUTPUT AS \#4

LOCATE 20, 10

NumOfBytes $=40000$

IF LOF(11) < NumOfBytes THEN NumOfBytes = LOF(11) - 2

FOR location\& $=1$ TO NumOfBytes STEP 2 ' ie every point

GET \#11, location\&, dist $\%$

GET \#12, location\&, 1spk\%

GET \#13, location\&, rspk\%

GET \#14, location\&, lpress\%

GET \#15, location\&, rpress \%

PRINT \#4, USING "\#\#\#\#, \#\#\#, \#\#\#, \#\#\#, \#\#\#, \#\#\#\#"; location\& \2 + 1; dist\%;

$((\mathrm{lspk} \% \backslash 1000)-2) * 3000 ;((\operatorname{rspk} \% \backslash 1000)-2) * 3000 ;$ lpress\%; rpress\%

NEXT location\&

CLOSE \#4

END SUB 


\section{APPENDIX B FUNDAMENTAL ANALYSIS PROGRAM}

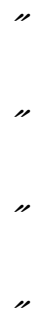

DIM ff AS SINGLE, qin AS SINGLE, xxx AS SINGLE, iconst AS SINGLE DIM velocity AS SINGLE

INPUT "enter the value of ff in newtons"; ff

$\mathrm{xs}=.04375$

$\mathrm{xm}=.05$

$\mathrm{pm}=244297.15 \#$

OPEN "c:/???.dat" FOR OUTPUT AS \#1

qin $=(2 * \mathrm{ff} * \mathrm{xs}) /\left(1-\left(((\mathrm{xm}-\mathrm{xs}) /(\mathrm{xm}+\mathrm{xs}))^{\wedge} .4\right)\right)$

pupm $=1+\left(\left(\right.\right.$ qin $\left.\left.*\left(((x m) /(x m-x s))^{\wedge}-.4\right) * .4\right) /\left(\mathrm{pm}^{*} \mathrm{xm} * .007853981634 \#\right)\right)$

iconst $=($ pupm $* 1.944193558 \#)+(5.743492111 \#)+($ ff $* .0004560366757 \#)$

PRINT qin, pupm, iconst

FOR $x x x=1 *-.04375$ TO $1 * .04375 \#$ STEP $1 * .00004375 \#$

velocity $=2 *\left(\left(\left(\left(\right.\right.\right.\right.$ pupm $\left.*\left((1+\mathrm{xxx} / .05)^{\wedge}-.4\right) /-.4\right)+\left(\left((1-\mathrm{xxx} / .05)^{\wedge}-.4\right) /-.4\right)-(\mathrm{ff} *$ $\operatorname{xxx} / 95.93526611 \#)+($ iconst $\left.\left.))^{\wedge} .5\right)\right)$

PRINT \#1, xxx, velocity

NEXT

END 


\section{APPENDIX C AIR-FUEL RATIO EFFECT DETERMINATION PROGRAM}

DIM Ff AS DOUBLE, qin AS DOUBLE, xxx AS DOUBLE, iconst AS SINGLE, pupm AS SINGLE

DIM mair AS DOUBLE, mfuel AS DOUBLE, cv AS DOUBLE

DIM airdens AS DOUBLE, bore AS DOUBLE, xm AS DOUBLE, xs AS DOUBLE, afr AS DOUBLE

DIM cr AS DOUBLE, qinf AS DOUBLE, pm AS DOUBLE

DIM velocity AS SINGLE, prr AS DOUBLE, prl AS DOUBLE

INPUT "Enter the bore of the engine in meters"; bore

INPUT "Enter the maximum stroke of the engine in meters"; xm

INPUT "Enter the air fuel ratio of the engine"; afr

INPUT "Enter the compression ratio of the engine"; cr

$\mathrm{cv}=44000$

airdens $=1.23$

$\mathrm{xs}=\mathrm{xm} *((\mathrm{cr}-1) /(\mathrm{cr}+1))$

$\mathrm{pm}=101325 *\left(((\mathrm{xm}+\mathrm{xs}) /(\mathrm{xm}))^{\wedge} 1.4\right)$

OPEN "c:/???.dat" FOR OUTPUT AS \#1

$$
\begin{aligned}
& \operatorname{mair}=2 * \mathrm{xs} *(3.14 / 4) *\left(\text { bore }^{\wedge} 2\right) * \text { airdens } \\
& \text { mfuel }=\text { mair } / \text { afr } \\
& \text { qinf }=\text { mfuel } * \mathrm{cv} \\
& \mathrm{Ff}=(\mathrm{qinf} *(1-((1 / \mathrm{cr}) \wedge .4))) /(2 * \mathrm{xs}) * 1000 \\
& \mathrm{qin}=(2 * \mathrm{Ff} * \mathrm{xs}) /\left(1-\left(((\mathrm{xm}-\mathrm{xs}) /(\mathrm{xm}+\mathrm{xs}))^{\wedge} .4\right)\right) \\
& \mathrm{pupm}=1+\left(\left(\left(\mathrm{qin} *\left(((\mathrm{xm}) /(\mathrm{xm}-\mathrm{xs}))^{\wedge}-.4\right) * .4\right) /\left(\mathrm { pm } * \mathrm { xm } * ( 3 . 1 4 / 4 ) * \left(\text { bore }^{\wedge}\right.\right.\right.\right.
\end{aligned}
$$

2))))

iconst $=\left((\mathrm{pupm} / .4) *\left((1+(\mathrm{xs} / \mathrm{xm}))^{\wedge}-.4\right)\right)+\left(\left((1-(\mathrm{xs} / \mathrm{xm}))^{\wedge}-.4\right) /(.4)\right)+((\mathrm{Ff} *$ $(\mathrm{xs} / \mathrm{xm})) /\left(\mathrm{pm} *(3.14 / 4) *\left(\right.\right.$ bore $\left.\left.\left.^{\wedge} 2\right)\right)\right)$

PRINT xs, pm, mair, mfuel, qinf, Ff, qin, pupm, iconst

FOR $x x x=(-x s)$ TO $(x s)$ STEP $(x s / 10000)$ 
velocity $=2 *\left(\left(\left(\operatorname{pupm} *\left((1+(\mathrm{xxx} / \mathrm{xm}))^{\wedge}-.4\right) /-.4\right)+\left(\left((1-(\mathrm{xxx} / \mathrm{xm}))^{\wedge}-.4\right) /-.4\right)-\right.\right.$ $\left((\mathrm{Ff} *(\mathrm{xxx} / \mathrm{xm})) /\left(\mathrm{pm}^{*}(3.14 / 4) *\left(\right.\right.\right.$ bore $\left.\left.\left.^{\wedge} 2\right)\right)\right)+($ iconst $\left.\left.)\right)^{\wedge} .5\right)$

$\mathrm{prr}=\mathrm{pm}^{*}\left(((\mathrm{xm}) /(\mathrm{xm}+\mathrm{xxx}))^{\wedge} 1.4\right)$

$\mathrm{prl}=\mathrm{pm} *\left(((\mathrm{xm}) /(\mathrm{xm}-\mathrm{xxx}))^{\wedge} 1.4\right)$

PRINT \#1, (xxx / xm), velocity, prr, prl

NEXT

END 


\section{SUBHASH NANDKUMAR}

223 Overdale Street, Morgantown, WV 26505

Phone: (304) 296-4337

email: snandkum@coe.wvu.edu

Fax: (304) 293-2582

\section{Educational Background}

MS Mechanical Engineering, West Virginia University (Dec. 1998)

Emphasis: Thermal Sciences

BS Mechanical Engineering, University of Poona, India (May 1996)

Emphasis: Thermal Sciences \& I.C. Engines

\section{Professional/Educational Work Experience}

Graduate Research Assistant, West Virginia University

Nov. 1996-Aug. 1998

Project: Two-stroke Linear Engine (Funded by U.S. DOD)

Dec. 1994-May 1996

Trainee Engineer, Oil \& Natural Gas Commission, India

\section{$\underline{\text { Professional Affiliations }}$}

SAE, ASME 